\title{
EXPERIMENTAL STUDY OF DELAY OF SEPARATION ON A NACA 0015 WING MODEL USING SYNTHETIC JET ACTUATORS
}

\author{
A Thesis presented to \\ the Faculty of California Polytechnic State University \\ San Luis Obispo \\ In Partial Fulfillment \\ of the Requirements for the Degree \\ Master of Science in Aerospace Engineering
}

by

Alan M. L'Esperance

August 2014 
(C) 2014

Alan M. L'Esperance

ALL RIGHTS RESERVED 


\section{COMMITTEE MEMBERSHIP}

TITLE:

AUTHOR:

DATE SUBMITTED:

COMMITTEE CHAIR:

COMMITTEE MEMBER:

COMMITTEE MEMBER:

COMMITTEE MEMBER:
Experimental Study of Delay of Separation on a NACA 0015 Wing Model Using Synthetic Jet Actuators

Alan L'Esperance

August 2014

Dr. Jin Tso

Professor of Aerospace Engineering

Dr. Russell Westphal

Professor of Mechanical Engineering

Dr. Faysal Kolkailah

Professor of Aerospace Engineering

Dr. Rob McDonald

Associate Professor of Aerospace Engineering 


\begin{abstract}
Experimental Study of Delay of Separation on a NACA 0015 Wing Model Using Synthetic Jet Actuators

Alan L'Esperance
\end{abstract}

An experimental study has been conducted in the Cal Poly ME $0.61 \mathrm{~m} \times 0.61 \mathrm{~m}(2 \mathrm{ft} \times 2 \mathrm{ft})$ subsonic wind tunnel of the effect of a piezoelectric synthetic jet actuator at $10 \%$ chord on a NACA 0015 finite wing up to $\alpha=20^{\circ}$ at $\operatorname{Re}_{\mathrm{C}}=100,000$. It was observed that the actuation is able to delay the separation over the NACA 0015 finite wing model up to $\alpha=20^{\circ}$. For all the $\mathrm{C} \mu$ values tested, the synthetic jet excitation is effective at $F^{+}=1,2.8$, and 13.9 at $\alpha=16^{\circ}$, but only at $\mathrm{F}+=13.9$ at $\alpha=20^{\circ}$. At $\alpha=16^{\circ}$, the $C_{p}$ suction peak under the synthetic jet excitation at $\mathrm{F}^{+}=$ 1, 2.8, and 13.9 all gradually reduce from $C_{p} \cong-4$ at in the inboard area to about $\mathrm{Cp} \cong-3$ near the wingtip, about $25 \%$ reduction. The situation is similar for $F^{+}=13.9$ at $\alpha=20^{\circ}$ except at $2 y / b=$ 0.30 , the most inboard testing position, where the excitation shows almost no effect. The surprising result is that slit is not the only actuation influencing the flow. For $F^{+}$from 1 to 2.8 , the synthetic jet is indeed the most effective configuration and is successful in causing flow attachment as seen in previous experiments. For $F^{+}=13.9$, however, the flow is successfully attached with the model vibration caused by the actuators alone without the slit at $16^{\circ}$. At $20^{\circ}$, this configuration was not successful in delaying separation. 


\section{TABLE OF CONTENTS}

LIST OF TABLES vii

LIST OF FIGURES viii

NOMENCLATURE

\section{CHAPTER}

1 Introduction .1

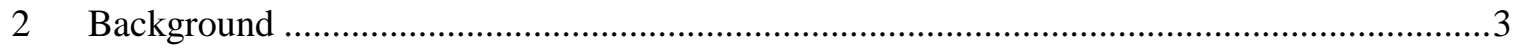

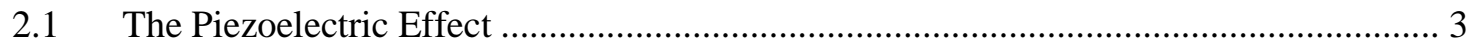

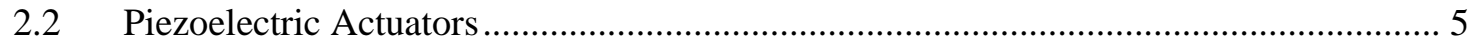

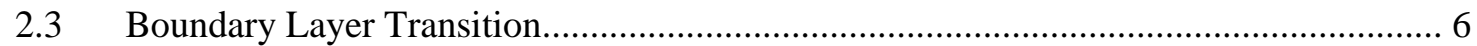

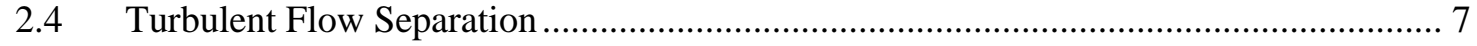

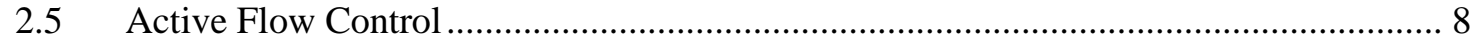

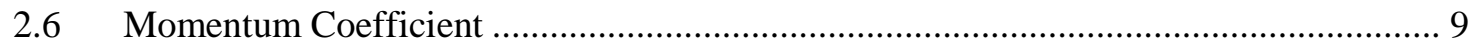

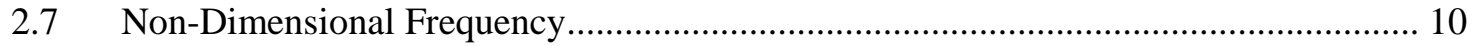

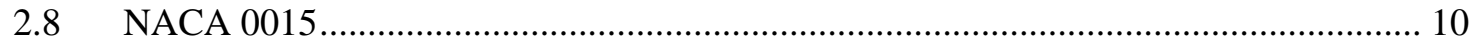

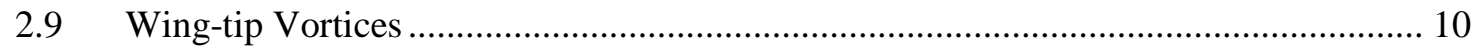

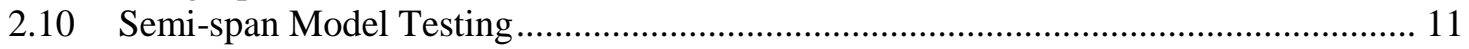

2.10.1 Dual Location Separation Control on a Semispan Wing ......................................... 11

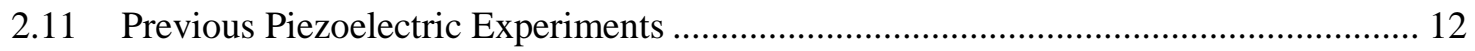

2.11.1 Synthetic Jets with Piezoelectric Diaphragms ..................................................... 12

2.11.2 Towards a practical piezoceramic diaphragm based SJA for high subsonic

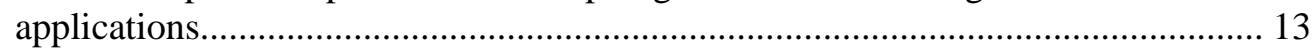

2.11.3 Momentum Coefficient as a Parameter for Aerodynamic Flow Control with

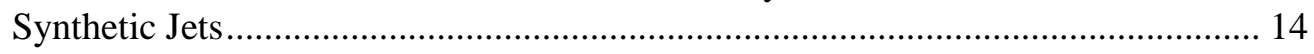

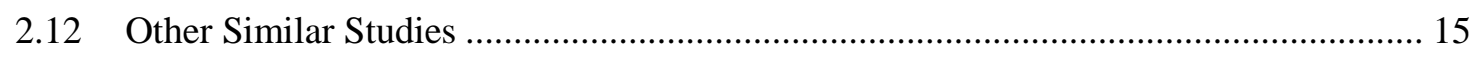

2.12.1 An Experimental Investigation of Pulsed Air Blowing Separation Control on a

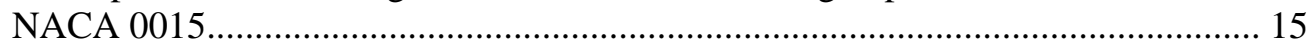

2.12.2 Delay of Airfoil Stall by Periodic Excitation ........................................................ 15

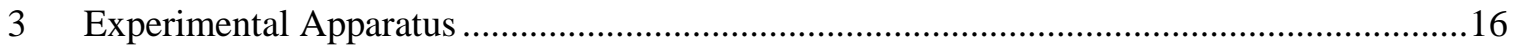

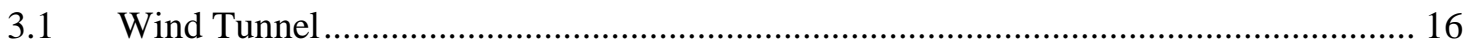

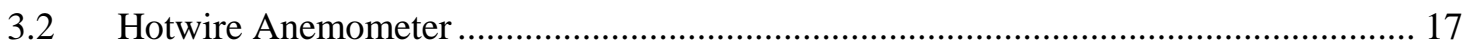

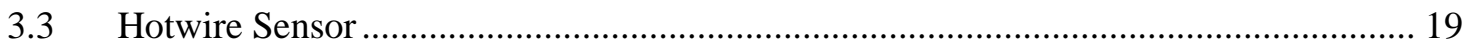

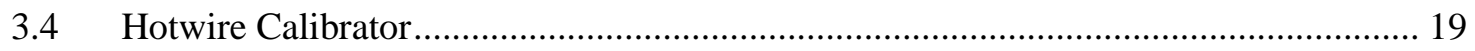

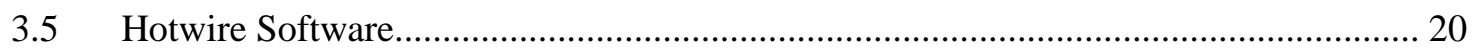

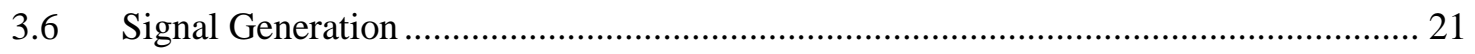

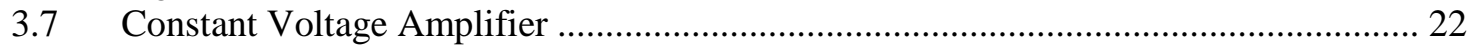

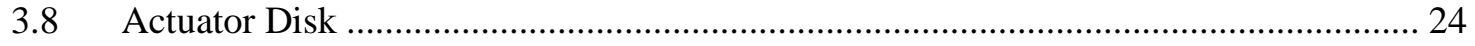

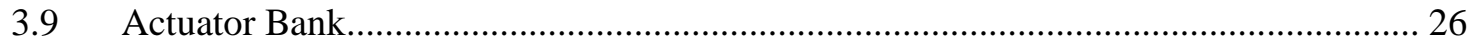

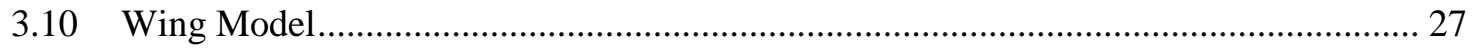

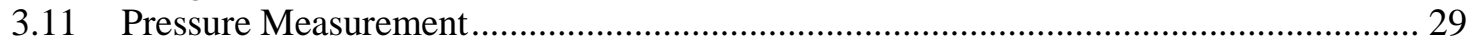

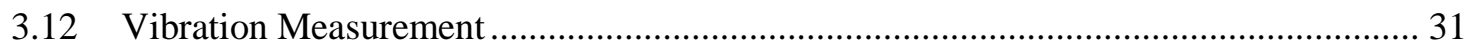

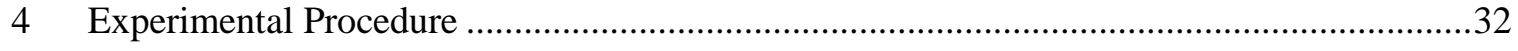

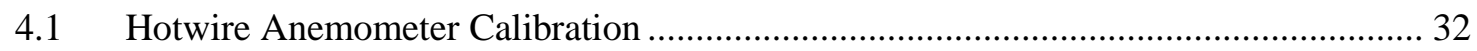

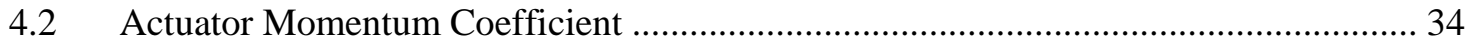




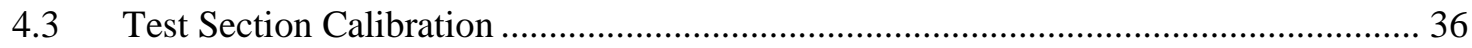

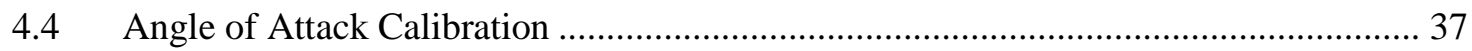

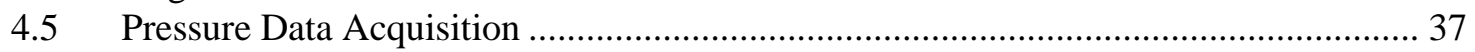

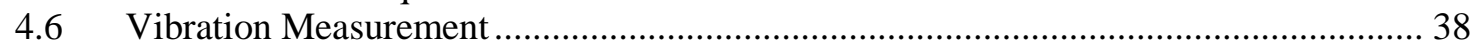

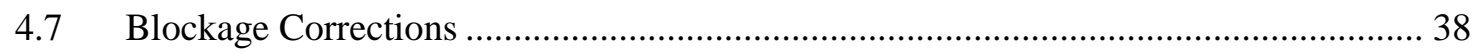

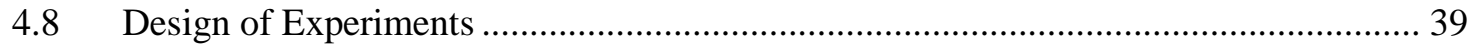

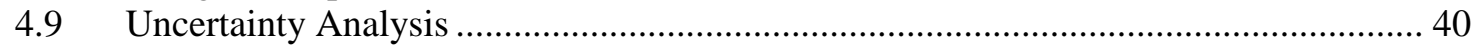

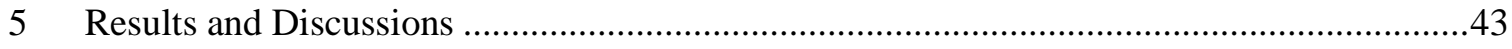

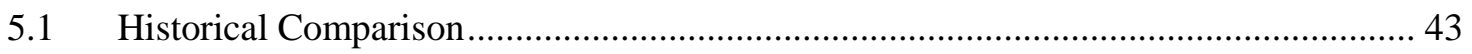

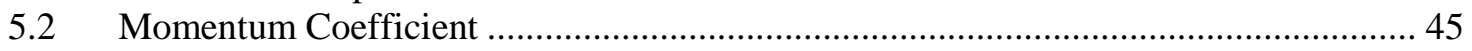

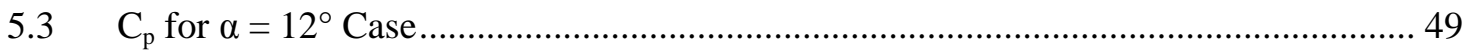

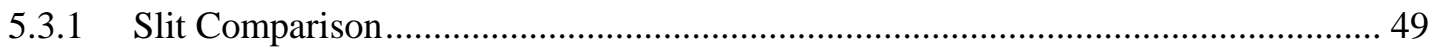

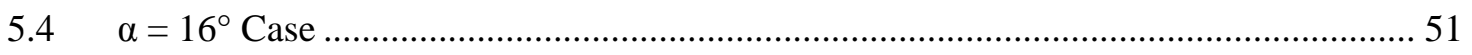

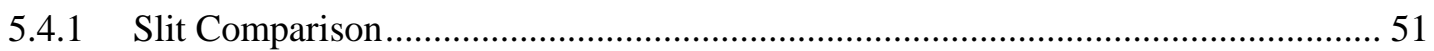

5.4.2 Spanwise Effect of Varying Actuation Amplitude.................................................. 55

5.4.3 Spanwise Effect of Varying Actuation Frequency .................................................. 56

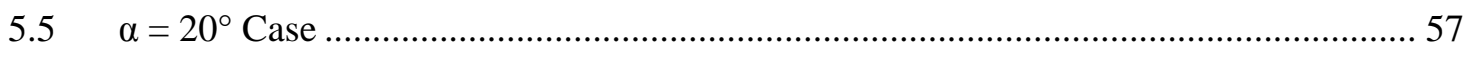

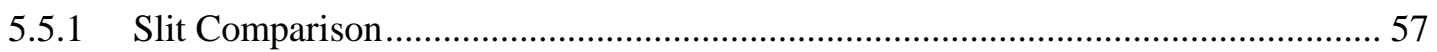

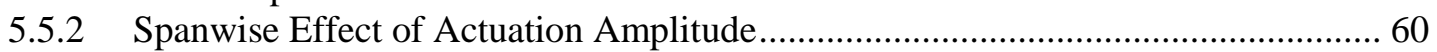

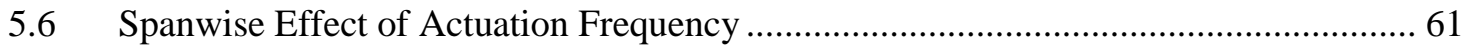

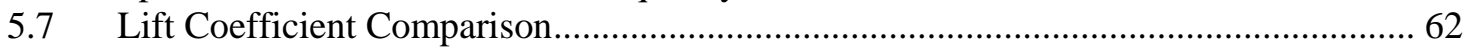

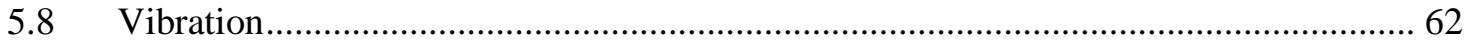

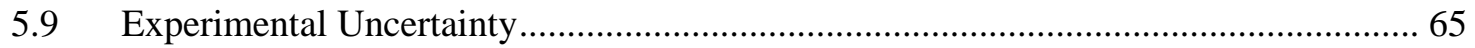

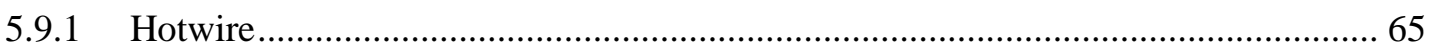

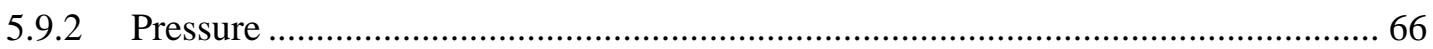

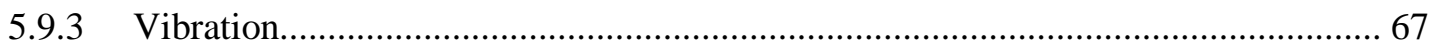

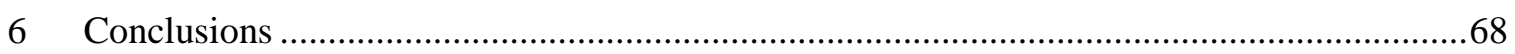

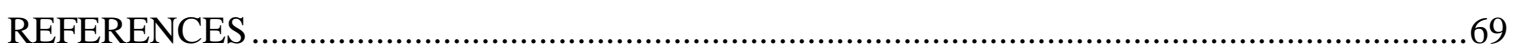

APPENDICES

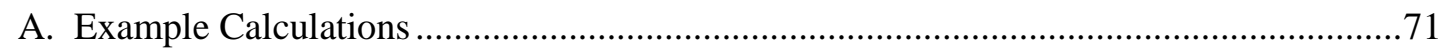

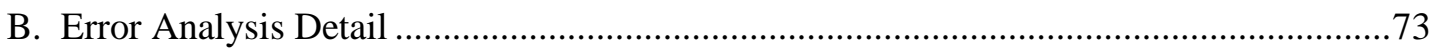

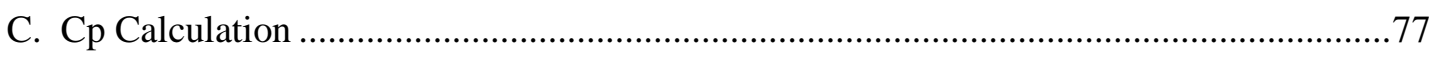

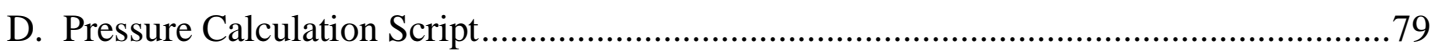

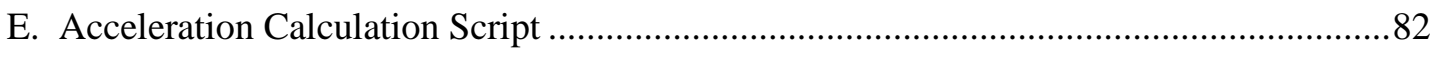

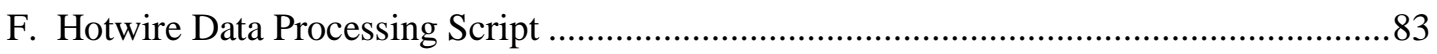




\section{LIST OF TABLES}

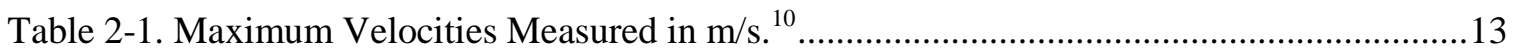

Table 3-1. IFA 300 Constant Temperature Anemometer specifications........................................18

Table 3-2. Hotwire sensor specifications. TSI Model 1210-T1.5 ….........................................19

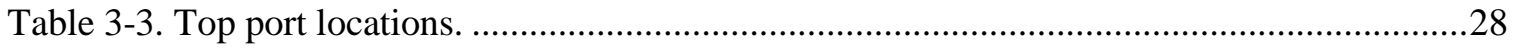

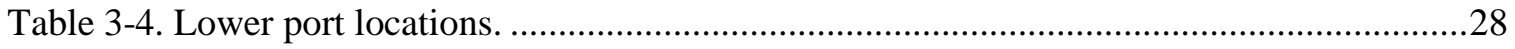

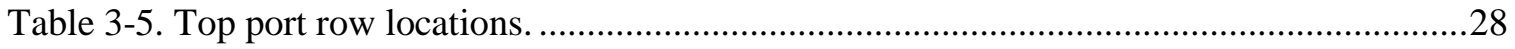

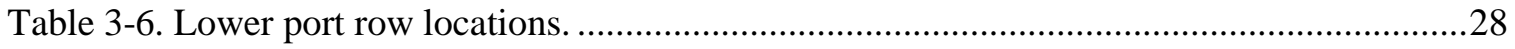

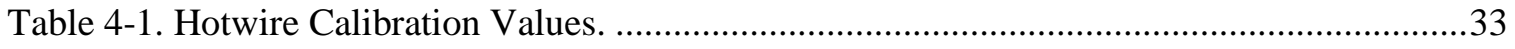

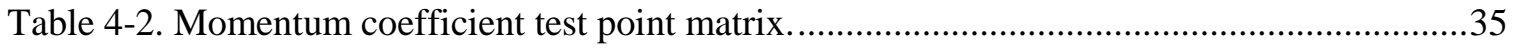

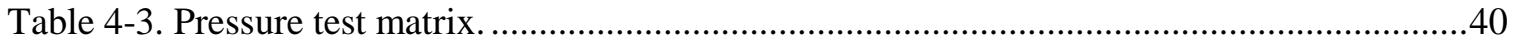

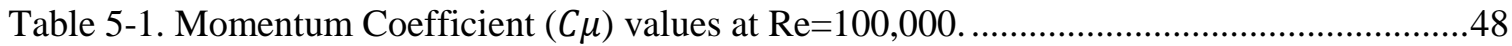




\section{LIST OF FIGURES}

Figure 3-1. Cal Poly 2 ft. x 2 ft. low speed wind tunnel.............................................................. 16

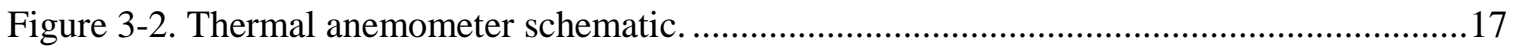

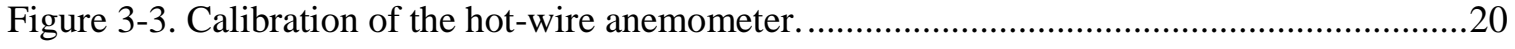

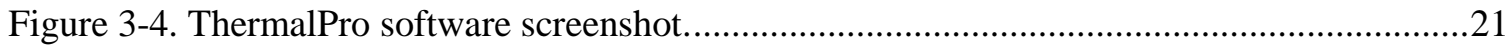

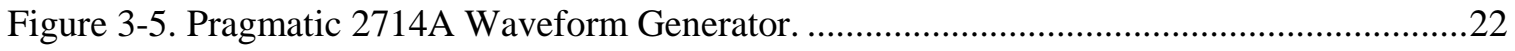

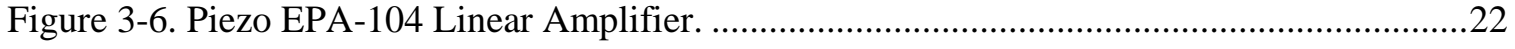

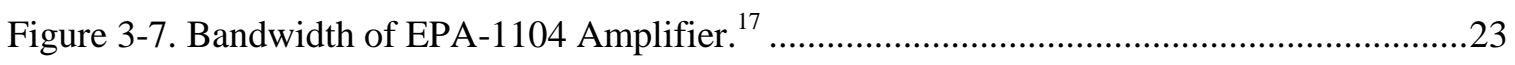

Figure 3-8. Piezoelectric disks with leads soldered to each side. Courtesy

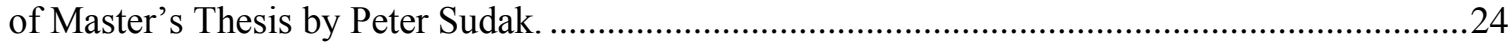

Figure 3-9. Two halves of the model with the actuator disks shown.

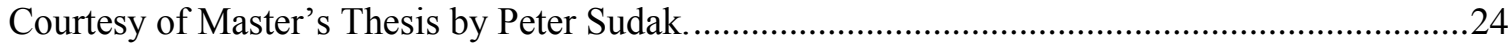

Figure 3-10. Top view of actuator cavity. Measurements in mm.................................................25

Figure 3-11. Front view of actuator cavity. Measurements in $\mathrm{mm}$. .............................................25

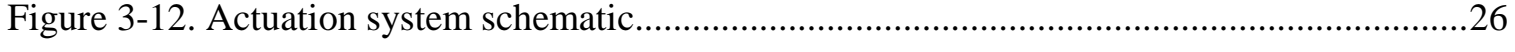

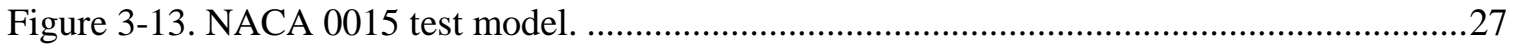

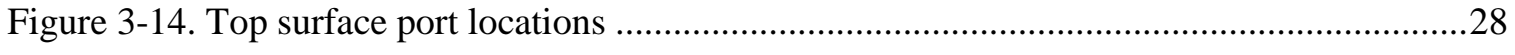

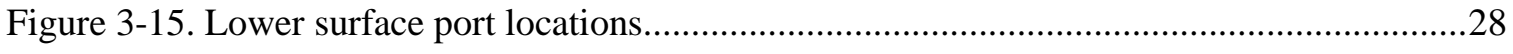

Figure 3-16. Scanivalve ZOC33/64Px-X1 pressure scanner.....................................................29

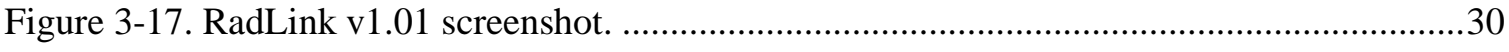

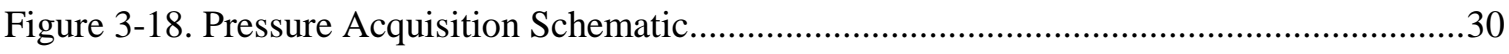

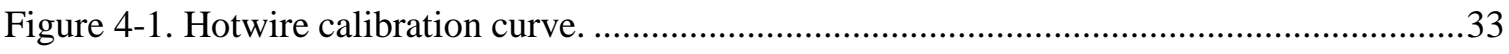

Figure 5-1. Pressure data comparison with Traub et al.'s 2D wing data $\alpha=20^{\circ}$. Traub et al.: $R e=420,000$, Current: $R e=100,000 .{ }^{13}$.....

Figure 5-2. Pressure data comparison with Seifert et al.'s 2D wing data at $\alpha=22^{\circ} . R e=150,000 .^{14}$

Figure 5-3. Hotwire velocity measurement for $100 \mathrm{~Hz}, 60 \mathrm{~V}$ actuation. .......................................46

Figure 5-4. Hotwire velocity measurement for $100 \mathrm{~Hz}, 180 \mathrm{~V}$ actuation. ....................................46

Figure 5-5. Hotwire velocity measurement for $36 \mathrm{~Hz}, 180 \mathrm{~V}$ actuation. ......................................47

Figure 5-6. Hotwire velocity measurement for $500 \mathrm{~Hz}, 60 \mathrm{~V}$ actuation. ......................................4

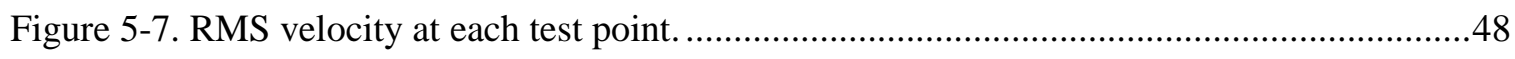

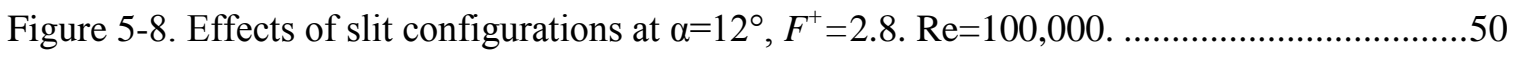

Figure 5-9. Effects of slit configurations with no actuation at $\alpha=16^{\circ}$.

$\operatorname{Re}=100,000$. 


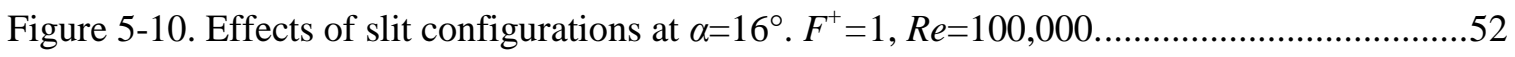

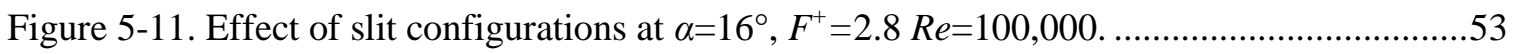

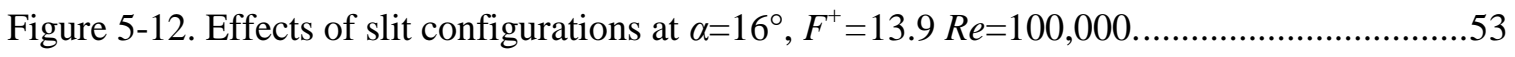

Figure 5-13. Effects of $\mathrm{F}^{+}=1$ actuation in the spanwise direction at $\alpha=16^{\circ}$.

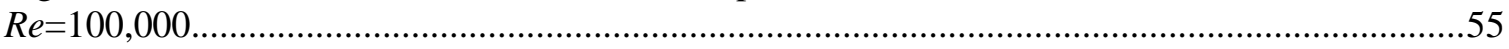

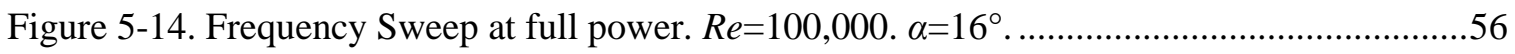

Figure 5-15. Effects of slit configurations with no actuation at $\alpha=20^{\circ}$.

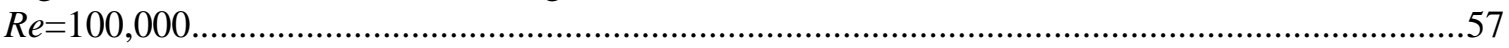

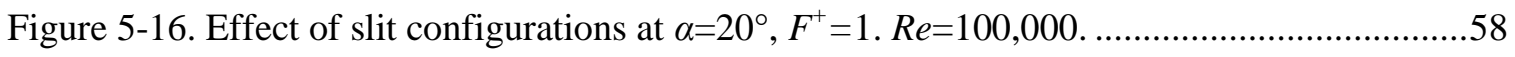

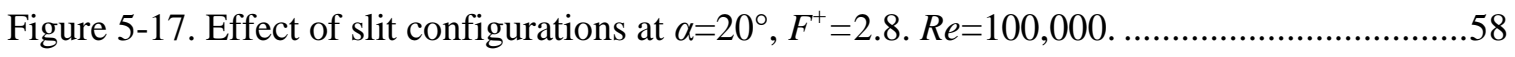

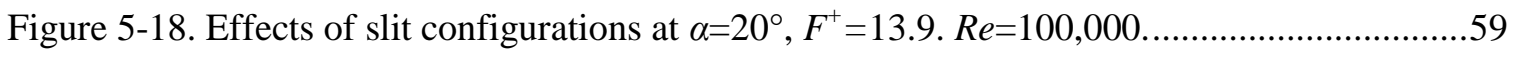

Figure 5-19. Effects of actuation power at $\alpha=20^{\circ}, F^{+}=13.9$. $R e=100,000 \ldots \ldots \ldots \ldots \ldots \ldots \ldots \ldots \ldots \ldots \ldots . . . .60$

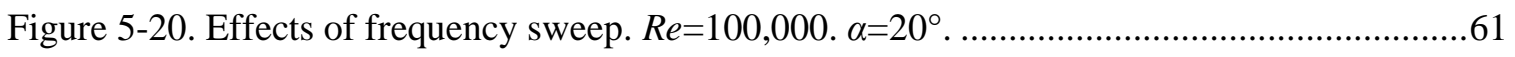

Figure 5-21. Section lift coefficient. $R e=100,000, F^{+}=13.9$.................................................62

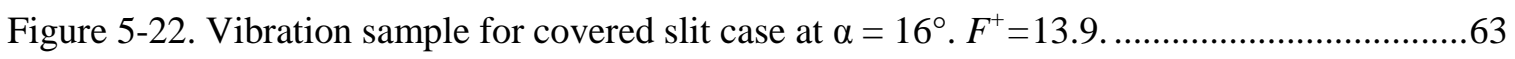

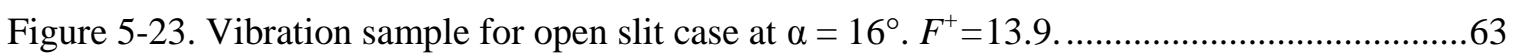

Figure 5-24. Average vibration for slit comparison test at $\mathrm{Re}=100,000$, $\alpha=16^{\circ}, 60 \mathrm{~V}$.

Figure 5-25. Maximum vibration for slit comparison test at $\mathrm{Re}=100,000$, $\alpha=16^{\circ}, 60 \mathrm{~V}$.

Figure 5-26. Average vibration for frequency and amplitude variation with open slit at $R e=100,000, \alpha=20^{\circ}$.

Figure 5-27. Maximum vibration for frequency and amplitude variation with open slit at $R e=100,000, \alpha=20^{\circ}$.

Figure 5-28. Uncertainty by slit condition for $\alpha=16^{\circ}, F+=2.8, R e=100,000$ 


\section{NOMENCLATURE}

\begin{tabular}{|c|c|}
\hline \multicolumn{2}{|c|}{ English Symbols } \\
\hline Symbol & Definition \\
\hline$A, B$ & Constants \\
\hline$A$ & Area \\
\hline$C$ & Capacitance \\
\hline $\mathrm{c}$ & Chord \\
\hline$C_{d}$ & Sectional drag coefficient, $d / q_{\infty} c$ \\
\hline$C_{l}$ & Sectional lift coefficient, $l / q_{\infty} c$ \\
\hline$C_{f}$ & Skin friction coefficient \\
\hline$C_{\mu}$ & Momentum Coefficient, $2 h v_{j, r m s}^{2} / c U_{\infty}^{2}$ \\
\hline$f$ & Actuation frequency \\
\hline$H$ & Momentum shape factor \\
\hline$h$ & Slit width \\
\hline$I$ & Current \\
\hline$J$ & Steady jet momentum $\rho U_{j}^{2} h$ \\
\hline$l$ & Length \\
\hline$k$ & Roughness height \\
\hline$P$ & Constant of proportionality \\
\hline$p$ & Pressure \\
\hline$q$ & Dynamic Pressure, $\frac{1}{2} \rho U^{2}$ \\
\hline$Q$ & Electric charge \\
\hline $\operatorname{Re}$ & Reynolds number, $\rho U_{\infty} c / \mu$ \\
\hline$S$ & Wing planform area \\
\hline$T$ & Total \\
\hline$t$ & Time \\
\hline th & Thickness \\
\hline$V$ & Voltage \\
\hline$v$ & Vertical velocity \\
\hline$u$ & Streamwise velocity \\
\hline$U$ & Velocity \\
\hline$x$ & Horizontal distance \\
\hline
\end{tabular}




$\begin{array}{ll}\mathrm{y} & \text { Vertical distance } \\ \mathrm{Vol} & \text { Volume } \\ K 1 & \text { Constant } \\ \tau 1 & \text { Constant }\end{array}$

\section{Greek Symbols}

$\begin{array}{ll}\text { Symbol } & \text { Definition } \\ \alpha & \text { Angle of Attack } \\ \lambda_{3} & \text { Blockage constant } \\ \delta^{*} & \text { Displacement thickness } \\ \mu & \text { Dynamic Viscosity } \\ \rho & \text { Density } \\ \tau & \text { Shear stress } \\ \theta & \text { Momentum thickness }\end{array}$

\section{Subscripts}

$\begin{array}{ll}\text { Symbol } & \text { Definition } \\ a & \text { Axial } \\ B & \text { Buoyancy } \\ e & \text { Local } \\ j & \text { Jet } \\ k & \text { Roughness height } \\ n & \text { Number of samples } \\ n & \text { Normal } \\ p & \text { Pressure } \\ q & \text { Dynamic pressure } \\ x & \text { Trip strip distance } \\ W & \text { Wake } \\ w & \text { Wall } \\ \infty & \text { Free-stream } \\ p e a k & \text { Peak } \\ r m s & \text { Root mean square } \\ \text { tunnel } & \text { Tunnel } \\ \text { pitot } & \text { Pitot } \\ \text { sb } & \text { Solid blockage }\end{array}$


$w b$

te

Wake blockage

Trailing edge 


\section{Introduction}

Boundary layer flow control has become a popular method for achieving high lift at low speeds. Such situations are useful for cargo or commercial aircraft that may need to generate a large amount of lift at low speeds for takeoff and landing. It has become well known that using a stream of air out of a slit can be used to delay separation. ${ }^{6}$ In large aircraft, this can mean a much higher maximum $C_{L}$, and can prevent stall at low speeds. The drawback from using this type of system is that the amount of air needed is large, necessitating a large compressor and heavy lines to run the air to where it is needed. This adds weight and complexity that make the vehicle more expensive to operate.

Synthetic jets can theoretically recreate the separation prevention possible with traditional steady jets, but without as much of the added weight and cost. Previous work on synthetic jets was performed largely on airfoils rather than finite wings. ${ }^{6}$ These studies found that synthetic jets were effective at reducing separation, but few were focused on examining the effectiveness of synthetic jet flow control along the span of a finite wing. ${ }^{6}$

The primary goal of the current study is to find the change in effectiveness of the control actuation along the span of a finite wing. It is necessary to delay separation for this investigation, so the preliminary goal was simply to verify that separation could be successfully delayed. During preliminary testing, it was observed that the model vibrations were influencing the flow, so another goal was added to investigate that phenomenon.

The airfoil chosen for this experiment was the NACA 0015, as this is a widely used geometry in similar previous experiments. Because cost is a major factor in this research, it is desirable to have the capability to test synthetic-jet applications with a limited budget. The piezoelectric 
actuators were chosen at a sizeable cost savings over voice coil actuators or an external compressor.

The specific goals of this experiment are to:

1. Verify that the piezoelectric actuators are viable for use in delaying separation.

2. Quantify the change in effectiveness of the flow control toward the wingtip, and the change in the stall pattern.

3. Evaluate the influence of model vibrations on the flow field. 


\section{Background}

\subsection{The Piezoelectric Effect}

A piezoelectric material is one in which a change in the mechanical stress of the material produces a correlating electric charge. The effect was first discovered by Jaques and Pierri Curie in 1880. Specifically, it is a dielectric material with noncentrosymmetric crystals whose strain varies directly with the external electric field.

This change in stress can be squeezing or stretching, depending on the direction of the electric field. The property is transitive; a change in mechanical stress should also result in a change in the electric field. A disk of such a material will contract and expand under various electrical conditions. This type of material can also be useful as a sensor, where the mechanical strain of the material causes a corresponding electric charge that can be measured. A tensile strain on the material results in a positive voltage difference across the material, while a compressive strain results in a negative voltage difference.

A dielectric material is one that changes shape in the presence of an external electric field. The dielectric crystal lattice is comprised of cations and anions connected by interionic chemical bonds. "When an external electric field is applied to the material, the cations get displaced in the direction of the electric field and the anions get displaced in the opposite direction, resulting in net deformation of the material.",

There are 32 total types of dielectric crystals. 11 of these are centrosymmetric, meaning that the crystal structure has a center of symmetry. The remaining 21 crystals are noncentrosymmetric, meaning that the structure has no center of symmetry. ${ }^{1}$

Placing the centrosymmetric materials in an electric field lead to what is called the electrostrictive effect. The crystal's symmetry causes the movement of the cations and the anions to cancel each other out, causing nearly no net deformation in the lattice. Due to the anharmonicity in the bonds, 
there is a small deformation of the lattice, proportional to the square of the electric field. Because all dielectrics have this property, all are said to be electrostrictive. This effect is represented in the equation

$$
x=Q P^{2}
$$

where $x$ is the deformation distance, $Q$ is charge, and $P$ is the material constant of proportionality. Placing the noncentrosymmetric materials in an electric field causes a condition called the piezoelectric effect. With the exception of the octahedral structures, the asymmetric movement of ions in the presence of an electric field will cause a significant net deformation in the structure. This movement is directly proportional to the electric field.

A subcategory of piezoelectric exist called pyroelectric materials, which have spontaneous polarization. Some of these materials can have the spontaneous polarization reoriented with an electric field. These are called ferroelectric materials. This material is the best for actuator applications, as it yields the greatest strain per electric field strength.

As previously stated, there is a linear relationship between the mechanical strain and the electrical field, although this is not an ideal description of the relationship. There is a hysteresis effect in this relationship. As the electric field is initially increases, the strain increases also until it approached a saturation point, where there are diminishing returns on the strain for the current electric field. For Lead Zirconate Titanate (PZT, PbZr(Ti)O3), the most commonly used piezoelectric material; this saturation point is in the $1-1.5 \mathrm{kV}$ range. When the electric field is reduced, as it would in the presence of an alternating voltage input, the change in strain is significantly reduced from the initial case until it reaches zero at some negative electric field. A further increase in electric field in this direction results in a quickly increasing strain until the saturation point. If the electric field now changes direction and increases, the strain will similarly act in such a way that is symmetrical with the decreasing case. It is noteworthy that the symmetry 
of the hysteresis effect with the absolute value of the strain, and that the strain would become negative in the presence of a negative electric field.

The most common form of piezoelectric material is Lead Zirconate Titanate (PZT). The first step in manufacturing a PZT material is to make a powder that can be molded into various applications. The powder is mixed with a binder and pressed in a high pressure mold. In the manufacturing process, the ferroelectric material must undergo a process called poling to permanently align individual ferroelectric domains. The material is heated nearly to the phase transition temperature and a powerful electric field is applied for several hours. The material is let to cool with the electric field in place so that the ferroelectric domains are frozen in place. ${ }^{1}$

\subsection{Piezoelectric Actuators}

Piezoelectric devices are layered discs of ceramic that react to a voltage difference across the disc. In these actuators, a mechanical displacement is caused by an electric voltage. The major types of actuators are the stack actuator, the bender actuator, and the cymbal actuator. Because this experiment employs a bender actuator, this will be the only topic of discussion.

A unimorph is comprised of an active piezoelectric layer and a separate passive metal layer. When the active layer is charged, it deforms and causes motion in the actuator. In a flat disc actuator, the contraction will cause the device to bend and resemble a dome, since the passive layer is not changing size.

A bimorph has two active piezoelectric layers with a passive metal layer sandwiched between. This allows each side of the disc to be actuated individually, allowing for a greater range of motion. In this case, the polarity of each disc would be oriented in the same direction with the passive layer grounded. It is also possible to have a bimorph actuator without the center metal plate, which is referred to as a shim. In this case, the two piezoelectric layers would simply be 
bonded to each other. In this case, the two layers would be situated such that their polarity is opposite, so that one side would contract and the other expand under the same electric field.

\subsection{Boundary Layer Transition}

The transition of a boundary from laminar to turbulent is particularly important. The commonly quoted visible example of this is smoke coming off the end of a cigarette. At first the smoke rises smoothly, and at some point becomes turbulent and mixes with the surrounding air.

After a century of research, the full mechanisms involved in the transition process are still not fully understood, although great progress has been made. Transition technically refers to the entire process from the breakdown of laminar flow until turbulence. Tollmein-Schlichting waves were predicted in 1929 , which are an initial instability that leads to turbulence. These are initially two-dimensional. The Tollmein-Schlichting waves quickly begin to show three-dimensional disturbances, which are amplified. From here, the still-laminar vortices begin to breakdown into smaller units until they approach randomness. From this state, turbulence erupts from various random spots. The spots grow downstream and engulf the local laminar flow until they coalesce into fully turbulent flow. ${ }^{2}$

The location of the transition is primarily dependent on Reynolds number. Other significant factors are the pressure gradient, free stream turbulence, and surface roughness. It is also possible to use suction or blowing to influence the transition location. ${ }^{3}$

In a high speed flow past a thin body, laminar flow is valuable because the skin friction drag is lower. For this reason, a designer might delay the transition point as much as possible, leading to the invention of natural-laminar airfoils. For bluff bodies, however, the main component of drag is pressure drag caused by separation. Turbulent flow is able to overcome adverse pressure gradients better than laminar flow, because of the higher energy in the boundary layer. It is 
therefore desirable to make the transition point as early as possible. This is the reason for having dimples on a golf ball.

\subsection{Turbulent Flow Separation}

Many airfoils and bluff bodies exhibit phenomena known as separation. When air accelerates around or over a body, a large change in pressure can take place very quickly. If this change happens too quickly over a short distance, the flow of air will not stay attached to the body and will separate. When the pressure is increasing in the flow direction, this is called an adverse pressure gradient. A higher pressure gradient $(d p / d x)$ will increase the likelihood of separation. It is assumed in this case that the flow is incompressible. ${ }^{4}$

According to Anderson, there are two major consequences of separated flow about an airfoil. ${ }^{4}$ The first is that the change in pressure distribution will cause a loss in lift. The high pressure on the upper surface of the airfoil causes a reduction in the pressure difference across the airfoil that creates lift. The second is that the large pressure increase in the aft section of the airfoil causes an increase in the amount of drag.

For two-dimensional boundary layer flow, If the momentum equation is reduced using the wall conditions $u=v=0$, the resulting equation is

$$
\left.\frac{\partial^{2} u}{\partial y^{2}}\right|_{y=0}=\frac{1}{\mu} \frac{d p}{d x}
$$

This shows that the concavity of the $u$ velocity in the $y$ direction has the same sign as the pressure gradient in the $x$ direction. A favorable pressure gradient occurs when $d p / d x<0$. The condition where $d p / d x>0$ is called an adverse pressure gradient. In this case, the positive pressure gradient causes a reversal of concavity in the boundary layer velocity profile. This negativeconcavity region is known as separation. 
There are some analytical methods for predicting separation. The Karman's integral-momentum equation states that

$$
\frac{d \theta}{d x}+(2+H) \frac{\theta}{U_{e}} \frac{d U_{e}}{d x}=\frac{C_{f}}{2}=\frac{\tau_{w}}{\rho U_{e}^{2}}
$$

where the momentum thickness $\theta$, momentum shape factor $H$, and displacement thickness $\delta^{*}$ are defined by the relations

$$
\begin{gathered}
\theta=\int_{0}^{\infty} \frac{\bar{u}}{U_{e}}\left(1-\frac{\bar{u}}{U_{e}}\right) d y \\
H=\frac{\delta^{*}}{\theta} \\
\delta^{*}=\int_{0}^{\infty}\left(1-\frac{\bar{u}}{U_{e}}\right) d y
\end{gathered}
$$

Using this relation, separation occurs when $C_{f}$ reaches zero. The lesson here is that a high shape factor is associated with separation. ${ }^{2}$

\subsection{Active Flow Control}

Flow control here refers to a method of delaying boundary layer separation, usually with the goal of reducing the associated pressure drag. Historically, many passive devices have been used for this purpose, such as dimples, vortex generators, etc. ${ }^{5}$ As the name implies, a passive flow control device does not use power, and is simply a design characteristic of the body. An active flow control device, on the other hand, uses some type of physical motion or air control to prevent separation. Because the current experiment is on an active device, these will be the topic of discussion going forward.

Among the first flow control applications was the addition of roughness patterns to a golf ball, around 1880. This new ball proved to fly much farther than its smooth predecessors, although the reason remained unknown. Ludwig Prandtl published a paper in August 1904 that introduced the 
concept of a boundary layer, which was proposed to explain the physics of skin friction and separation. With knowledge of the boundary layer, physicists and engineers were able to begin to work towards boundary layer control. ${ }^{5}$

The most common type of active flow control is steady suction or blowing, where a fan or compressor pulls or pushes air through a slit or perforated surface to influence the boundary layer. The complexity of these systems, and the weight they incur, generally prevent them from being implemented on regular aircraft. One significant example of this type of control is on the C-17 Globemaster, which diverts exhaust gas over its flaps to greatly reduce the stall speed of the aircraft.

Another type of active flow control is periodic excitation. This method uses either a zero-massflux excitation where the momentum in and out of the actuator orifice is equal, or a superimposed excitation where the periodic actuation is added to a steady flow. The advantage of these excitation methods is that the same benefit in separation prevention can be had with an order of magnitude less power required. Also, these systems may be simpler, making them cheaper and lighter than their steady-flow counterparts. The actuators used in the present experiment are of the zero-mass-flux variety, also known as synthetic jets.

The main characteristics of active flow control with synthetic jets are the power required to operate the actuator, the resultant RMS mass flow through the orifice, and the frequency at which the actuation is implemented. These topics are further defined in the following sections.

\subsection{Momentum Coefficient}

In order to communicate the relative power of the momentum addition influencing the flow field, a non-dimensional value is needed. The coefficient of momentum $C_{\mu}$ is used for this purpose.

$$
C_{\mu}=\frac{\rho U_{j}^{2} h}{c q}=\frac{2 U_{j}^{2} h}{c U_{\infty}^{2}}
$$


The jet momentum value can either be constant for the case of steady active flow control, or timeaveraged root mean square (RMS) for oscillatory flow control. If there are steady and oscillatory components superimposed on each other, the momentum coefficient is traditionally reported in the form (steady, RMS). ${ }^{6}$ Since the synthetic jet actuator is a zero-mass-flux actuator, $U_{j}$ represents only the RMS of the velocity excitation.

\subsection{Non-Dimensional Frequency}

In a similar manner to the momentum coefficient, a value is needed to compare the relative frequency of the actuation so that it can be compared and scaled. For the frequency the value $F^{+}$ is defined such that

$$
F^{+}=\frac{f c}{U_{\infty}}
$$

It has been noted in previous studies that the optimal $F^{+}$range seems to be near one. ${ }^{6}$

\subsection{NACA 0015}

The NACA 0015 airfoil is the geometry used in this experiment. It was chosen for its extensive use in previous testing using synthetic jet actuators. ${ }^{13,14}$ It is a simple geometry, and its thickness is representative of airfoils in use today. ${ }^{8}$ The airfoil has zero camber, and a maximum thickness of $15 \%$ of the chord length. This maximum thickness location is located at $30 \%$ chord. $^{7}$

\subsection{Wing-tip Vortices}

The end of a finite wing section causes three dimensional effects that inhibit lift and produce drag. These vortices are the main factor that reduces performance from the two-dimensional airfoil.

An airfoil creates lift by moving the air in such a way that there is a pressure difference between the top and bottom surfaces of the airfoil. This presents a problem at the wing tip, where the 
higher pressure air from the bottom surface moves around the wing toward the lower-pressure top surface. This constant circulation causes a vortex to form at the wing tip, greatly affecting the lift and drag caused by the wing.

For the purposes of the current test, it is desired to investigate how the presence of the wing tip influences the flow field while the actuators are running. Because the model wing is rectangular, it is expected that separation will start at the root of the wing and travel out towards the tip as angle of attack is increased.

\subsection{Semi-span Model Testing}

A semi-span model, also known as a reflection plane model ${ }^{3}$, uses a model that is cut in half and mounted against one of the wind tunnel walls. For a given chord length, the use of the semi-span allows a wing model with a larger effective aspect ratio to be used in a given wind tunnel. This increases the useful Reynolds number range, which is a major limitation in many low speed wind tunnels. ${ }^{3}$

The main drawback to using a semi-span model is that the wind tunnel wall may obstruct the natural flow field of the full-scale model. This has been shown to effect stall performance. A bulk of the available research on the viability of semi-span testing has been on sizing the standoff section which separates the model from the wind tunnel wall, and using heat control and boundary layer suction to reduce the effects of the wall. ${ }^{9}$ A standoff was not used in this experiment.

\subsubsection{Dual Location Separation Control on a Semispan Wing}

A semi-span separation control experiment was conducted at the NASA Langley Research Center Basic Aerodynamics Research Tunnel (28” x 40”). This experiment featured a NACA 0015 with a $30 \%$ flap, with a chord length of 12 " and a span of 24 ". The model had a set of two-dimensional zero mass-flux actuator slots. The first was located at the leading edge, and the second was located at the deflected flap shoulder. The flap was separated into three sections so that the 
experiment could be run in three configurations: only the two inboard flaps deflected to $20^{\circ}$, all flaps deflected to $20^{\circ}$, and with all three deflected to $40^{\circ}$. The sizes of the actuator slots were not stated. $^{8}$

The model was mounted horizontally, and lift and drag forces were calculated by integrating the pressure measurements made over the surface of the airfoil. The paper does not describe the actuators in detail, although they were located outside of the model, with two interior plenums to even out the oscillations along the span.

Test runs of leading-edge control at $\mathrm{Re}=500,000$ were compared with a similar experiment at Tel-Aviv University at $\mathrm{Re}=200,000$. The tested frequency range was $0.5 \leq F_{l e}^{+} \leq 4.5$, and it was found that the optimal range was $0.5 \leq F_{l e}^{+} \leq 2$ although increasing $C_{\mu}$ lead to an increased effective frequency range. ${ }^{8}$

Unfortunately, neither configuration tested in this experiment had the flaps at zero deflection. While this prevents the direct comparison of data, it shows that the precedence exists for such an experiment. Also, the fact that the span-wise pressure port locations were centered on the flaps prevents an accurate account of how the wingtip influenced the separation on the wing.

\subsection{Previous Piezoelectric Experiments}

It was of vital performance to review previous work. This process ensured that the final goal was feasible before spending money acquiring the necessary parts.

\subsubsection{Synthetic Jets with Piezoelectric Diaphragms}

One experiment involved testing various actuators using sine, square, and saw-tooth waveforms and evaluating the resulting jet velocities. The experiment was run using three different types of actuator construction. The Bimorph actuator was driven at $140 \mathrm{Vpp}$, the Thunder at $400 \mathrm{Vpp}$, and the RFD at $800 \mathrm{Vpp}$. 
Table 2-1 shows the maximum velocities for each condition as tested by Mane, et. al. ${ }^{10}$ It can be seen that the Bimorph actuator achieves the highest peak velocity for each driven waveform. Of these, the saw-tooth and square waveforms produced significantly higher velocities than the sine waveform. In addition, the voltage requirement of the Bimorph was the least. The authors note

Table 2-1. Maximum Velocities Measured in $\mathbf{m} / \mathrm{s}^{10}$

\begin{tabular}{|c|c|c|c|}
\hline Waveform/Diaphragm & Sine & Saw-tooth & Square \\
\hline Bimorph & $7 \pm 2$ & $35 \pm 6$ & $36 \pm 5$ \\
\hline Thunder & $5 \pm 2$ & $26 \pm 2$ & $27 \pm 2$ \\
\hline RFD & $6 \pm 2$ & $28 \pm 2$ & $32 \pm 2$ \\
\hline
\end{tabular}

that the peak jet velocity resulted from a frequency in the range of 40-100 Hz. $100 \mathrm{~Hz}$ was the maximum frequency used for the bimorph actuator.

The main lesson taken from this experiment was that the sine wave was ineffective for creating a synthetic jet. This was confirmed by conducting preliminary testing with a single actuator. It was decided that the square wave would be tested in the present experiment.

\subsubsection{Towards a practical piezoceramic diaphragm based SJA for high subsonic applications}

The next experiment, performed by Gomes et. al., ${ }^{11}$ tested the effects of the chamber and orifice depth on the maximum jet velocity. The chamber depth was varied until a maximum was found with a constant orifice depth. The orifice was then varied until another maximum was found which optimized each variable. ${ }^{11}$

This investigation resulted in a maximum jet velocity of $130 \mathrm{~m} / \mathrm{s}$ through a $1.2 \mathrm{~mm}$ orifice at frequencies around $2500 \mathrm{~Hz}$. The ideal parameters were a chamber depth-to-orifice diameter ratio of 0.6, and an orifice depth-to-orifice diameter ratio of 2.1. This is vital to the present endeavor, since it was helpful in proving that the piezoelectric SJA would be capable of reaching the necessary $\mathrm{C}_{\mu}$ to compare with the voice-coil actuators. ${ }^{1}$ 
This study evaluated the maximum jet velocity of a piezoelectric SJA at various frequencies. It was expected that the maximum would occur either at the natural resonant frequency of the actuator, or at the Helmholtz frequency which is the resonant frequency of the cavity. This study showed that the natural frequency of the actuator would maximize the jet velocity. In this case, the natural frequency of the actuator was $3.9 \pm 0.5 \mathrm{kHz} .{ }^{11}$

This experiment provided a basis for the idea that the natural frequency of the actuator disk could influence the resultant jet velocity. This information was useful in preparing the test matrix for the present experiment to prevent actuator failure. It also showed that the cavity volume could play a role in the resulting jet velocity.

\subsubsection{Momentum Coefficient as a Parameter for Aerodynamic Flow Control with Synthetic Jets}

A similar experiment was tested at $R e=100,000$ and using a NACA 0025 airfoil with a chord length of $30 \mathrm{~cm}$. All testing was done at an angle of attack of $\alpha=5^{\circ}$. In this test the actuator slit was $140 \mathrm{~mm}$ by $0.5 \mathrm{~mm}$. The majority of the study was based on the natural frequency of the actuators at $935 \mathrm{~Hz}$. The slit was located $101 \mathrm{~mm}$ downstream of the leading edge (33.7\%), and had a width of $0.5 \mathrm{~mm} .^{12}$

The baseline experiment measured a $C_{d}$ of 0.076 . By actuating the synthetic jets to $C_{\mu}=1.2 \times 10^{-2}$, the authors state that the wake width was substantially reduced as compared to the uncontrolled case. It is also stated that the maximum jet velocity was $16.65 \mathrm{~m} / \mathrm{s}$, and that the minimum velocity was $3 \mathrm{~m} / \mathrm{s}$. Although actuation at $C_{\mu}=1.56 \times 10^{-3}$ yielded no change in drag, increasing the actuation strength to $C_{\mu}=3.09 \times 10^{-3}$ yielded a $C_{d}$ of 0.036 . A further increase to $C_{\mu}=6.76 \times 10^{-3}$ caused the $C_{d}$ to drop to 0.0276 . Additional increases of $C_{\mu}$ had a negligible effect on drag. ${ }^{12}$

This test showed that piezoelectric devices are capable of delaying separation and reducing drag on an airfoil. At $C_{\mu}=3.09 \times 10^{-3}$, a $52 \%$ reduction in drag was observed. Further increases in led to only modest further drag reduction. ${ }^{12}$ 


\subsection{Other Similar Studies}

\subsubsection{An Experimental Investigation of Pulsed Air Blowing Separation Control on a NACA 0015}

Traub et al. ${ }^{13}$ studied a case with a 2D NACA 0015 wing with slits at $10 \%, 30 \%$, and $50 \%$ chord at $\operatorname{Re}=420,000$. Their model used an external pulsed air blower for actuation with the inside of the model acting as a settling chamber. ${ }^{13}$

This study found that separation was delayed from $\alpha=17^{\circ}$ to $22^{\circ}$. Also, the position of the slit changed the shape of the separated region. No change in lift was observed in the angles less than the stall angle. This study provided a useful point of reference, since it included a pressure distribution at a test condition that could be replicated for comparison.

\subsubsection{Delay of Airfoil Stall by Periodic Excitation}

Seifert et al. ${ }^{14}$ also experimented with periodic excitation on a 2D NACA 0015 wing model, as well as Eppler E-214, I.A.I PR8-40, and SPCA-1 models. The NACA 0015 model had a 25\% chord trailing-edge flap with excitation slits at the leading edge and at the flap shoulder. This test used a Reynolds number range up to $150,000 .{ }^{14}$

The study concluded that the most effective actuation point was at the natural separation point. As with the Traub case, this study included a figure of the pressure distribution over a NACA 0015 wing that was a useful point of comparison for the current case. 


\section{Experimental Apparatus}

\subsection{Wind Tunnel}

Testing was conducted in the $0.61 \mathrm{~m} \times 0.61 \mathrm{~m}$ ( $2 \mathrm{ft} . \mathrm{x} 2 \mathrm{ft}$.) low speed wind tunnel in the Cal Poly Fluid Dynamics Lab run by the Mechanical Engineering department. The tunnel is an opencircuit design, with a maximum velocity of $49 \mathrm{~m} / \mathrm{s}(110 \mathrm{mph})$. The inlet of the tunnel measures $1.52 \times 1.52 \mathrm{~m}(5 \mathrm{ft} . \times 5 \mathrm{ft}$.) leading to a contraction ratio of $6.25: 1$. This tunnel was designed and manufactured by Engineering Laboratory Design Inc.

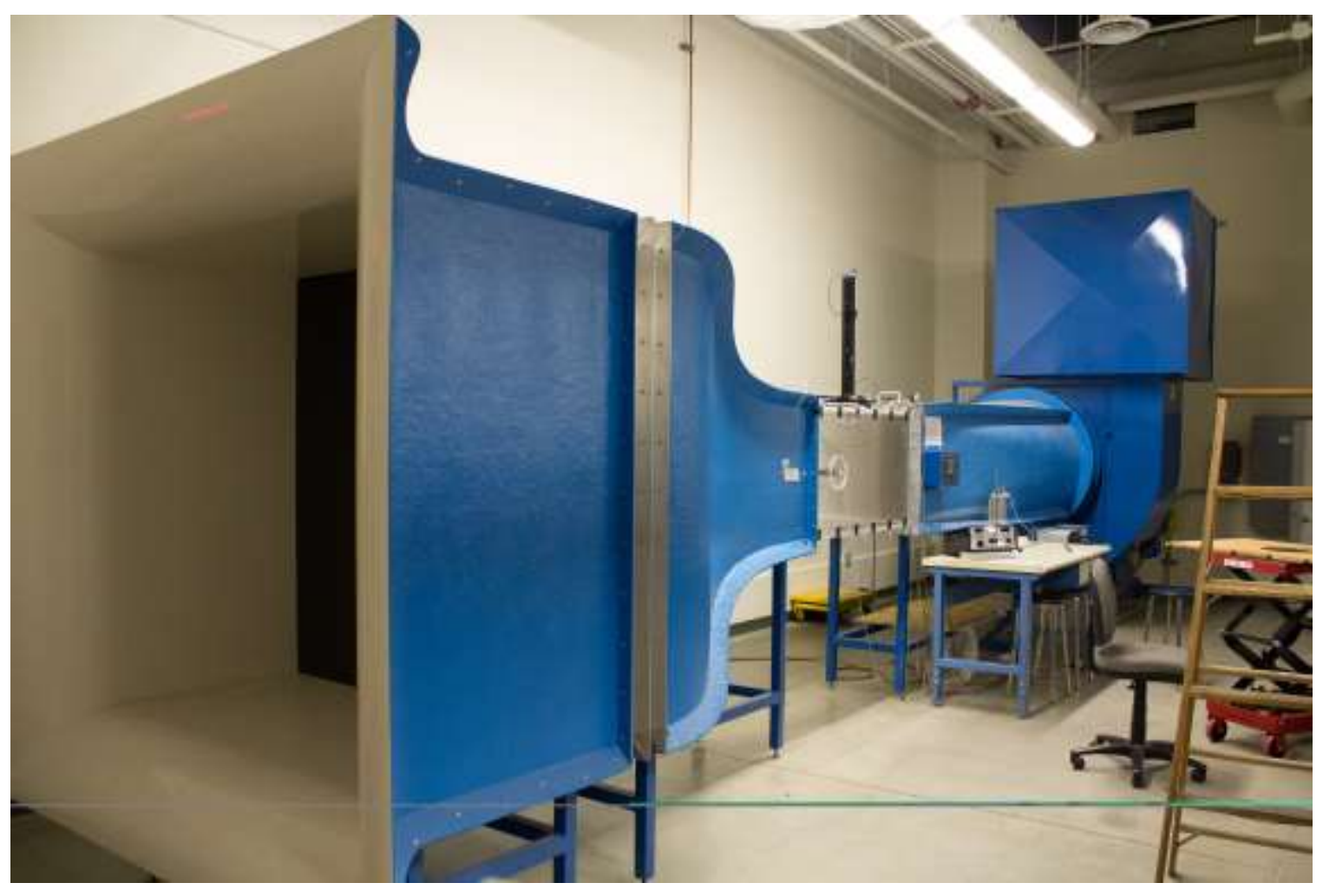

Figure 3-1. Cal Poly 2 ft. $x 2$ ft. low speed wind tunnel.

The tunnel is driven by a $40 \mathrm{hp}$ three-phase electric motor made by Toshiba, Model 80404FLF3USH02. The fan is made by Aerovent, model 39 ARR.9R CL.2.

The model was placed 0.6 meters $(2 \mathrm{ft})$ into the test section, which measured 1.2 meters $(4 \mathrm{ft})$ in length. This test section has two removable panels, one of which was custom made for this 
experiment. This panel comprised the floor of the wind tunnel, with the model protruding through.

\subsection{Hotwire Anemometer}

A hotwire anemometer was used to measure the momentum coefficient generated by the actuators. The IFA 300 Constant Temperature Anemometer System was used. The device consists of an A/D board, the IFA300 cabinet, a cable to connect the probe, the probe support, and the probe itself.
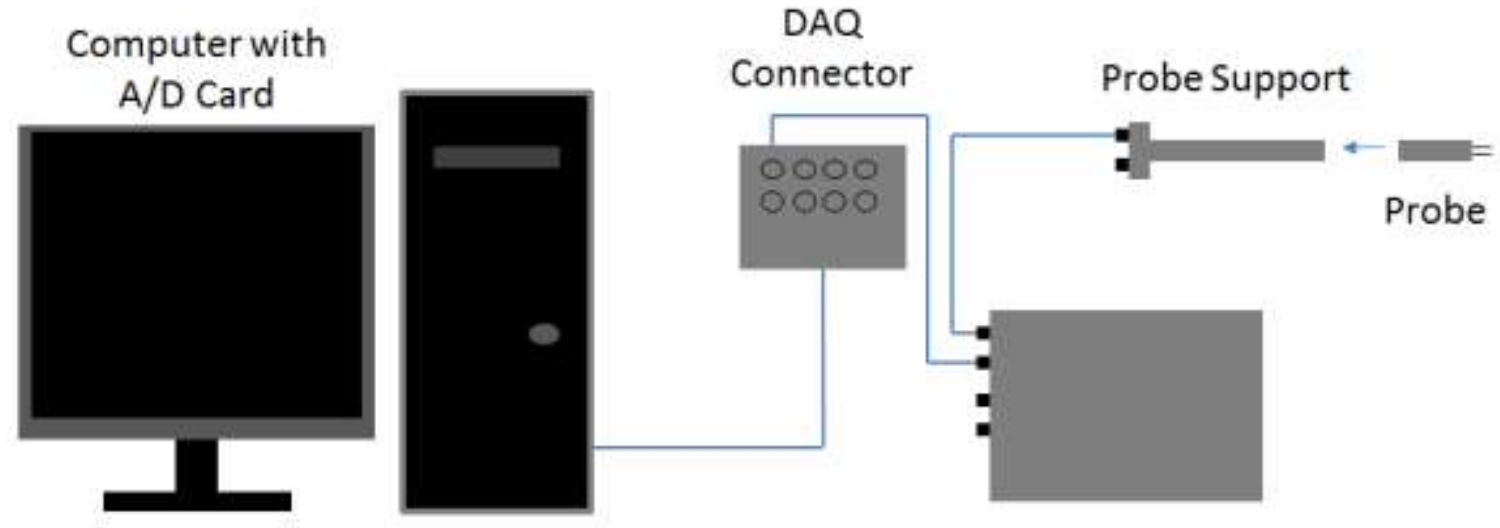

IFA 300

Figure 3-2. Thermal anemometer schematic.

A constant temperature system works by using a Wheatstone bridge circuit with the sensor making up one side of the bridge. The flow past the hotwire sensor causes convective cooling, thus reducing its temperature, resistance, and voltage. The feedback amplifier reacts by increasing the voltage, and therefore the current, through the sensor. This heats the sensor back to its original temperature. The elevated voltage reading can then be compared with a calibrated value to yield the velocity of the flow past the sensor. ${ }^{15,16}$

The hotwire is calibrated using a fourth order polynomial,

$$
U j=A V^{4}+B V^{3}+C V^{2}+D V+E
$$


where $\mathrm{V}$ is voltage in Volts and $U_{j}$ is the flow speed in $\mathrm{m} / \mathrm{s}$. This order of polynomial is used because the voltage changes much more quickly for the lower velocity range than it does in the higher range. This makes the higher order polynomial a good choice for this application.

Table 3-1. IFA 300 Constant Temperature Anemometer specifications.

\begin{tabular}{|l|l|}
\hline Number of Channels & 2 \\
\hline Amplifier Drift & $0.3 \mu \mathrm{V} /{ }^{\circ} \mathrm{C}$ \\
\hline Frequency Response & $260 \mathrm{kHz}$ \\
\hline Maximum Probe Current & $0.8 \mathrm{~A}$ \\
\hline Maximum Bridge Voltage & $12 \mathrm{VDC}$ \\
\hline Sensor Operating Resistance & $1.5 \Omega$ to $80 \Omega$ in $0.01 \Omega$ steps \\
\hline
\end{tabular}




\subsection{Hotwire Sensor}

The probe used in this study was a TSI 1210-T1.5. The sensor is a platinum plated tungsten wire, with an aspect ratio of 333 . The aspect ratio of a hotwire is defined to be the length over the

diameter. ${ }^{15}$ It is recommended that the aspect ratio be greater than 100 , which this wire exceeds. $^{15}$

Table 3-2. Hotwire sensor specifications. TSI Model 1210-T1.5 .

\begin{tabular}{|l|l|l|l|l|l|}
\hline $\begin{array}{l}\text { Sensor } \\
\#\end{array}$ & $\begin{array}{l}\text { Probe RES } \\
\text { at } 0^{\circ} \mathrm{C} \text { R0, } \Omega\end{array}$ & R100-R0, $\Omega$ & $\begin{array}{l}\text { Recommended } \\
\text { Oper. RES } \\
\text { R0p, } \Omega\end{array}$ & $\begin{array}{l}\text { Recommended } \\
\text { Oper. Temp. } \\
\text { T0p, deg }{ }^{\circ} \mathrm{C}\end{array}$ & $\begin{array}{l}\text { Internal Probe } \\
\text { RES Rint, } \Omega\end{array}$ \\
\hline 1 & 5.86 & 2.12 & 11.16 & 250 & 0.36 \\
\hline
\end{tabular}

\subsection{Hotwire Calibrator}

The accuracy of the jet velocity measurement is vital to the accuracy of this test. For this reason, the hotwire attached to the IFA300 anemometer is calibrated using the TSI 1127A Air Velocity Calibrator with a MKS Baratron 220DD-0100A2B pressure transducer. This pressure transducer has a full scale range of 1,000 Torr. Pressure for the system comes from the building supply air at $44.8 \mathrm{kPa}(65 \mathrm{psi})$.

The calibrator consists of a flow conditioning section with a pressure regulator, a settling chamber which allows the velocity to be read accurately, and a stand that allows for the calibration of a hotwire in multiple orientations. The calibrator also features coarse and fine adjustment knobs for the jet exit velocity. 


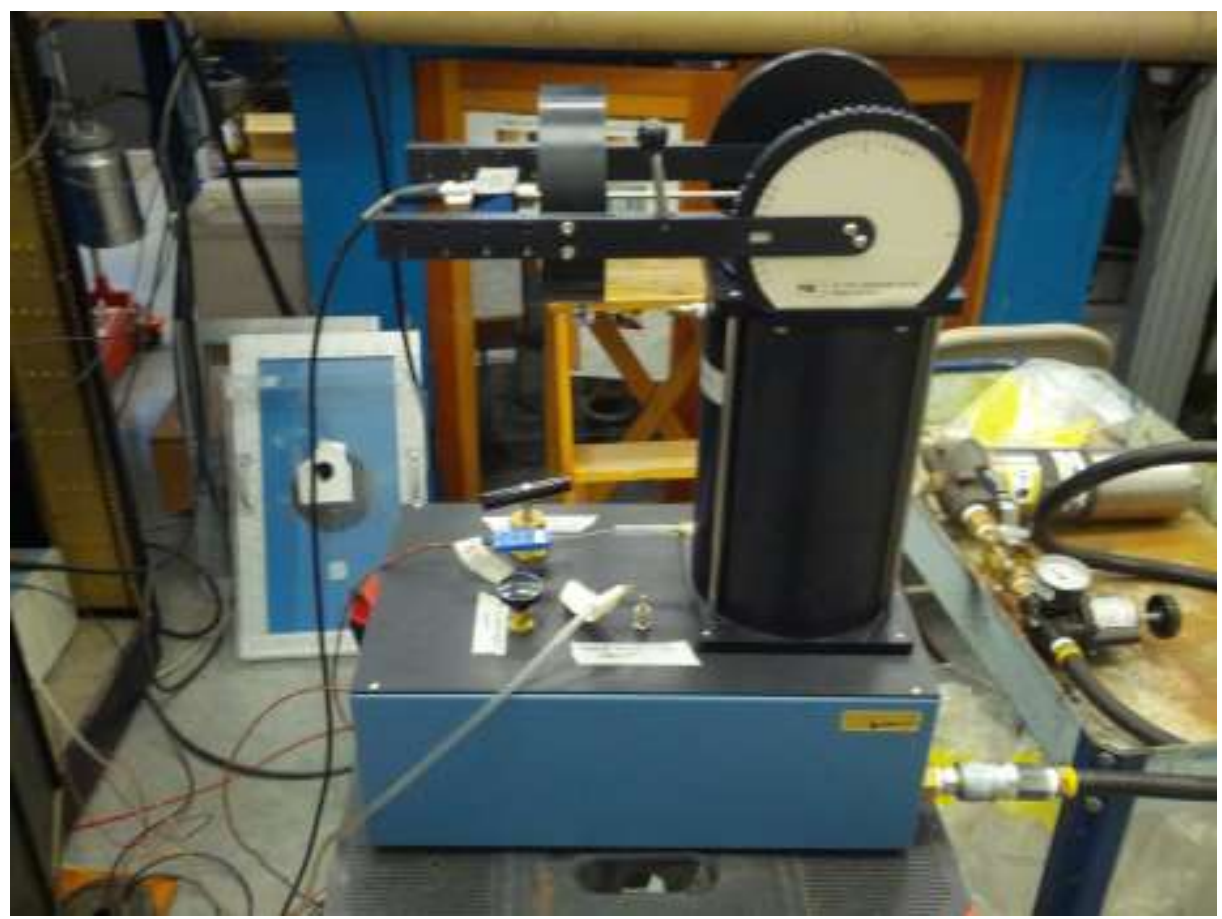

Figure 3-3. Calibration of the hot-wire anemometer.

\subsection{Hotwire Software}

The IFA300 system uses data acquisition software called ThermalPro. This software allows precise control over all of the features of the IFA300 hotwire anemometer. In this experiment the software was used to calibrate the hotwire, to run the momentum coefficient test, as well as to process the raw data into an ASCII text file that could be read by other software for further post processing. 


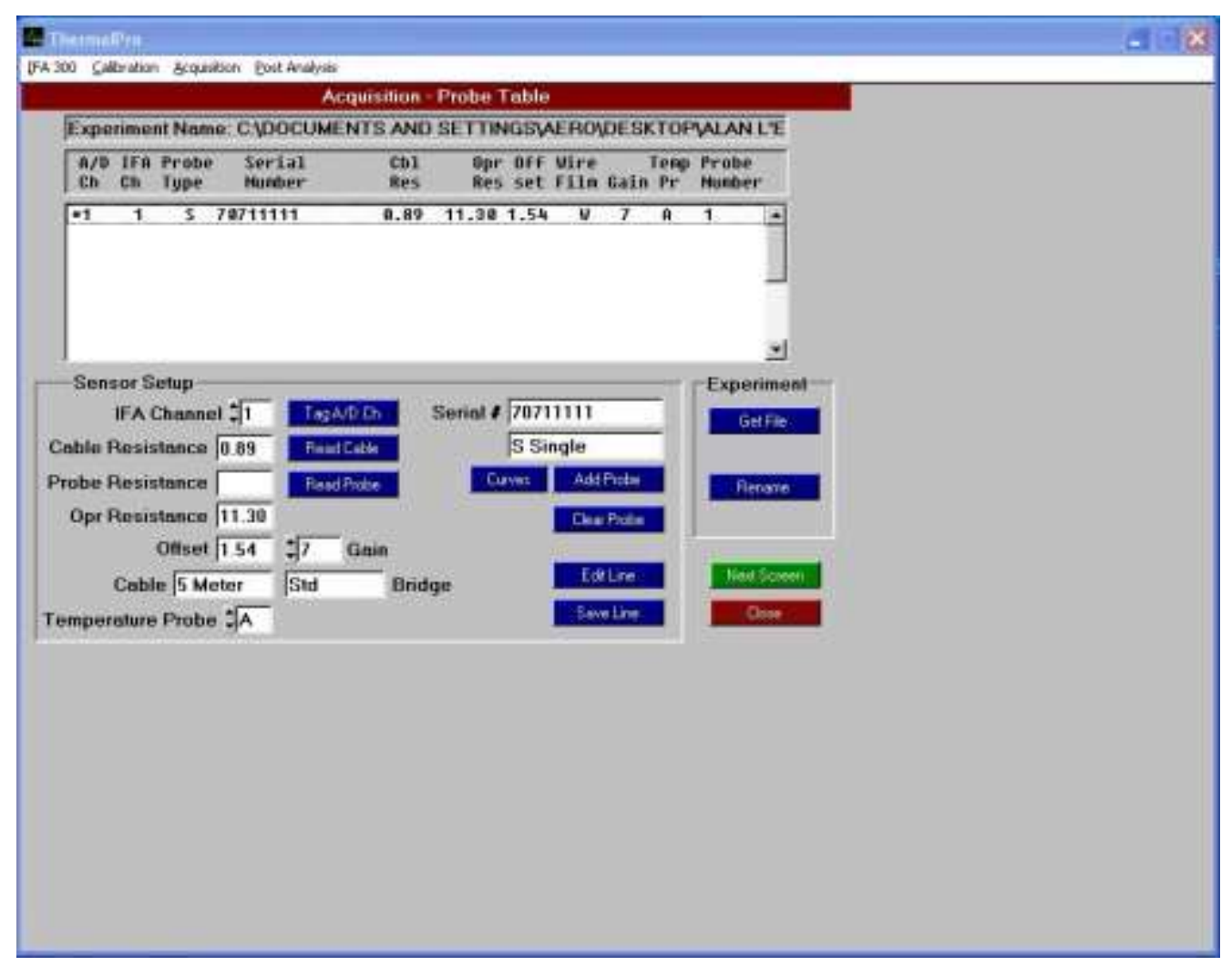

Figure 3-4. ThermalPro software screenshot.

\subsection{Signal Generation}

The origin of the actuation signal was a Pragmatic 2714A waveform generator. This system has a signal generation rate of 20,000,000 signal data points per second, and comes with 10 preprogrammed waveforms. These include the square wave, which was used in this experiment based on previous research. ${ }^{10}$ It is capable of generating waveforms with frequencies between 0.1 $\mathrm{Hz}$ and $20 \mathrm{MHz}$, at up to $10 \mathrm{~V}$. The minimum amplitude is $1.0 \mathrm{e}-4$ Volts and the frequency accuracy is $0.01 \mathrm{~Hz}$. 


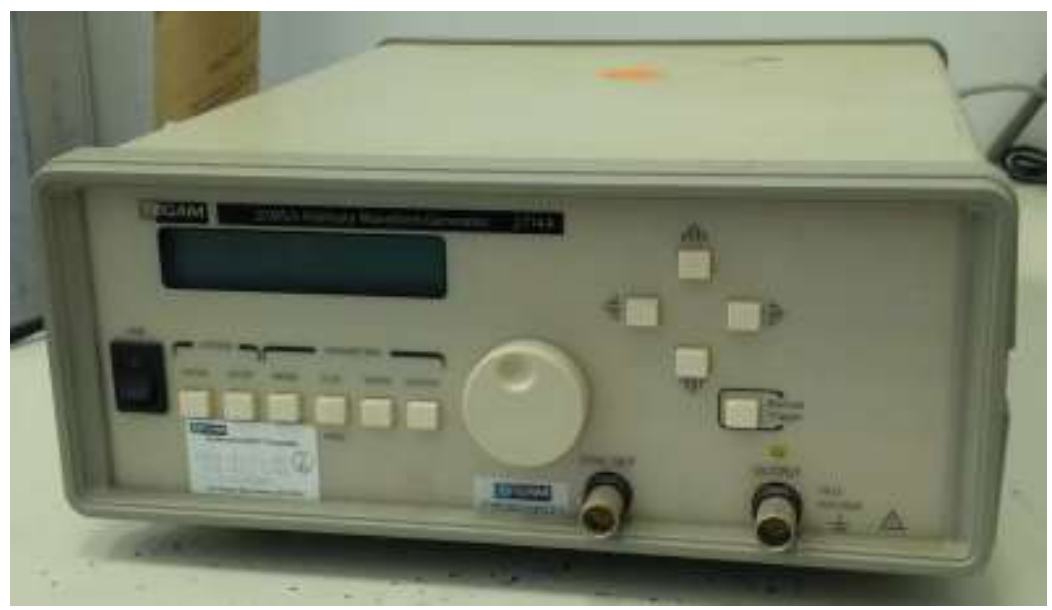

Figure 3-5. Pragmatic 2714A Waveform Generator.

\subsection{Constant Voltage Amplifier}

The amplifier used in this test was the Piezo EPA-104-115 Linear Amplifier. This model is preconfigured for $110 \mathrm{VAC}, 60 \mathrm{~Hz}$ which is the standard power source for North America. It is able to produce $\pm 200 \mathrm{~V}$ at a maximum current of $\pm 200 \mathrm{~mA}$. The maximum input voltage is $\pm 10 \mathrm{~V}$, and the output is controlled using a gain knob that goes up to 20 times.

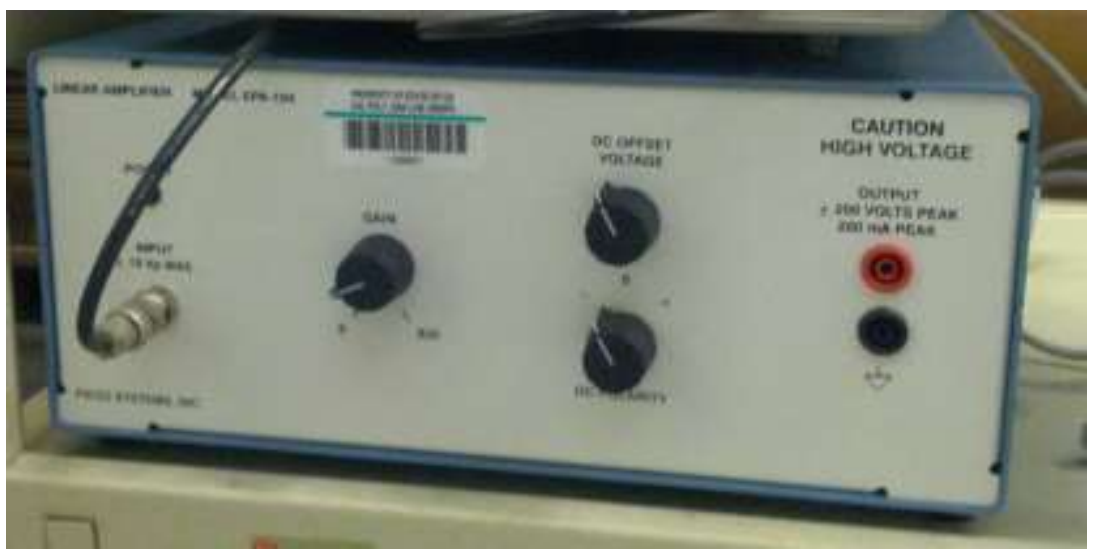

Figure 3-6. Piezo EPA-104 Linear Amplifier.

The frequency range of the amplifier is DC to $250 \mathrm{KHz}$, although this is heavily subject to the load. The amplifier bandwidth is shown in Fig. 3-10 for various levels of capacitance. 


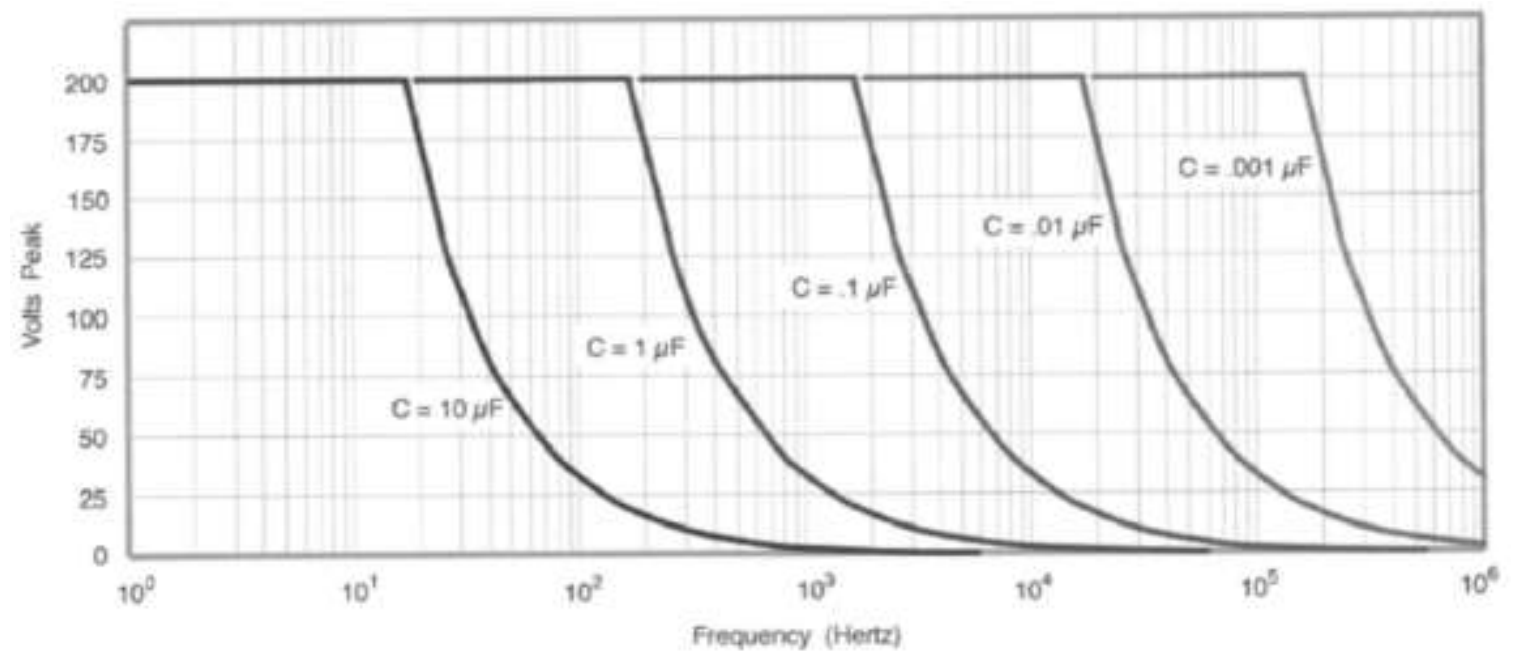

Figure 3-7. Bandwidth of EPA-1104 Amplifier. ${ }^{17}$

The maximum current available for use at a given voltage and capacitance also depends on the waveform in use. For a sine waveform, the available current is estimated using the equation

$$
I_{\text {peak }}=2 \pi f C V_{\text {peak }}
$$

For a triangle wave, the estimate is made using

$$
I_{\text {peak }}=4 f C V_{\text {peak }}
$$

For a square wave, the estimate is

$$
I_{\text {peak }}=C \frac{d V}{d t}
$$

where $d V$ is the peak-to-peak voltage and $d t$ is the rise time between the peak voltages. A small rise time becomes the limiting factor in this case, because it necessitates a large current. Because the necessary rise time was not known, the current loads were initially estimated using the sine wave, since it was not immediately obvious that the square wave would be used. 


\subsection{Actuator Disk}

The actuator used in this test was a Piezo Systems T216-A4NO-573X bending disk actuator. It has a 2.5 " diameter, rated voltage of $\pm 180 \mathrm{~V}$, capacitance of $107 \mathrm{nF}$, and a resonant frequency of $290 \mathrm{~Hz}$. Unlike some bimorphs, this actuator does not contain a shim, and is simply two layers of piezo disks bonded together. This actuator was chosen because of its use in past testing. ${ }^{10}$

The disk had a lead attached to each side and were soldered to the surface. The disk was held in its apparatus by the seam between the top and bottom halves of the enclosure. Neoprene gaskets between the two halves of the model hold the actuator disk in place, while allowing it to deform.

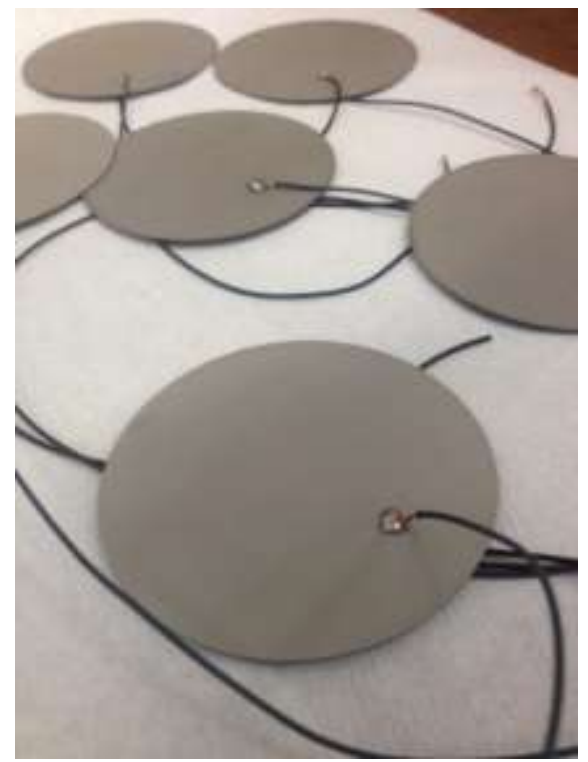

Figure 3-8. Piezoelectric disks with leads soldered to each side. Courtesy of Master's Thesis by Peter Sudak.

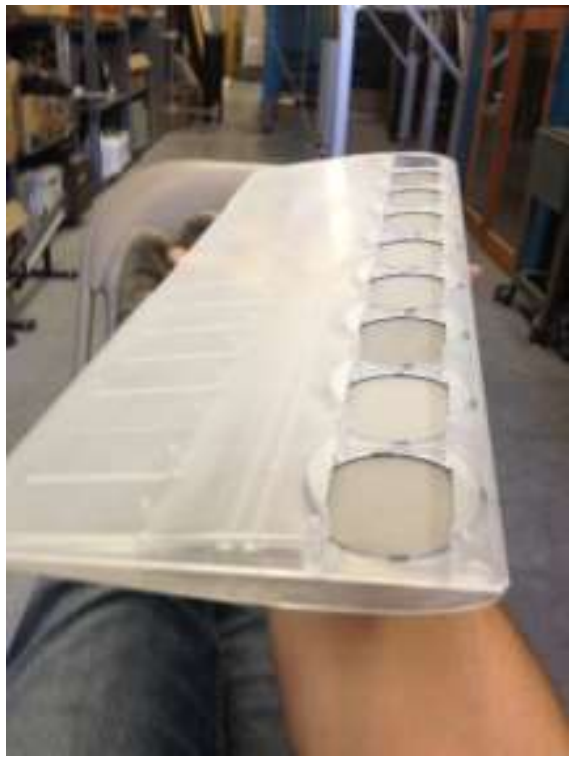

Figure 3-9. Two halves of the model with the actuator disks shown. Courtesy of Master's Thesis by Peter Sudak.

The enclosure of the model was made from two halves of cast acrylic. This material was chosen because it would be easily machinable, and transparent when finished. The transparency was necessary for inspection of the actuator disks, which are very brittle. The two halves of the model were held together by machine screws. 


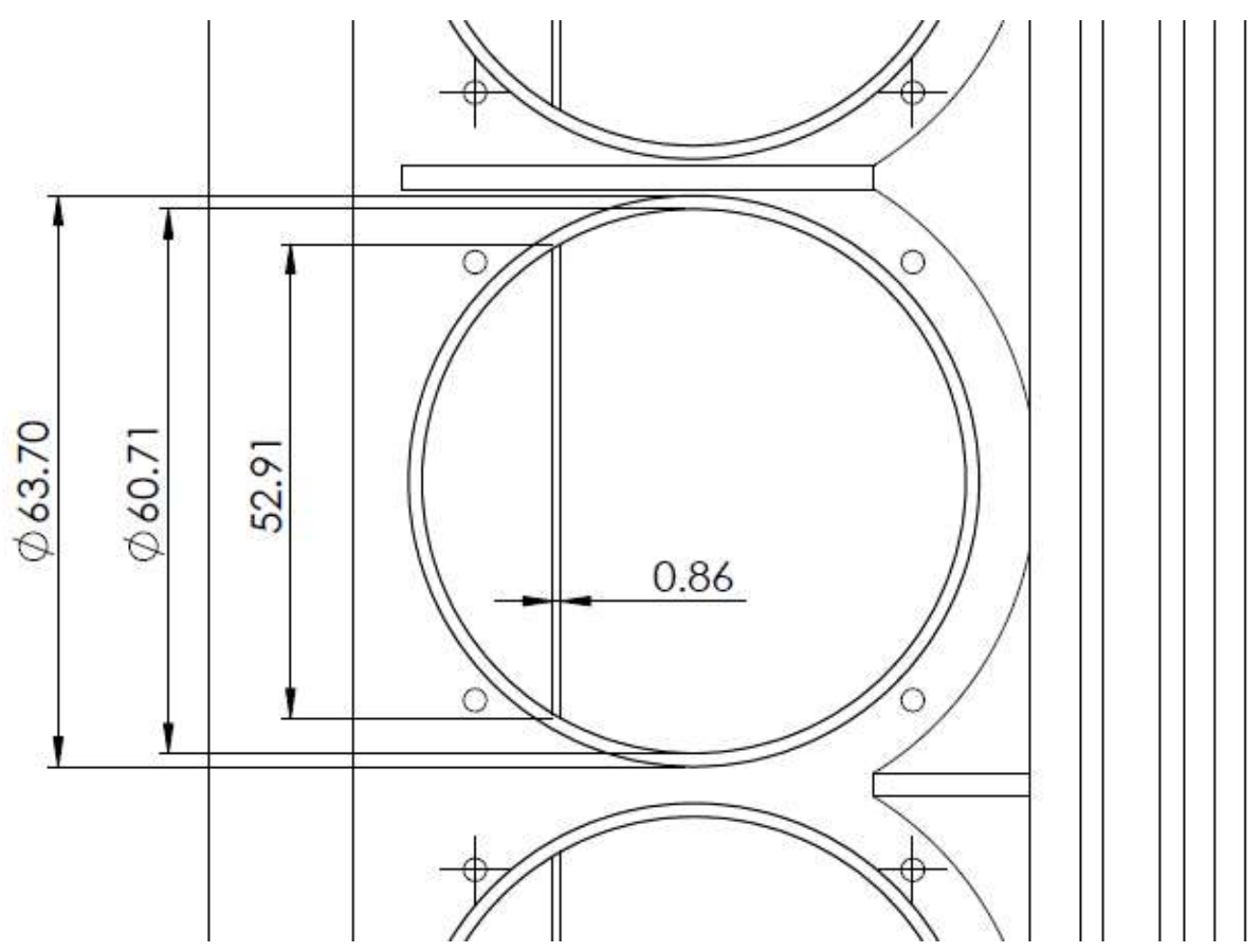

Figure 3-10. Top view of actuator cavity. Measurements in mm.

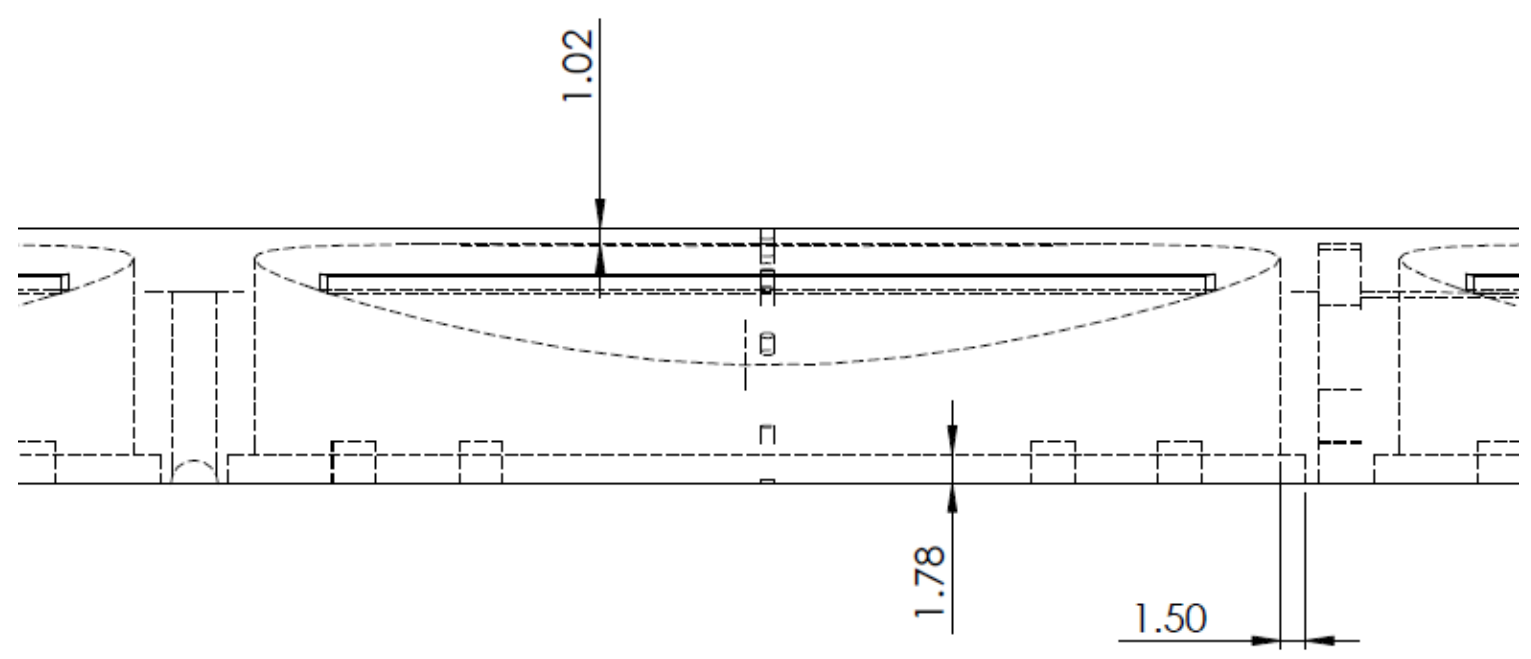

Figure 3-11. Front view of actuator cavity. Measurements in mm. 


\subsection{Actuator Bank}

The actuator section used 8 actuators to span 20 inches about the centerline of the wing. Figure 312 shows the actuators inside the test model. Because the test was run in the $0.6 \mathrm{~m} \mathrm{x} 0.6 \mathrm{~m}(2 \mathrm{ft} . \mathrm{x}$ $2 \mathrm{ft}$.) wind tunnel, several inches of the wing was submerged below the wind tunnel wall. This meant that only 6 of the actuators were in use for this experiment.

All 8 actuators were connected in parallel, using one channel of the amplifier set to $180 \mathrm{Vpp}$. The actuators were set to the same settings as the $C \mu$ tests, so that the momentum coefficient would be known for each test point.

\section{Waveform Generator}

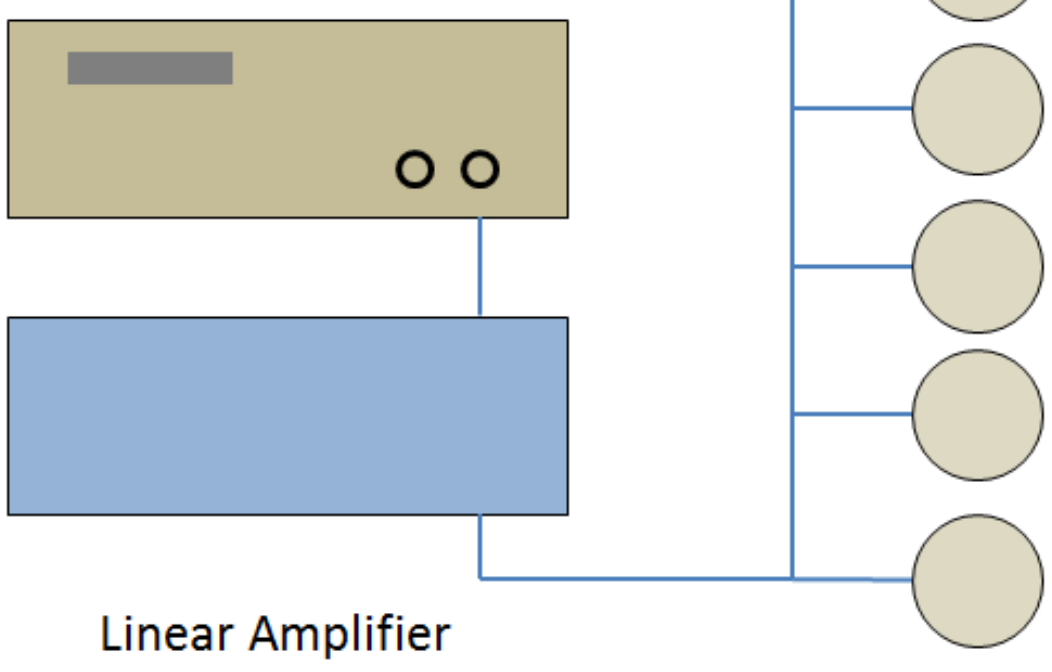

\section{Actuator \\ Discs}

Figure 3-12. Actuation system schematic. 


\subsection{Wing Model}

The wing model is a NACA 0015 semi-span section, 0.427 meters (16.813 in.) semi-span and 0.203 meters ( 8 in.) in chord. It has actuator cavities near the leading edge, with the slit located at $10 \%$ chord. This slit location was chosen because it was a plausible location based on the model design, and was effective in previous studies. ${ }^{13}$

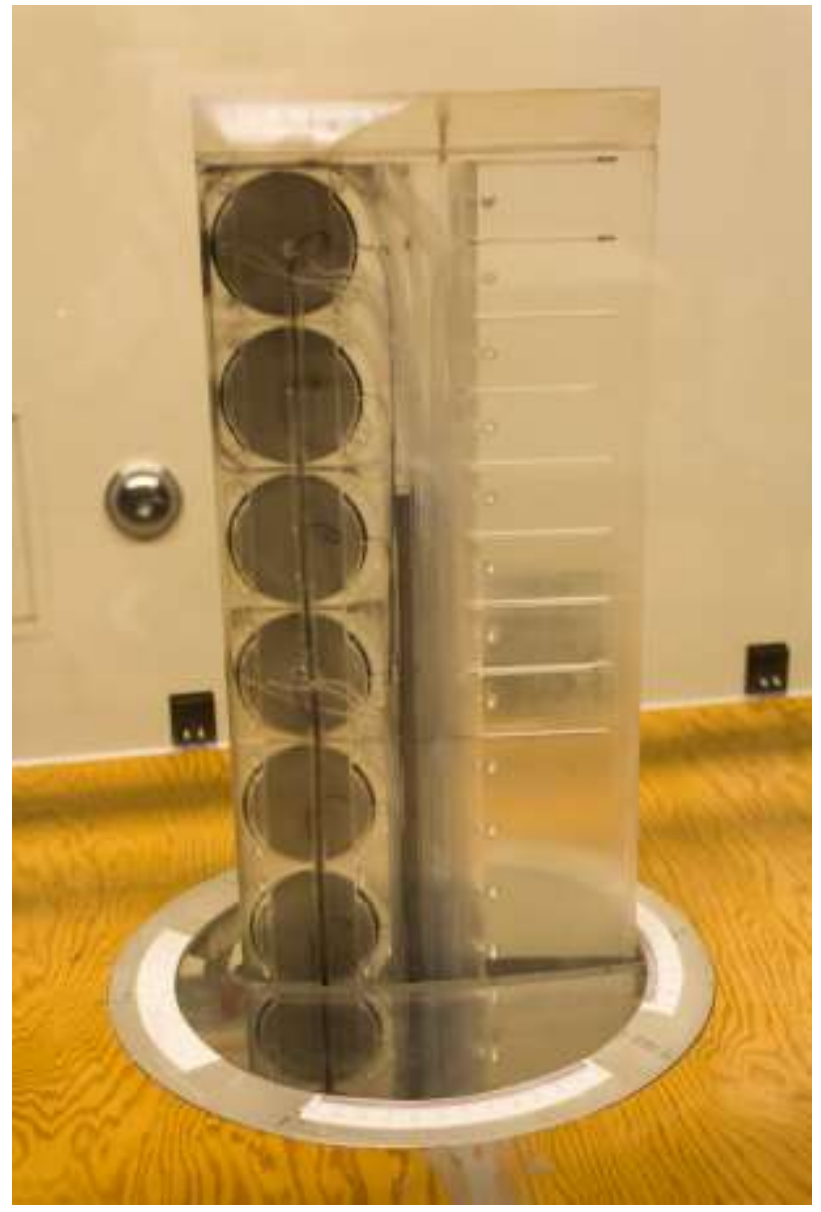

Figure 3-13. NACA 0015 test model.

The model had 60 pressure ports at the $x / c$ locations listed in Tables 3-3 and 3-4. The top surface of the area had four rows of ports at $2 y / b=0.38,0.70,0.85$, and 0.93 . The outermost row was as close as possible to the wingtip, but was constrained by the tip piece made for a separate experiment. The lower surface of the model contained two more rows of ports at $2 y / b=0.7$, and 
0.93. These locations allowed the pressure over the span of the wing to be evaluated, with an extra set near the wing tip to capture the effects of the wing tip vortices.

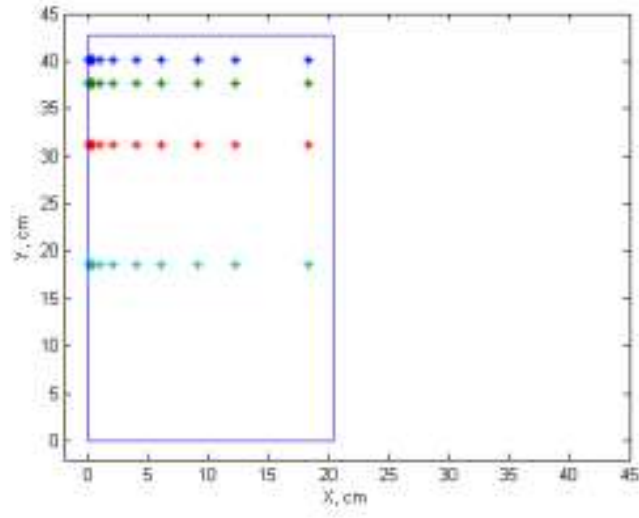

Figure 3-14. Top surface port locations

Table 3-3. Top port locations.

\begin{tabular}{|l|l|}
\hline Port\# & $\mathbf{x} / \mathbf{c}$ \\
\hline 1 & 0.000 \\
\hline 2 & 0.005 \\
\hline 3 & 0.013 \\
\hline 4 & 0.021 \\
\hline 5 & 0.047 \\
\hline 6 & 0.100 \\
\hline 7 & 0.200 \\
\hline 8 & 0.300 \\
\hline 9 & 0.450 \\
\hline 10 & 0.600 \\
\hline 11 & 0.900 \\
\hline
\end{tabular}

Table 3-5. Top port row locations.

\begin{tabular}{|l|l|}
\hline Row & $\mathbf{2 y} / \mathbf{b}$ \\
\hline 1 & 0.38 \\
\hline 2 & 0.70 \\
\hline 3 & 0.85 \\
\hline 4 & 0.93 \\
\hline
\end{tabular}

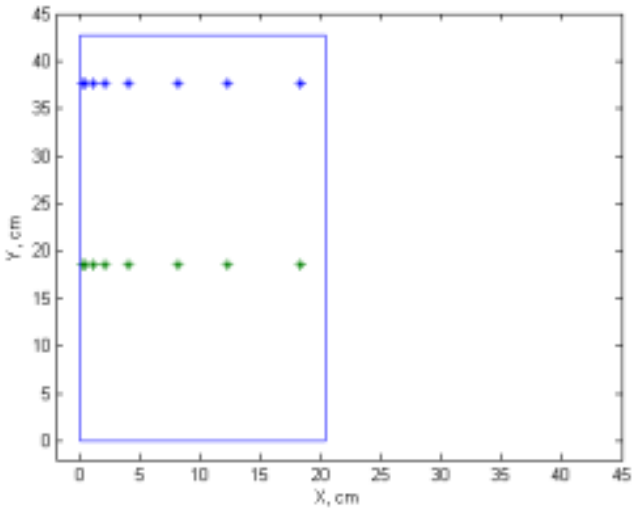

Figure 3-15. Lower surface port locations.

Table 3-4. Lower port locations.

\begin{tabular}{|l|l|}
\hline Port\# & $\mathbf{x} / \mathbf{c}$ \\
\hline 1 & 0.010 \\
\hline 2 & 0.020 \\
\hline 3 & 0.052 \\
\hline 4 & 0.100 \\
\hline 5 & 0.200 \\
\hline 6 & 0.400 \\
\hline 7 & 0.600 \\
\hline 8 & 0.900 \\
\hline
\end{tabular}

Table 3-6. Lower port row locations.

\begin{tabular}{|l|l|}
\hline Row & $\mathbf{2 y} / \mathbf{b}$ \\
\hline 1 & 0.38 \\
\hline 2 & 0.85 \\
\hline
\end{tabular}

The model had one slit at $10 \%$ chord. Each actuator had an individual slit section with a length of $4.57 \mathrm{~cm}(1.8 \mathrm{in}$.$) and a width of 0.86 \mathrm{~mm}(0.034$ in.), with a $2 \mathrm{~cm}(0.8 \mathrm{in}$.$) gap between them.$ While many active flow control slits are tangential with the model surface, the slit was cut at a $30^{\circ}$ angle from the local surface for manufacturability. 


\subsection{Pressure Measurement}

A Scanivalve pressure scanner system was used to measure the measure distribution over the wing. The device used in this experiment was a Scanivalve ZOC33/64Px-X1 pressure scanning module. It features 64 total pressure ports; 32 of which have a range of $0.36 \mathrm{psid}$, and the other 32 with 1.0 psid range. The accuracy of the 0.36 psid range ports is $\pm 0.15 \%$ FS while the 1 psid ports have an accuracy of $\pm 0.10 \%$ FS. ${ }^{18}$

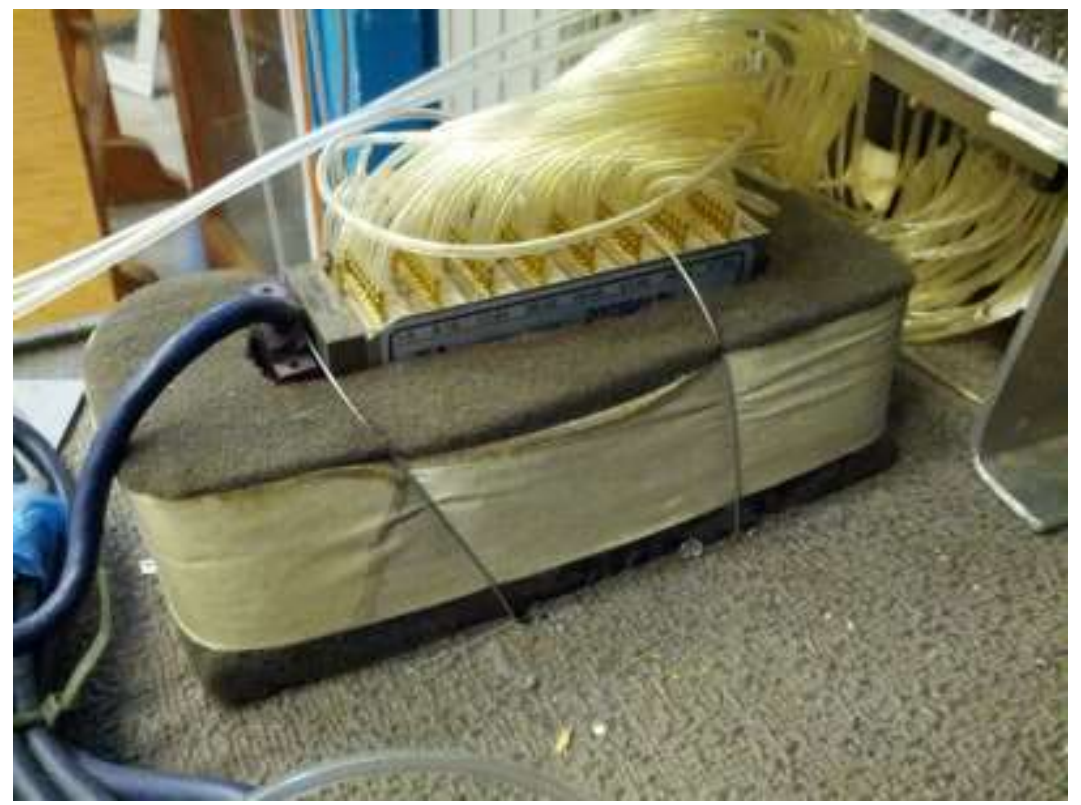

Figure 3-16. Scanivalve ZOC33/64Px-X1 pressure scanner.

Additionally, the system consisted of a RadBase 3200 and a USB Extender 3200 that connected the pressure scanner to the computer running the RadLink software.

The Scanivalve supplied software was used for this experiment. The program, RadLink v1.01, was used to acquire and save data from the pressure scanner. 


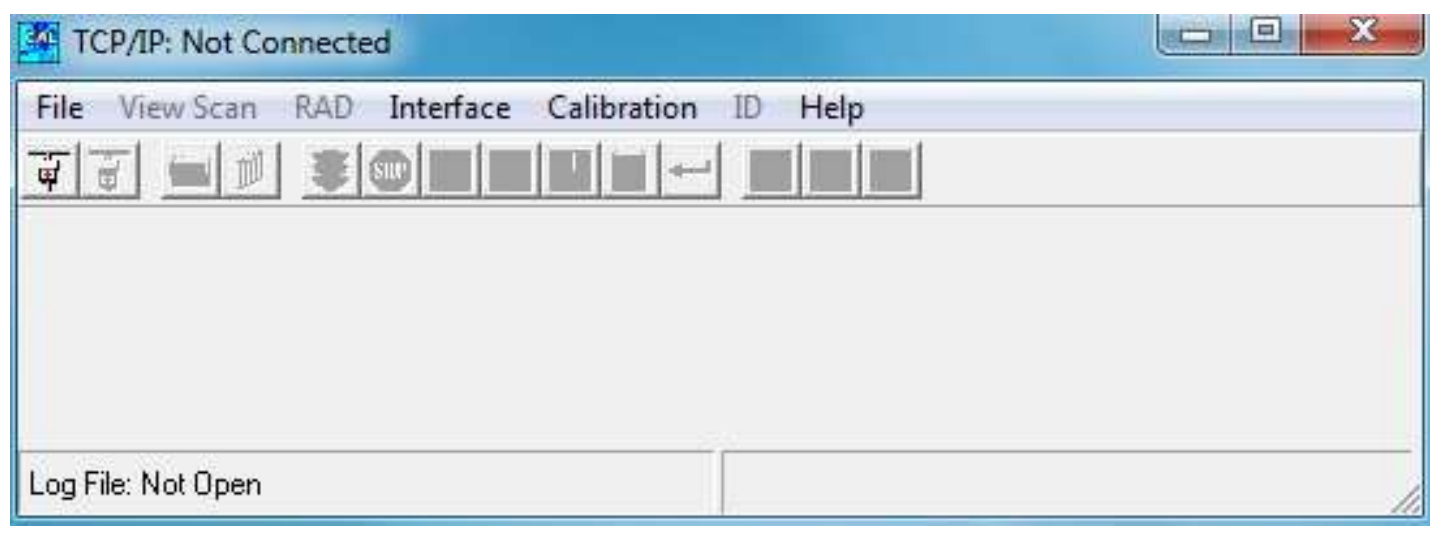

Figure 3-17. RadLink v1.01 screenshot.

The scanivalve operates by comparing the pressure of a known source to the port pressures. The coefficients of pressure can then be calculated if the freestream pressure is known. A pressure ring is installed in the Cal Poly wind tunnel for this purpose, but there is an error between this pressure and the true freestream pressure at the wing. This is compensated using a calibration procedure outlined in the next section.

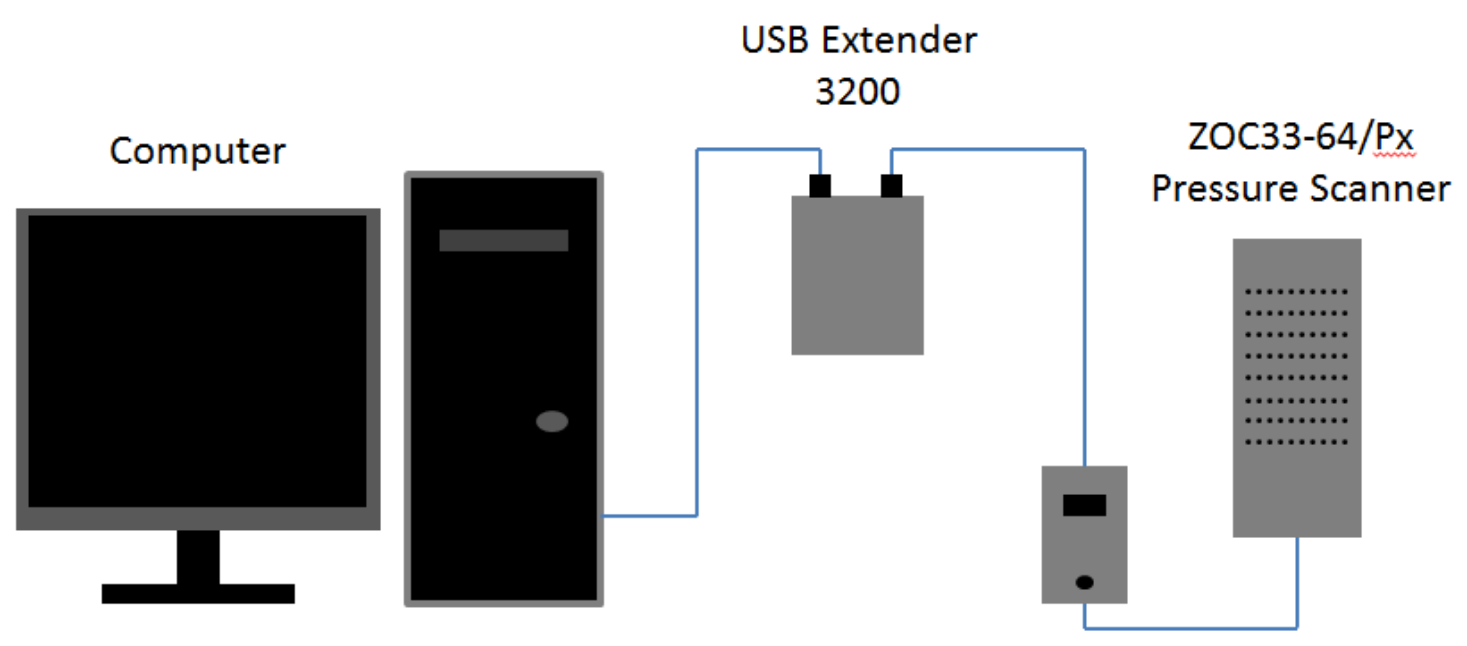

RADBASE 3200

Figure 3-18. Pressure Acquisition Schematic. 


\subsection{Vibration Measurement}

A small accelerometer was needed to measure the surface vibration of the model. After a short review of available accelerometers a small piezo type made for drop testing was chosen due to its small size and mass. The specific accelerometer used in the test was a PCB Piezotronics 352C22, with a sensitity of $10 \mathrm{mV} /\left(\mathrm{m} / \mathrm{s}^{2}\right) \pm 15 \%$. This was connected to a PCB $482 \mathrm{~A} 21$ signal conditioner which amplified the signal and sent it to the LabView DAQ to be recorded. 


\section{Experimental Procedure}

\subsection{Hotwire Anemometer Calibration}

Before the hotwire anemometer can be used to find the velocity distribution in the jet, a calibration must be performed. The standard method for calibration is to use an open jet flow at a set velocity past the sensor as it is held in a fixed location. The calibrator uses a pressure transducer to find the reference velocity.

To begin the calibration, the hotwire stand must be first connected. One air hose connects to the building compressed air supply, which is regulated at the connection to 65 psi. The air then travels through another pressure regulator before connecting to the calibration stand. From the IFA300, the pressure transducer hose, the temperature probe, and the coaxial sensor connector must all be in place.

After defining the maximum expected velocity, the ThermalPro software develops a table of test points to achieve the greatest accuracy in the calibration curve. These test point define the desired velocity, which is known through the pressure transducer. The two knobs on the calibrator are adjusted until the velocities match, then the voltage is read from the hotwire. Once all data is taken, a fourth-order polynomial curve is created of the type in Equation 3-1. The resulting fit is shown in Fig. 4-1. For this case, the maximum velocity of the calibration was $50 \mathrm{~m} / \mathrm{s}$. 
Table 4-1. Hotwire Calibration Values.

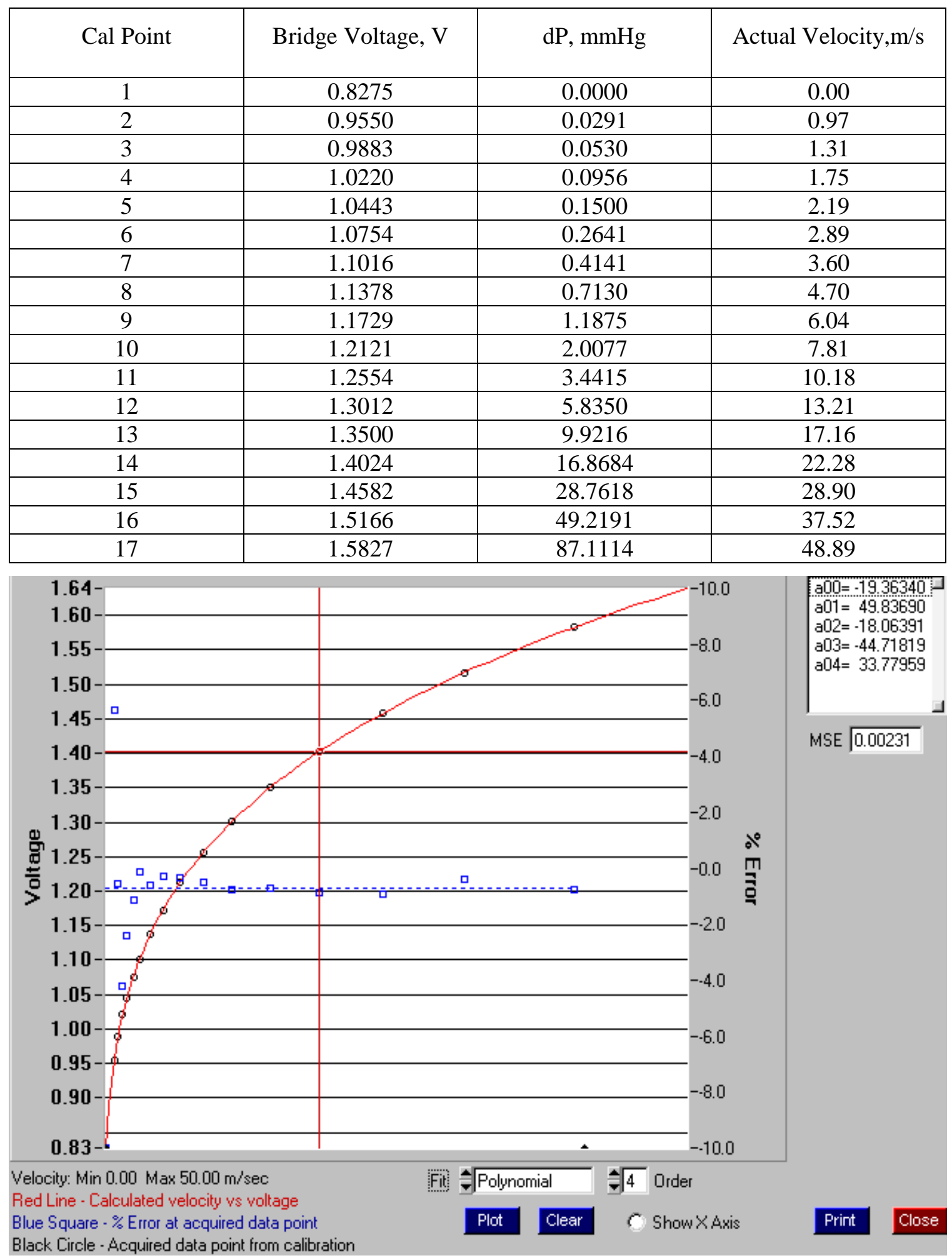

Figure 4-1. Hotwire calibration curve. 


\subsection{Actuator Momentum Coefficient}

Before the piezoelectric actuators could be used in a full-scale test, it was necessary to examine the properties of the resultant synthetic jet. The main property of concern is $C_{\mu}$, which enables the comparison with other studies.

The actuators were powered at up to $180 \mathrm{VAC}$. The tested frequencies were $36 \mathrm{~Hz}, 100 \mathrm{~Hz}$, and $500 \mathrm{~Hz}$. The low frequency of $36 \mathrm{~Hz}\left(\mathrm{~F}^{+}=1\right)$ was chosen because of its relevance to other studies. A lower frequency was not considered because of the resultant jets' ability to produce a meaningful velocity distribution. The upper bound of $500 \mathrm{~Hz}$ was dictated by the current capabilities of the amplifier. Although the amp could power one actuator all the way to approximately $1600 \mathrm{~Hz}$, the full bank of actuators in parallel causes the frequency to be limited to $200 \mathrm{~Hz}$ using a sine wave signal, before experiencing some loss in power. The other main consideration was to avoid the natural frequency of the actuator, which is $290 \mathrm{~Hz}$, to avoid breaking the actuator per manufacturer recommendation. The current requirements for a square wave depend on the rise time. Because the desired rise time was not known, the current requirements were based on the sine wave calculations.

For this section of the experiment, the hotwire was set to acquire 8,000 samples at a rate of 20,000 Hz. The high sampling rate was necessary to capture the resultant jet velocities under the highest actuation frequencies.

To measure the momentum coefficient, the actuator and hotwire were mounted such that the hotwire was just above the surface of the actuator, with the sensor wire parallel with and centered above the slit. The sensor support was oriented along the slit to reduce its effect on the reading. Because the maximum voltage of the actuator disk is $180 \mathrm{Vp}$, an output of $9 \mathrm{Vp}$ was fed to amplifier, which was set to produce 20x amplification. A lack of control on the actuator meant that it was easiest to run it at its maximum 20x amplification and adjust the input voltage, rather than send $10 \mathrm{~V}$ to the amplifier and adjust the gain accordingly. According to previous 
experiments, the square and triangle waveforms were most effective at producing higher peak jet velocities. It was also desired to know the effect of a slightly lower power output on the resultant jet velocity. With all these considerations, an experiment was conducted according to the test matrix shown in Table 4-2.

Table 4-2. Momentum coefficient test point matrix.

\begin{tabular}{|l|l|}
\hline Frequency Hz & Voltage \\
\hline 36 & $10,20,60,100,140,180$ \\
\hline 50 & $10,20,60,100,140,180$ \\
\hline 100 & $10,20,60,100,140,180$ \\
\hline 250 & $10,20,60$ \\
\hline 500 & $10,20,30,40,50,60$ \\
\hline
\end{tabular}

Once the jet velocity distribution is known, it must be time averaged to be used in the momentum coefficient equation. During preliminary testing, it was found that the velocity measurements showed that the jet expulsion was faster than the inflow. Because mass must be conserved in a zero-mass-flow synthetic jet, these jets must be of equal strength. For this reason, the out-flow strokes were copied over the in-flow strokes for a more accurate estimation of momentum coefficient.

Because of the zero-mass nature of the velocity excitation, a root-mean-square was taken for the velocity signal. For discrete, evenly spaced values, the RMS can be taken as

$$
x_{r m s}=\sqrt{\frac{1}{n}\left(x_{1}^{2}+x_{2}^{2}+\cdots+x_{n}^{2}\right)}
$$

With the RMS velocity calculated in this manner, the momentum coefficient could be calculated as 


$$
C_{\mu}=\frac{2 U_{j}^{2} h}{c U_{\infty}^{2}}
$$

\subsection{Test Section Calibration}

The calculation of pressure coefficient relies on the measurement of the test section static and dynamic pressure. In this experiment, these were measured with pressure rings in the test section inlet just inside the flow straightener, and just before the test section. Because there is pressure loss over the length of the test section, it is necessary to calibrate the pressures at the test location to those from the inlet.

Each pressure ring consists of four pressure ports, one on each of the walls of the wind tunnel. 2000 samples were taken at a rate of $50 \mathrm{~Hz}$ to find the velocity. This number of points was suggested by previous students who had tested with the same equipment. It was desired to calibrate this pressure ring with a pitot-static probe placed at the model location. The calibration constants were defined as

$$
\begin{gathered}
C_{q}=\frac{q_{\text {pitot }}}{q_{\text {tunnel }}} \\
C_{p_{\infty}}=\frac{p_{\infty_{\text {pitot }}}}{p_{\infty_{\text {tunnel }}}}
\end{gathered}
$$

The tunnel was run at the test speed of $20 \mathrm{~m} / \mathrm{s}$, and pressure readings were taken from the pressure rings and from the pitot-static probe mounted in place of the test model. The constants were calculated to be

$$
\begin{gathered}
C_{q}=1.002 \\
C_{p_{\infty}}=1.012
\end{gathered}
$$

Once the calibration constants were known, $C_{p}$ can be corrected using 


$$
C_{p}=\frac{p_{i}-p_{\infty_{\text {tunnel }}} C_{p_{\infty}}}{\left(p_{T_{\text {tunnel }}}-p_{\infty_{\text {tunnel }}}\right) C_{q}}
$$

where $p_{i}$ is a measured pressure. The use of this correction can be seen in the example calculations shown in Appendix A.

\subsection{Angle of Attack Calibration}

In order to repeat the test conditions from the previous experiment, the zero angle of attack must be found. This point is vital, since all angle of attack measurements will be made based on the zero point.

The model did not have a pressure port at the leading edge because of the construction method that was chosen. It was therefore necessary to find the zero angle of attack geometrically. This was done by visually lining the rotating section of the apparatus to line up with marks that indicated the orthogonal directions. This was necessary because the model had to be turned 90 degrees to sample lift and drag for a separate experiment. Based off this point, the angle of attack adjustments were made by lining up marks on the base of the apparatus that was marked with a scale.

\subsection{Pressure Data Acquisition}

Pressure data was taken using the Scanivalve system described in the previous section. The system is calibrated to a set pressure supply of 65 psi. Control of the Scanivalve is done through the related RAD software, also detailed in the previous section. The unit is pre-calibrated from the factory, and no further calibration of the Scanivalve system itself was necessary for this experiment.

Once the wing was positioned and the actuators are at their test point condition, a data set of the pressure distribution was taken. Each test point consisted of 2000 samples at a rate of $50 \mathrm{~Hz}$. The 
samples were taken with 400 frames of 5 scans per frame, meaning that each data point written to file was an average of five individual scans. This initial average was done by the RADbase to increase the sampling frequency of the pressure scanner.

The output of the Scanivalve system from Labview is a text data file which was read into Matlab for analysis and plotting. The mean and standard deviation were the items calculated.

\subsection{Vibration Measurement}

In order to accurately capture the surface vibrations, it was necessary to use a sampling frequency that was significantly higher than the $500 \mathrm{~Hz}$ maximum actuation frequency. It was decided that 5,000 samples at $20,000 \mathrm{~Hz}$ would be adequate to capture the vibrations. This was the same sample size and rate as was used with the hotwire anemometer for the same actuations.

Samples were recorded primarily at the frequencies and amplitudes where it was obvious that some factor other than the slit flow was having an influence. By testing at these points, a comparison could be made as to whether the surface vibration had any major correlation with the cases where flow attachment was caused by the actuation.

\subsection{Blockage Corrections}

The existence of the wind tunnel walls make every wind tunnel test slightly different than free-air conditions a similar test subject would experience in the real world. Barlow et al.'s Low Speed $\underline{\text { Wind Tunnel Testing outlines several methods for accounting for these differences. }}{ }^{3}$

The first blockage correction is the solid blockage. This is due to the air going around the model interacting with the wind tunnel walls and artificially increasing the effective speed of the flow.

$$
\varepsilon_{s b}=\frac{K_{1} \tau_{1} V o l}{A^{3 / 2}}
$$

The constant $K_{1}$ was found to be 1.04 and $\tau_{1}$ was 0.9 using a figure from Barlow. ${ }^{3}$ 
The volume of the effective tunnel was $0.74 \mathrm{~m}^{2}\left(8 \mathrm{ft}^{2}\right)$. This was the only solid blockage term used in this experiment, as the model was simply a cantilever mounted wing.

The second blockage is wake blockage, which stems from conservation of momentum. The slower air in the wake of the model requires that the unimpeded air speed up to maintain continuity.

$$
\varepsilon_{w b}=\frac{S}{4 A} C_{D u}
$$

After finding the wake and solid blockage, the final blockage can be found by summing the two, such as

$$
\varepsilon_{T}=\varepsilon_{s b}+\varepsilon_{w b}
$$

The dynamic pressure can then be corrected using

$$
q_{C}=q_{A}\left(1+\varepsilon_{T}\right)^{2}
$$

\subsection{Design of Experiments}

The main variables in the wing test were the actuation frequency, amplitude, and model angle of attack. It was desired to choose a matrix that explored these parameters thoroughly without an excessive number of test points.

The actuation frequency range was originally desired to be 50-300 Hz. After breaking the actuator disk used in the initial proof-of-concept testing, Piezo Systems recommended avoiding the natural frequency of $290 \mathrm{~Hz}$ for full power actuation to prevent disk failure. It was decided that the actuators could only be run over $60 \mathrm{~V}$ at or below $100 \mathrm{~Hz}$.

Initially, it was believed that the maximum amplitude would be needed to create a jet of sufficient momentum to influence the flow around the model. During initial testing, however, it was observed that lower voltage actuation could cause noticeable effects. For this reason, the voltage 
was varied such that all frequencies had the same momentum coefficient. These points were in addition to a full power actuation at each frequency.

The reduced voltage actuations allowed for a sample to be taken at a frequency of $500 \mathrm{~Hz}$. A lower frequency of $36 \mathrm{~Hz}$ was also included to help observe the effect of $\mathrm{F}+$ on the actuation. The $\mathrm{F}+$ values of these frequencies were $1,2.8$, and 13.9, respectively.

Because the experiment focused on the delay of separation, the main area of interest is near the separation point. For a $2 \mathrm{D}$ wing, this was estimated using Javafoil to be approximately $13^{\circ}$. For this reason, the angle of attack points were chosen to evaluate separate conditions. The initial angle of $12^{\circ}$ was chosen to observe the effect of the actuation on an attached flow. An angle of $16^{\circ}$ was included as a condition where the actuation should be able to attach a separated flow. The final angle was $20^{\circ}$ as a condition where it would be difficult for the actuation to overcome the severe negative pressure gradient and cause the flow to attach.

Table 4-3. Pressure test matrix.

\begin{tabular}{|l|l|l|l|}
\hline \multirow{2}{*}{ Angle of Attack } & \multicolumn{2}{l|}{ Voltages } \\
\cline { 2 - 4 } & $\boldsymbol{F}^{+}=\mathbf{1}$ & $\boldsymbol{F}^{+}=\mathbf{2 . 8}$ & \multirow{2}{l}{$\boldsymbol{F}^{+}=\mathbf{1 3 . 9}$} \\
\hline $\mathbf{1 2}^{\circ}$ & $60 \mathrm{~V}, 180 \mathrm{~V}$ & $60 \mathrm{~V}, 180 \mathrm{~V}$ & $60 \mathrm{~V}$ \\
\hline $\mathbf{1 6}^{\circ}$ & $60 \mathrm{~V}, 180 \mathrm{~V}$ & $60 \mathrm{~V}, 180 \mathrm{~V}$ & $30 \mathrm{~V}, 60 \mathrm{~V}$ \\
\hline $\mathbf{2 0}^{\circ}$ & & & \\
\hline
\end{tabular}

\subsection{Uncertainty Analysis}

The error of any sample must be known to ensure the reliability of the data taken during the experiment. The measured quantities in this experiment were the jet velocity used to calculate the momentum coefficient and the pressure from the airfoil used to analyze stall characteristics. A third measurement (an accelerometer) was added to evaluate the surface vibration of the model. 
It is necessary to find the uncertainty of each of these measurements, so that there can be confidence that the test results are accurate. In general, a function of many variables $q\left(x_{1}, x_{2}, \ldots, x_{n}\right)$ has an associated error given by the function

$$
\delta q=\sqrt{\left(\frac{\partial q}{\partial x_{1}} \delta x_{1}\right)^{2}+\left(\frac{\partial q}{\partial x_{2}} \delta x_{2}\right)^{2}+\cdots+\left(\frac{\partial q}{\partial x_{n}} \delta x_{n}\right)^{2}}
$$

for independent random errors. ${ }^{19}$

One set of data is the wing pressure distribution. The pressure is given by

$$
C_{p}=\frac{p_{i}-p_{s} C_{p_{s}}}{\left(p_{t}-p_{s}\right) C_{q}}
$$

From this equation, performing the necessary partial derivatives and inserting them into Eq. 4-12 yields

$$
\delta C_{p}=\sqrt{\left[\left(\frac{-1}{C_{q}\left(p_{s}-p_{t}\right)}\right) \sigma_{p_{i}}\right]^{2}+\left[\left(\frac{p_{i}-p_{t} C_{p_{s}}}{C_{q}\left(p_{s}-p_{t}\right)^{2}}\right) \sigma_{p_{s}}\right]^{2}+\left[\left(\frac{-\left(p_{i}-p_{s} C_{p_{s}}\right)}{C_{q}\left(p_{s}-p_{t}\right)^{2}}\right) \sigma_{p_{t}}\right]^{2}}
$$

Another measurement is the jet velocity distribution to calculate the momentum coefficient. Voltage data from the hot wire must be passed through a calibration function. The calibration function is a fourth order polynomial, given as

$$
U j=A V^{4}+B V^{3}+C V^{2}+D V+E
$$

Because the measurements being taken are cyclical, a standard deviation of the entire data set would be large just from the expected oscillation in the flow velocity. This would not give a true reading of the uncertainty in the measurements being taken by the hotwire. Instead, the uncertainty was based on the calibration data, which lists the expected error from each data point in the calibration against the expected value from the resulting calibration curve. While this is not an ideal solution, it was thought to be reasonable for the situation of the present experiment. 
The final measurement taken in this experiment was the strength of the surface vibrations using a low mass accelerometer. The output signal from the signal conditioner had a gain, so the acceleration calculation was

$$
a=G V
$$

From this equation, the uncertainty in the acceleration is simply the gain constant times the uncertainty in the voltage.

$$
\delta a=G \sigma_{V}
$$

The uncertainty in the velocity was estimated by taking the standard deviation of measurements with the accelerometer at rest.

The results of the analysis are presented in section 5.7. Further detail on the derivation of the error terms are presented in Appendix B. 


\section{Results and Discussions}

\subsection{Historical Comparison}

Before examining the data from the current experiment, it was desired to compare the data to similar tests from previously documented experiments. The $2 \mathrm{D}$ data from the following cases was compared to data from the current experiment at $y / b=0.687$.

Data from an experiment conducted by Traub et al. was chosen for the first comparison. ${ }^{13}$ The experiment presented a 2D NACA 0015 model at $R e=420,000$, which was actuated at $10 \%$ chord with $C_{\mu}=0.0275$. Pressure data was digitized from a plot showing the pressure distribution at $\alpha=$ $20^{\circ}$. While the Reynolds number and dimensionless frequency could not be matched, it was believed that the comparison was still valuable. The un-actuated comparison shows that the flow is separated in both cases, although the pressure in the separated region was higher for Traub et al.'s data. The attachment shown from both actuations show that the pressure distribution of the current experiment is very similar to that recorded by Traub et al.

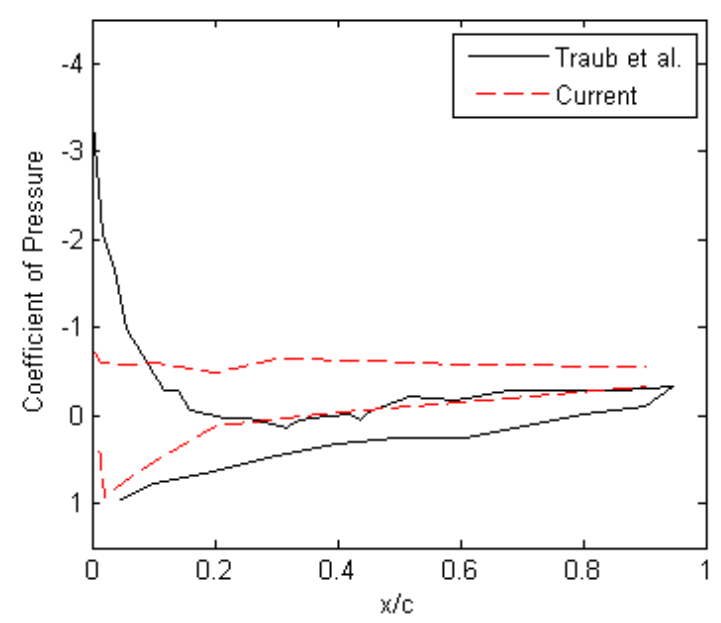

a) No Actuation

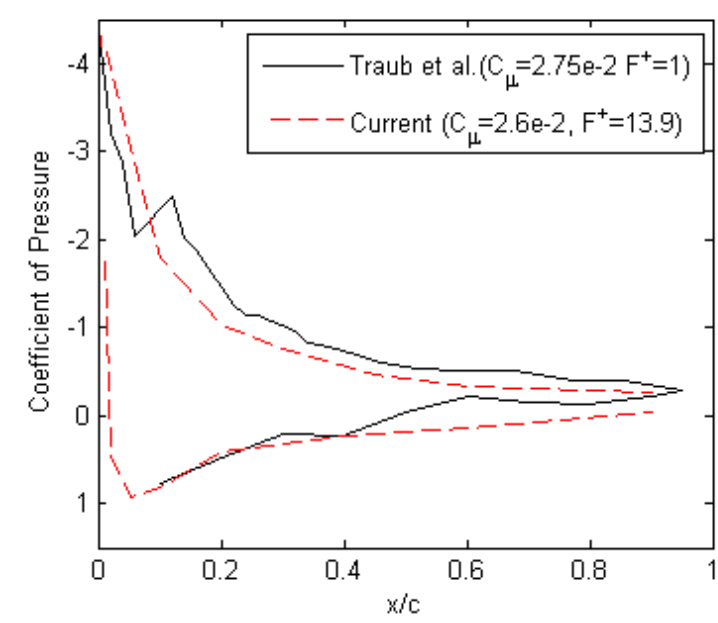

b) Active

Figure 5-1. Pressure data comparison with Traub et al.'s 2D wing data $\alpha=20^{\circ}$. Traub et al.: $\operatorname{Re}=420,000$, Current: $\operatorname{Re}=100,000 .^{13}$ 
Because the Reynolds number in the previous comparison could not be matched, it was desired to find a second point of reference to validate the pressure data. The other significant test used as a reference was the test by Seifert et al. of a 2D NACA 0015 model. ${ }^{14}$ The reference point was taken at $R e=150,000, \alpha=22^{\circ}$. Although this point is also not included in the test matrix of the current test, it was the closest available pressure distribution by Seifert et al. The actuation was at $F^{+}=1.1, C_{\mu}=1.3 \%$, and came from a leading edge slit. In this case, the pressure distribution of the unactuated case was nearly identical. The actuated case, however, shows that the current model was not able to cause a full attachment using the most powerful actuation at $F^{+}=13.9$. There was some attachment at the leading edge, with separation at approximately $20 \%$ chord.

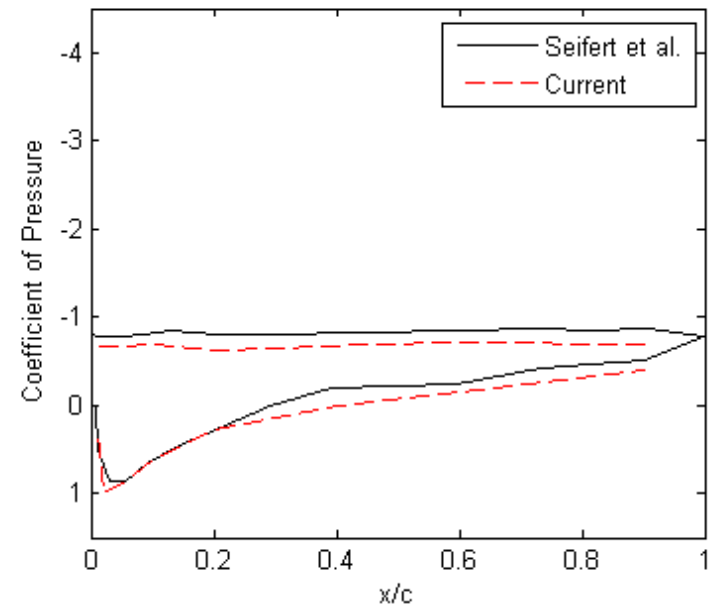

a) No Actuation

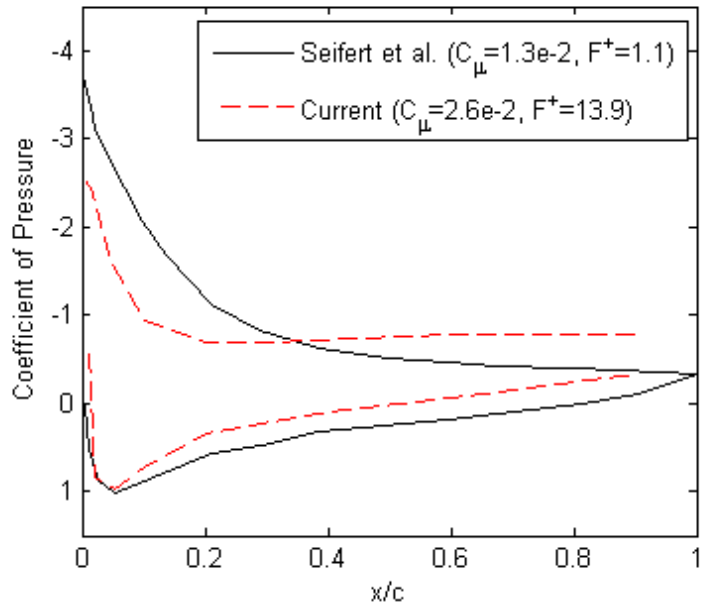

b) Active

Figure 5-2. Pressure data comparison with Seifert et al.'s 2D wing data at $\alpha=22^{\circ} . R e=150,000 .{ }^{14}$

Although it was not possible to fully replicate either case with the current model, the second case in particular has close enough $R e$ and $C_{p}$ patterns with and without actuation that compare well with the current experiment. 


\subsection{Momentum Coefficient}

It was necessary to investigate the momentum coefficient of the jet of air created by the synthetic jet actuators. Because the resulting jet of air had a zero net mass flux, it was necessary to measure the velocity using a hotwire anemometer rather than a plenum pressure measurement. The momentum coefficient would then be used to quantify the relative power of each actuation.

To test the slit velocity with a hotwire anemometer, the sensor had to be placed just above the slit exit. This was to prevent the model from touching the hotwire and breaking the sensor. Because of this, the expulsion velocity profiles were not the same as the ingestion. To obtain a closer estimate of momentum coefficient, the hotwire data was rectified such that the expulsion data was used in place of the ingestion data. The rectified data is shown in the figures that follow.

While an extensive test matrix was run, the discussion here will focus on the data points that were most important to the experiment. The first comparison was to see the effect of voltage applied to the actuators. The $60 \mathrm{~V}$ and $180 \mathrm{~V}$ actuations at $100 \mathrm{~Hz}\left(F^{+}=2.8\right)$ were compared first. The $60 \mathrm{~V}$ actuation resulted in peak velocities of approximately $5 \mathrm{~m} / \mathrm{s}$, while the RMS velocity was calculated to be $1.8 \mathrm{~m} / \mathrm{s}(5.9 \mathrm{ft} / \mathrm{s})$. By increasing the voltage to $180 \mathrm{~V}$, the peak velocities rise to approximately $8 \mathrm{~m} / \mathrm{s}$ for an RMS velocity of $2.6 \mathrm{~m} / \mathrm{s}(8.5 \mathrm{ft} / \mathrm{s})$. 


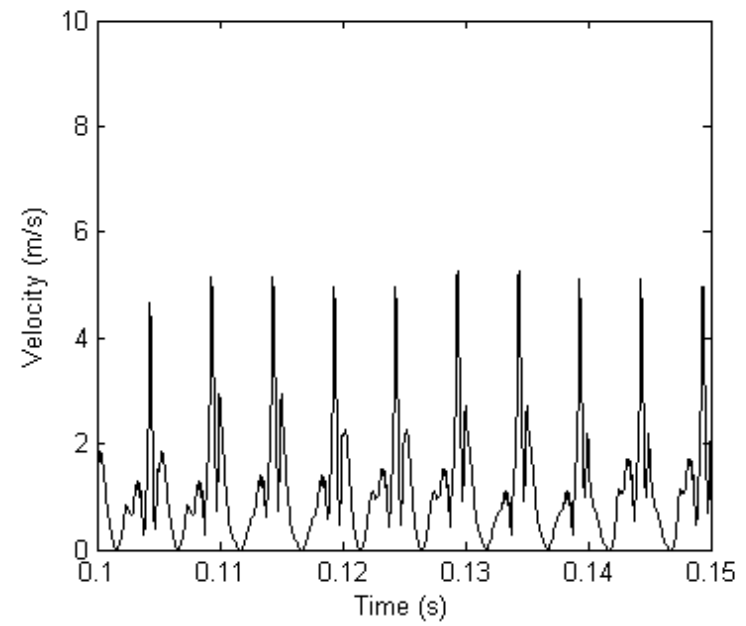

Figure 5-3. Hotwire velocity measurement for $100 \mathrm{~Hz}$, $60 \mathrm{~V}$ actuation.

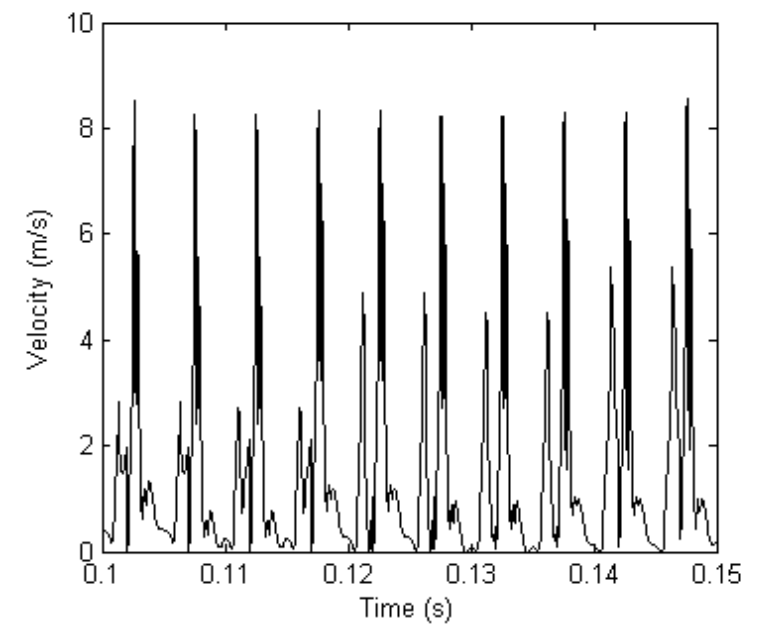

Figure 5-4. Hotwire velocity measurement for 100 $\mathrm{Hz}, 180 \mathrm{~V}$ actuation.

The resulting velocity profile was also evaluated for the $180 \mathrm{~V}$ actuation at $36 \mathrm{~Hz}\left(F^{+}=1\right)$. In this case, the ingestion and expulsion phases are more clearly defined due to the longer amount of time for the flow to equalize. For this case, the velocity peaks were approximately $9 \mathrm{~m} / \mathrm{s}$ for a RMS velocity of $1.9 \mathrm{~m} / \mathrm{s}(6.2 \mathrm{ft} / \mathrm{s})$.

The $60 \mathrm{~V}$ actuation at $500 \mathrm{~Hz}\left(F^{+}=13.9\right)$ resulted in velocity peaks of approximately $15 \mathrm{~m} / \mathrm{s}$. This case had a very high RMS velocity of $7.4 \mathrm{~m} / \mathrm{s}(24.3 \mathrm{ft} / \mathrm{s})$. 


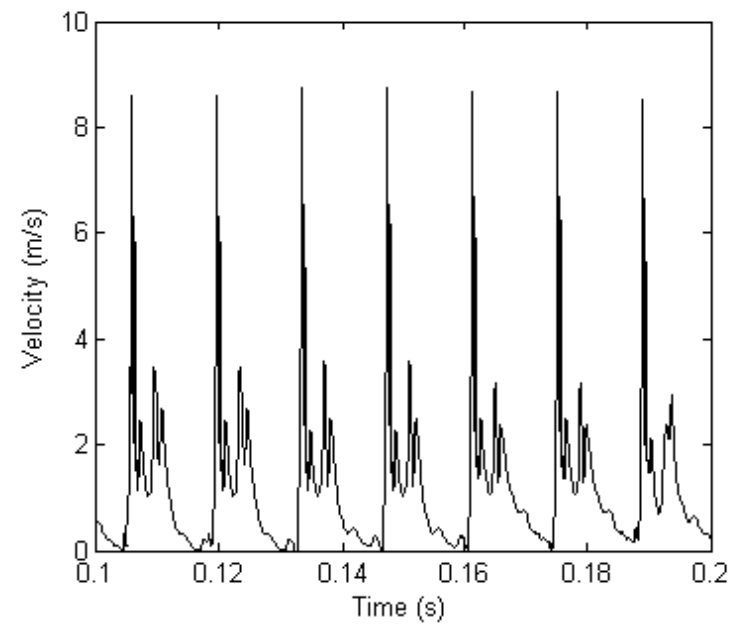

Figure 5-5. Hotwire velocity measurement for $36 \mathrm{~Hz}$, $180 \mathrm{~V}$ actuation.

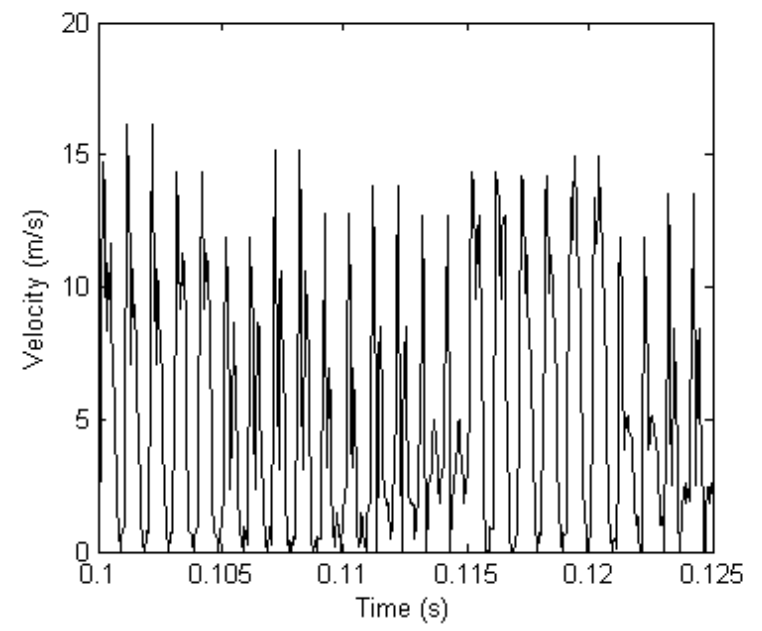

Figure 5-6. Hotwire velocity measurement for 500 Hz, 60 V actuation.

With the RMS velocity calculated for each actuation frequency and voltage in the test matrix, the momentum coefficient could be calculated. Surprisingly, it was seen that there was no major increase in momentum coefficient for an increase in actuation voltage between 60 and 180 volts for the frequency range from $36 \mathrm{~Hz}$ to $100 \mathrm{~Hz}$. Because the RMS velocity of the $500 \mathrm{~Hz}$ actuation was so high, the momentum coefficient was correspondingly high.

Table 5-1 details the calculated momentum coefficient based on the details of the experiment: a chord length of $0.2 \mathrm{~m}$ (8 in.), a slit length of 0.0025 meters $(0.1 \mathrm{in}$.$) , and a freestream velocity of$ $7.3 \mathrm{~m} / \mathrm{s}$ for the Reynolds number of 100,000 . While the $50 \mathrm{~Hz}$ and $250 \mathrm{~Hz}$ frequencies were tested for momentum coefficient, they were not used in the test matrix for pressure testing. 


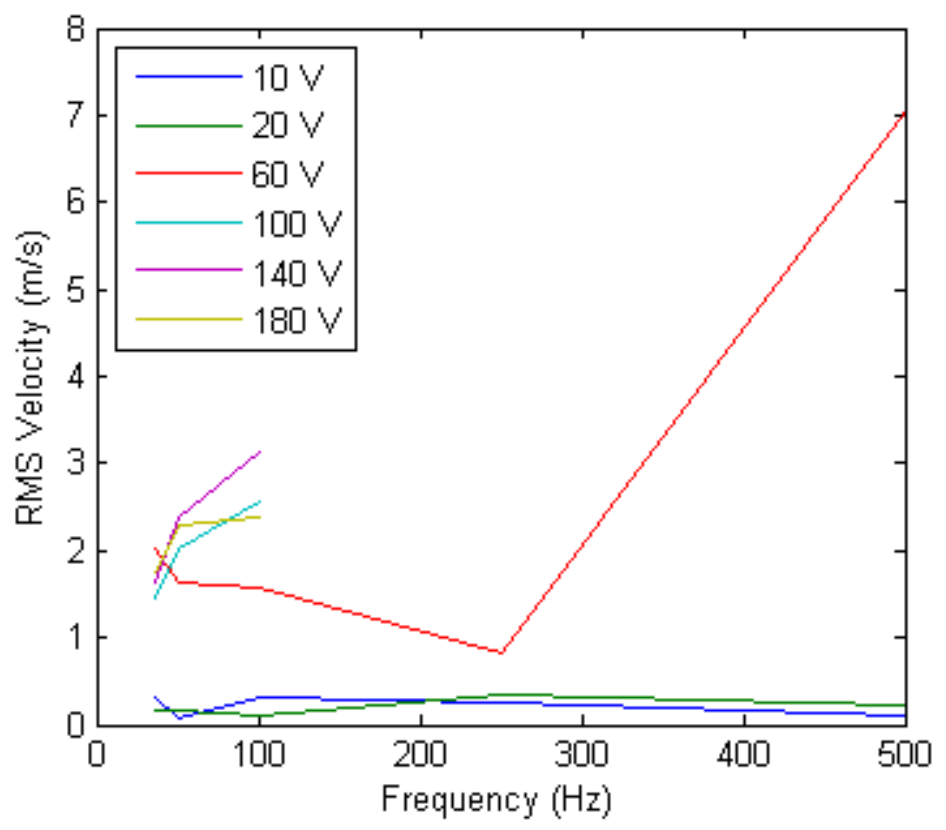

Figure 5-7. RMS velocity at each test point.

Table 5-1. Momentum Coefficient $\left(C_{\mu}\right)$ values at $\operatorname{Re}=100,000$.

\begin{tabular}{|c|c|c|c|c|c|}
\hline Frequency & $\mathbf{3 6 ~ H z}$ & $\mathbf{5 0 ~} \mathbf{~ H z}$ & $\mathbf{1 0 0} \mathbf{~ H z}$ & $\mathbf{2 5 0} \mathbf{~ H z}$ & $\mathbf{5 0 0} \mathbf{~ H z}$ \\
\hline $\mathbf{F}^{+}$ & $\mathbf{1}$ & $\mathbf{1 . 4}$ & $\mathbf{2 . 8}$ & $\mathbf{6 . 9}$ & $\mathbf{1 3 . 9}$ \\
\hline $\mathbf{1 0} \mathbf{V}$ & $2.7 \mathrm{e}-5$ & $1.2 \mathrm{e}-6$ & $1.4 \mathrm{e}-5$ & $9.8 \mathrm{e}-5$ & $6.0 \mathrm{e}-5$ \\
\hline $\mathbf{2 0} \mathbf{V}$ & $1.6 \mathrm{e}-5$ & $3.0 \mathrm{e}-5$ & $6.1 \mathrm{e}-5$ & $8.2 \mathrm{e}-4$ & $1.8 \mathrm{e}-4$ \\
\hline $\mathbf{6 0} \mathbf{V}$ & $2.4 \mathrm{e}-3$ & $1.6 \mathrm{e}-3$ & $1.6 \mathrm{e}-3$ & $1.7 \mathrm{e}-3$ & $2.7 \mathrm{e}-2$ \\
\hline $\mathbf{1 0 0} \mathbf{V}$ & $1.2 \mathrm{e}-3$ & $2.3 \mathrm{e}-3$ & $3.7 \mathrm{e}-3$ & $\mathrm{x}$ & $\mathrm{x}$ \\
\hline $\mathbf{1 4 0} \mathbf{V}$ & $1.5 \mathrm{e}-3$ & $3.1 \mathrm{e}-3$ & $5.4 \mathrm{e}-3$ & $\mathrm{x}$ & $\mathrm{x}$ \\
\hline $\mathbf{1 8 0} \mathbf{~ V}$ & $1.7 \mathrm{e}-3$ & $2.9 \mathrm{e}-3$ & $3.2 \mathrm{e}-3$ & $\mathrm{x}$ & $\mathrm{x}$ \\
\hline
\end{tabular}




\section{3 $\quad C_{p}$ for $\alpha=12^{\circ}$ Case}

The initial angle chosen for comparison was $\alpha=12^{\circ}$. Based on 2D approximations, it was expected that this angle of attack would not yield any separation over the surface of the wing. It was still desirable to test this angle, however, to ensure that the presence of the slit was not having any adverse effects on the pressure distribution.

\subsubsection{Slit Comparison}

The following comparisons show the pressure distribution for the two top and bottom rows of pressure ports at $2 \mathrm{y} / \mathrm{b}=0.38$ and 0.85 with an actuation in each case at the maximum allowable voltage. The "open slit" cases are the cases with the slits open to the flow, and the "covered slit" cases are the cases with the slits covered with tape. Also, the model is at both positive and negative angles of attack. For the positive angle of attack the slits are on the suction side while for the negative angle of attack the slits are on the pressure side. All these tests were to confirm that the presence of the slit itself was not causing attachment.

The results of the $\alpha=12^{\circ}$ case are shown in Fig. 5-8. In this case, the flow shows no significant difference in $C_{p}$ distributions between the slit configurations. The only noteworthy difference is around $20 \%$ chord at the no actuation case which shows a small $C_{p}$ deficit region. This $C_{p}$ deficit region is likely due to a separation bubble and apparently is smoothened out with actuation. This figure also confirms the zero angle calibration because there is no distinction between the pressure distribution between the $+12^{\circ}$ and $-12^{\circ}$ cases. 


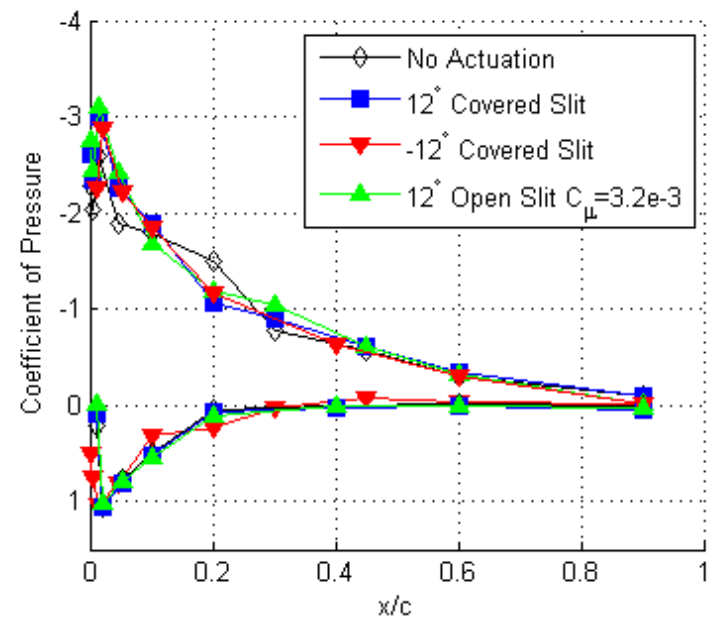

a) $2 y / b=0.38$

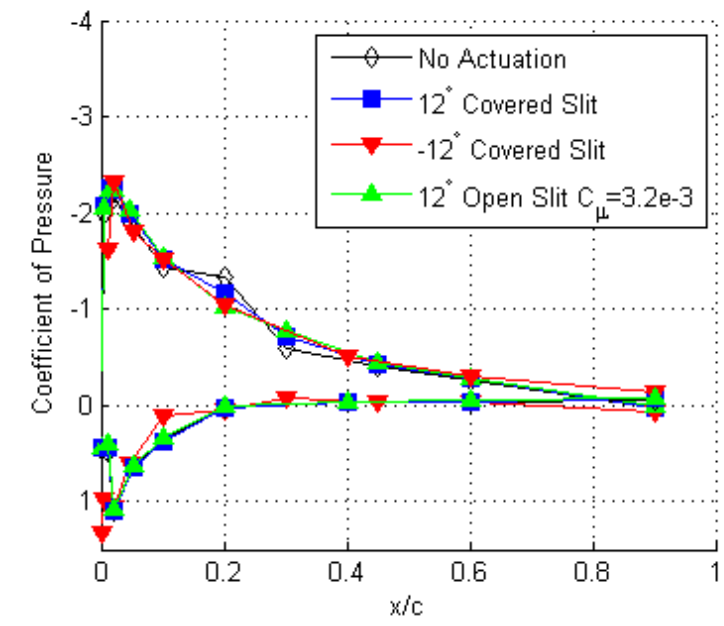

b) $2 y / b=0.85$

Figure 5-8. Effects of slit configurations at $\alpha=12^{\circ}, F^{+}=2.8 . \operatorname{Re}=100,000$.

Because the flow was completely attached for every slit configuration at $12^{\circ}$, the full test matrix of frequencies and amplitudes was not tested. This test was considered successful for confirming that the presence of the slit was not having adverse effects on the flow without actuation at low angles of attack. 


\section{$5.4 \alpha=16^{\circ}$ Case}

The pressure data taken at $16^{\circ}$ was meant to be the focal point of this experiment. At this angle, the flow was expected to be fully separated, which would allow the investigation into all three of the experiments main goals: confirm that actuation could delay separation, quantify any change in spanwise pressure distribution, and explore the influence of the model vibration on the pressure distribution.

\subsubsection{Slit Comparison}

Figure 5-9 shows the results of the test with no actuation over the wing at $\alpha=16^{\circ}$ and $-16^{\circ}$. Note that the slit is on the suction side for $\alpha=16^{\circ}$ and on the compressed side for $\alpha=-16^{\circ}$. This test was to confirm that the presence of the slit itself was not causing attachment. As can be seen, there is no discernible difference between the two cases.

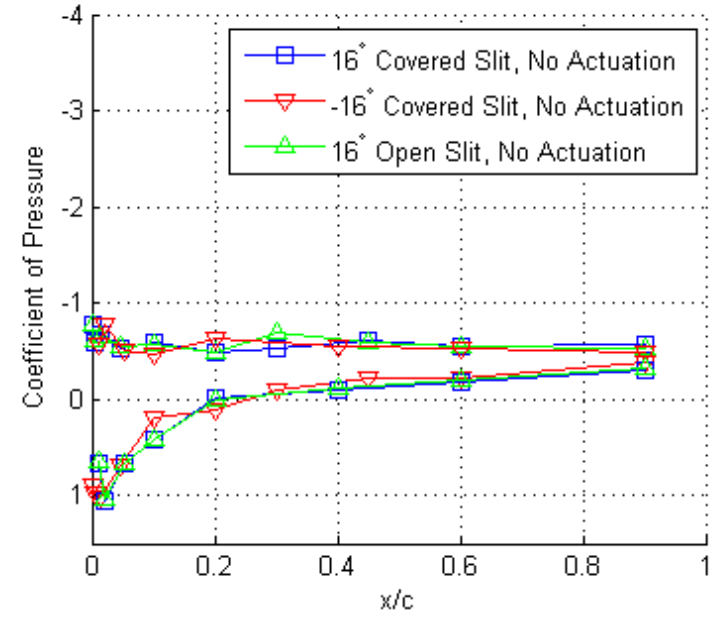

a) $2 y / b=0.38$

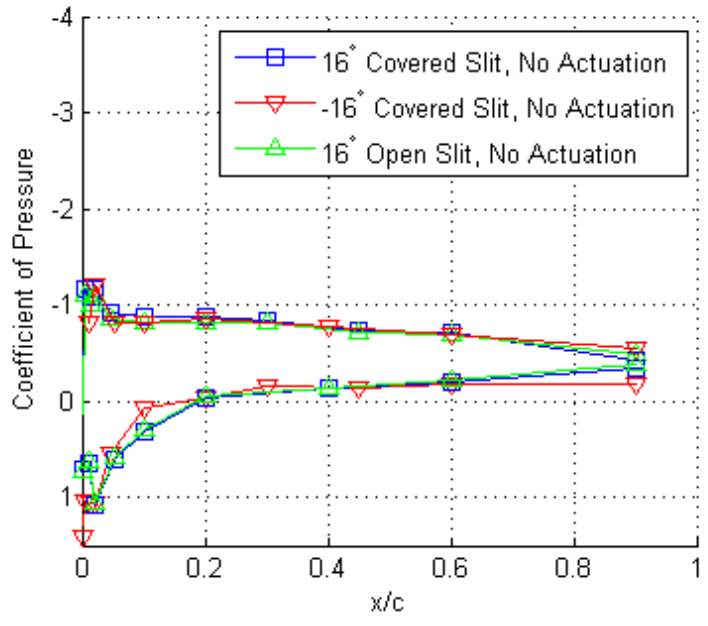

b) $2 y / b=0.85$

Figure 5-9. Effects of slit configurations with no actuation at $\alpha=16^{\circ} \cdot \operatorname{Re}=100,000$. 
The next step was to evaluate the model in this context with various conditions of actuation. First a $F^{+}=1, C_{\mu}=1.7 \mathrm{e}-3$ actuation was tested in each condition, as shown in Fig. 5-10. In this case the negative angle case exhibits no clear signs of influencing the flow, while the covered case with a positive angle of attack where the slit is on the suction side does have some moderate effect. The open slit case at $\alpha=16^{\circ}$ caused a full attachment, as was expected.

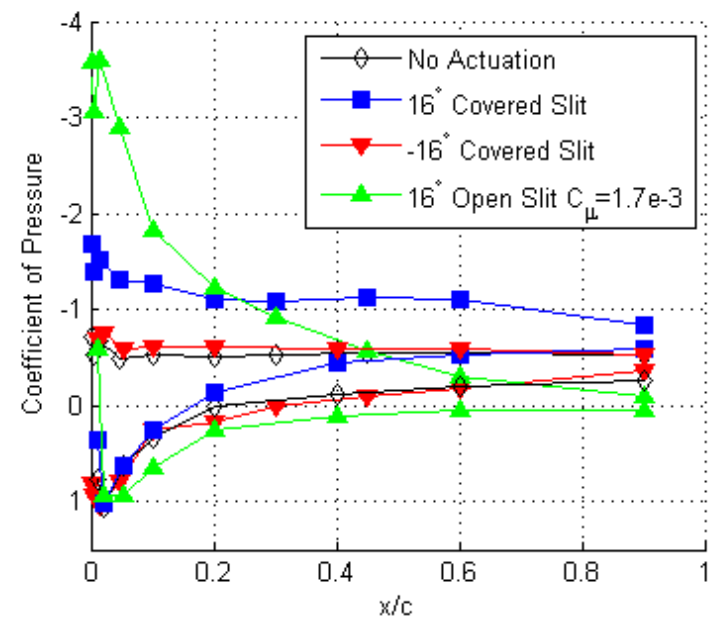

a) $2 y / b=0.38$

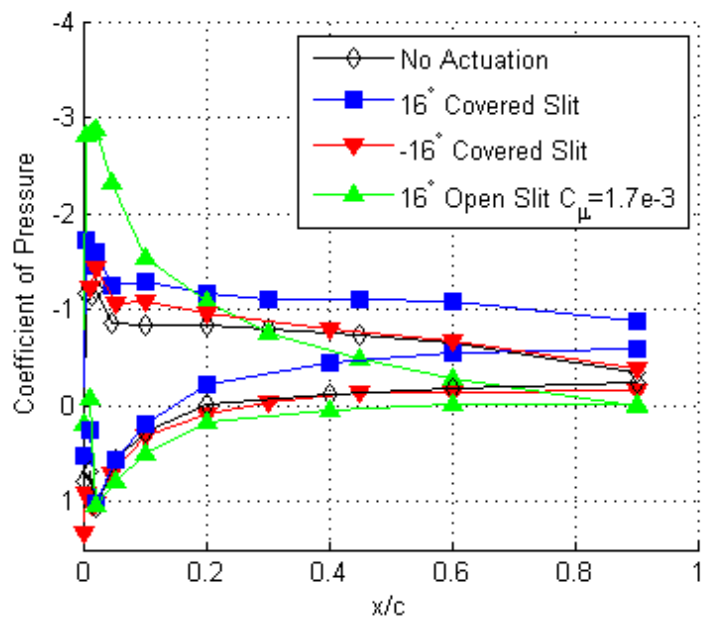

b) $2 y / b=0.85$

Figure 5-10. Effects of slit configurations at $\alpha=16^{\circ} . F^{+}=1, R e=100,000$.

The same three configurations were tested with a $F^{+}=2.8$ actuation, shown in Fig. 5-11. As with the $F^{+}=1$ case, only the open slit was successful in causing the full attachment of flow over the wing model, and the suction peak at $\mathrm{C}_{\mathrm{p}} \cong-3.9$ at the inboard location $2 y / b=0.38$ is definitely higher than the suction peak at $C_{p} \cong-3.2$ at the outboard location at $2 y / b=0.85$. The covered slit cases closely mirror each other. While neither case cause full attachment, there is a definite suction peak toward the leading edge at $2 y / b=0.85$. 


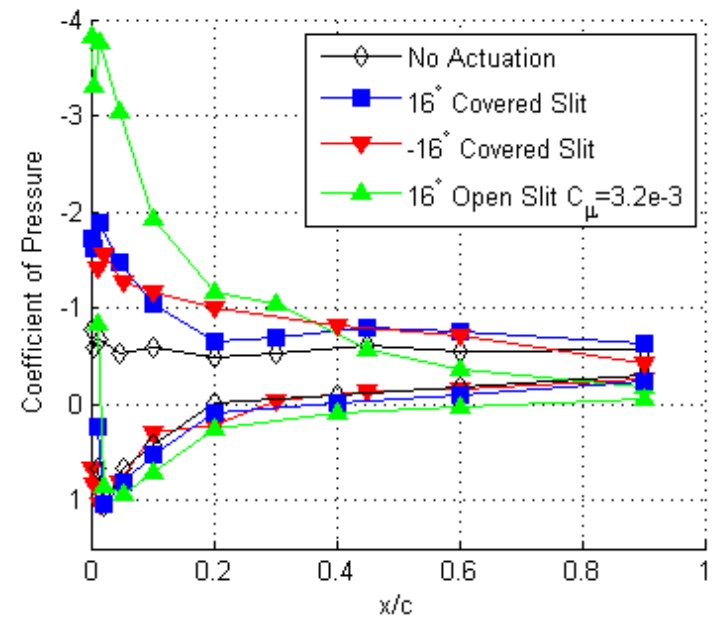

a) $2 y / b=0.38$

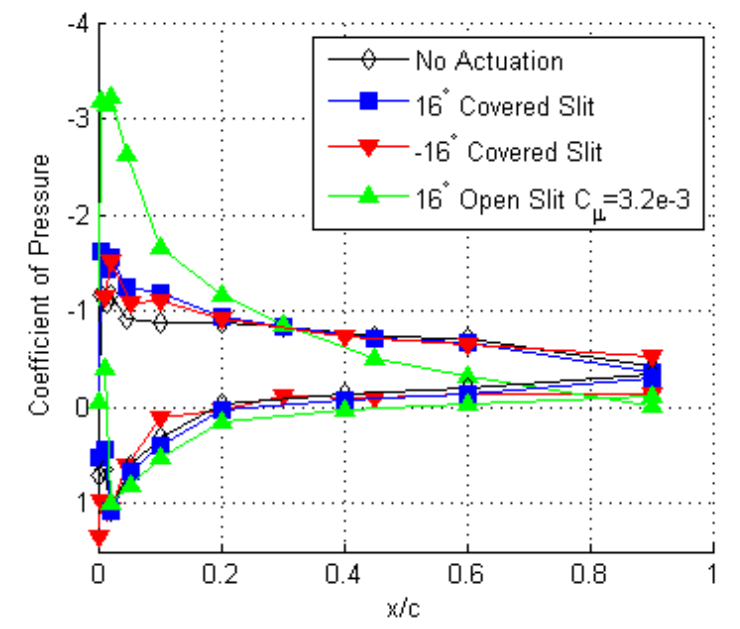

b) $2 y / b=0.85$

Figure 5-11. Effect of slit configurations at $\alpha=16^{\circ}, F^{+}=2.8 R e=100,000$.

The final actuation condition for the slit test was an actuation at $F^{+}=13.9$, as shown in Fig. 5-12.

As shown in the figure the covered slit actuation at $\alpha=16^{\circ}$ and $-16^{\circ}$ and the open slit actuation caused an almost identical attachment of the flow. That is really a surprising observation. Although the vibration (covered-slit actuation) is expected to have some effects on the flow, it was not expected to lead to full boundary layer attachment. It implies that the presence of the slit in this case is not necessary for the flow attachment. Also at $2 y / b=0.85$, the $C p$ pattern of the open slit case seems to suggest the occurrence of local separation bubbles at $x / c=0.1$ and 0.44 .

This is not observed in the closed-slit case.

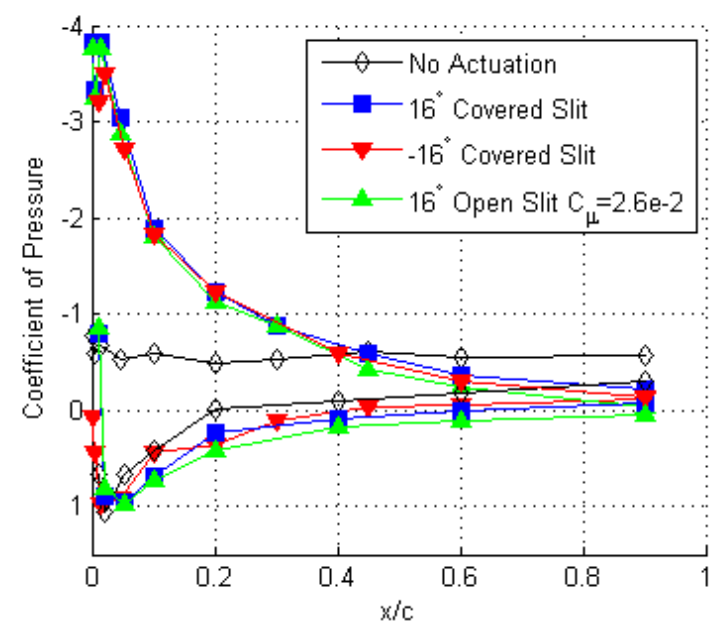

a) $2 y / b=0.38$

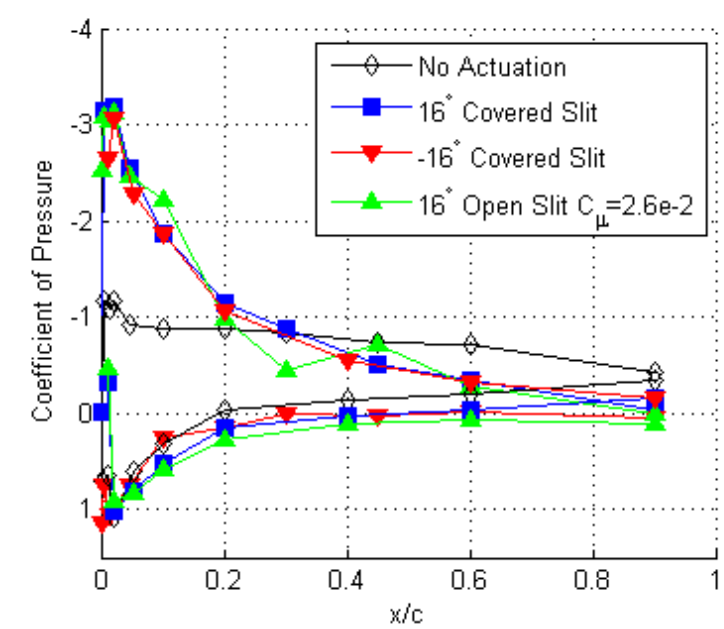

b) $2 y / b=0.85$

Figure 5-12. Effects of slit configurations at $\alpha=16^{\circ}, F^{+}=13.9 R e=100,000$. 
After evaluating the results of the four slit configurations, it appears that the actuation at $\mathrm{F}^{+}=$ 13.9 is able to cause flow attachment without the slit. It was decided to use an accelerometer to further quantify the model vibration in these cases. (See Section 5.6) 


\subsubsection{Spanwise Effect of Varying Actuation Amplitude}

The next phase of testing was to re-evaluate the $16^{\circ}$ case with varying amplitude actuations. First, the $F^{+}=1$ case was studied as this is the non-dimensional frequency that was most effective in previous experiments. The results, seen in Fig. 5-13, show that each of the actuations caused a nearly identical attachment. Also, the $C_{p}$ peaks have seen fast attenuation at $2 y / b=0.85$ and 0.93 , very close to the tip. Because the pressure distributions at each span-wise location were so similar, this case gave little insight to the span-wise variation from actuation.

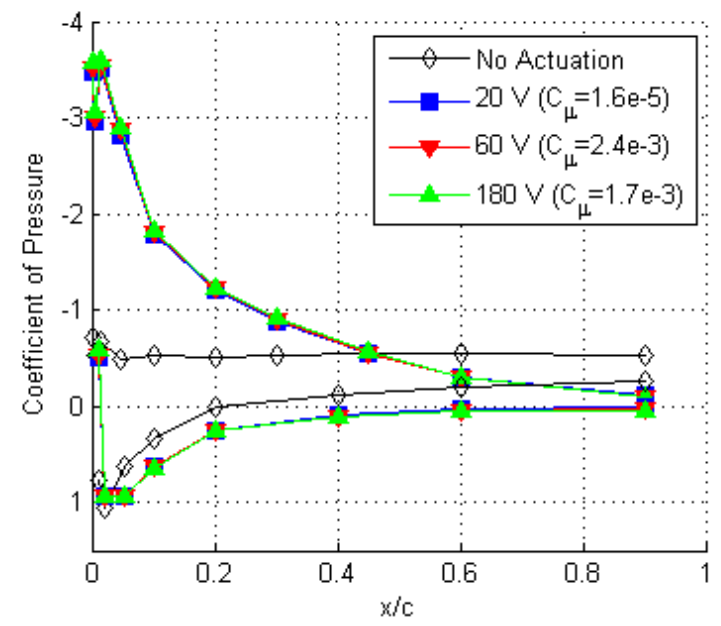

a) $2 y / b=0.38$

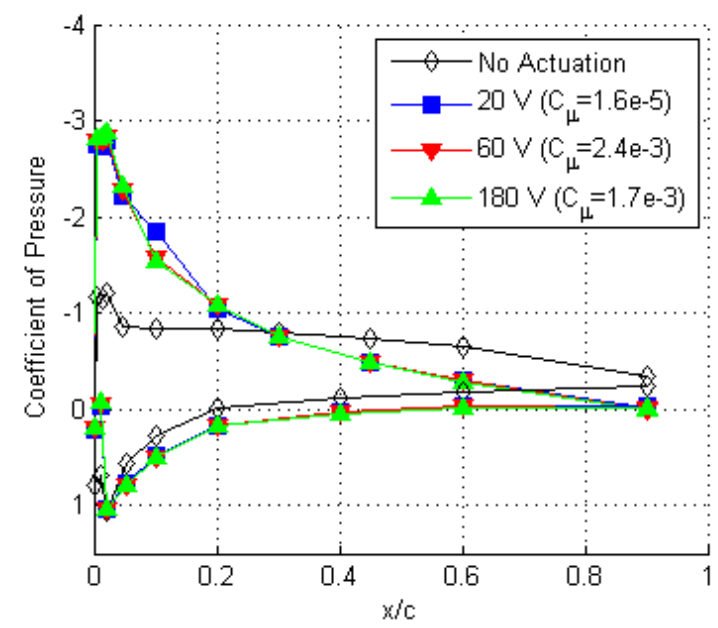

c) $2 y / b=0.85$

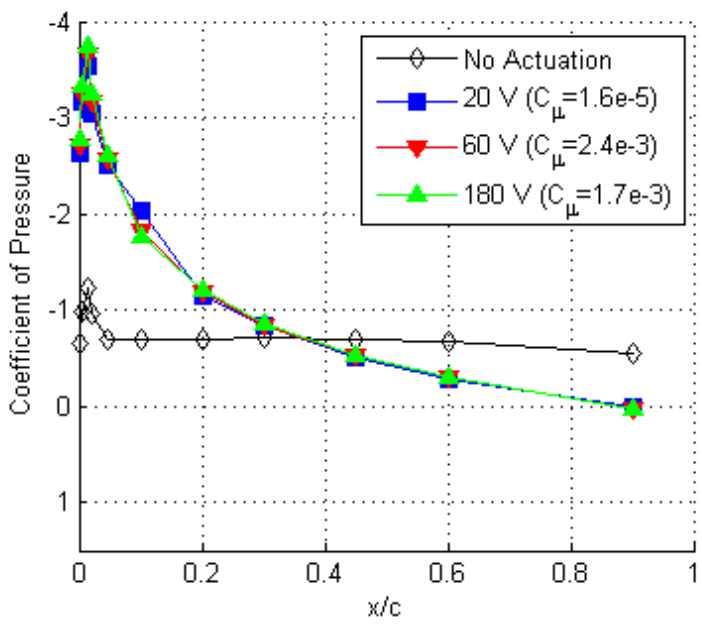

b) $2 y / b=0.70$

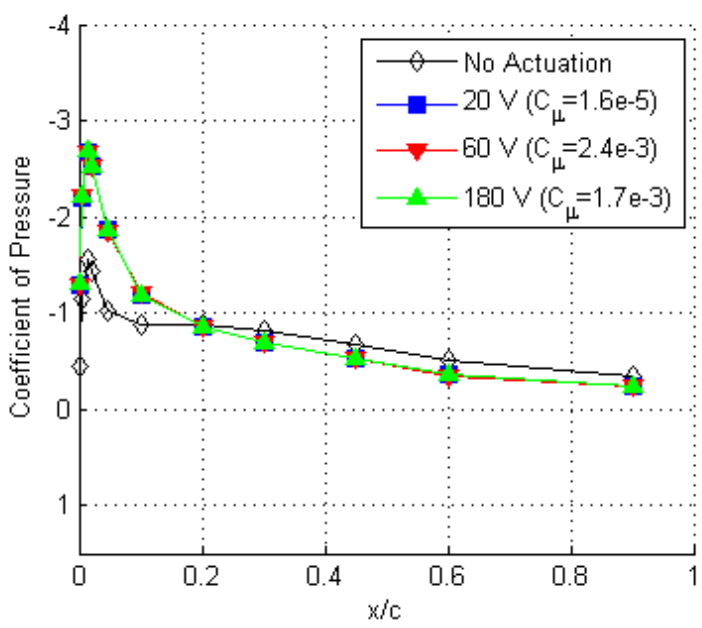

d) $2 y / b=0.93$

Figure 5-13. Effects of $\mathrm{F}^{+}=1$ actuation in the spanwise direction at $\alpha=16^{\circ} . R e=100,000$. 


\subsubsection{Spanwise Effect of Varying Actuation Frequency}

The next step was to evaluate the $16^{\circ}$ case with various actuation frequencies. The actuators were powered such that the momentum coefficient was as consistent as possible for each frequency. The test was conducted for a momentum coefficient of approximately $2 \mathrm{e}-3$ for $F^{+}=1,2.8$, and 13.9. As with the previous case, all conditions in this test were successful in causing the flow to attach. Because the flow in each case was nearly identical, no major conclusion can be drawn about the spanwise change in pressure distribution.

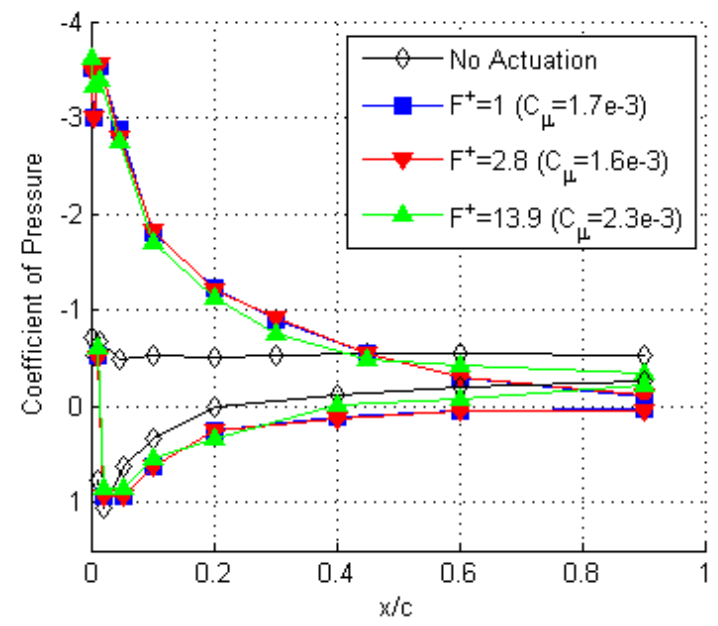

a) $2 y / b=0.38$

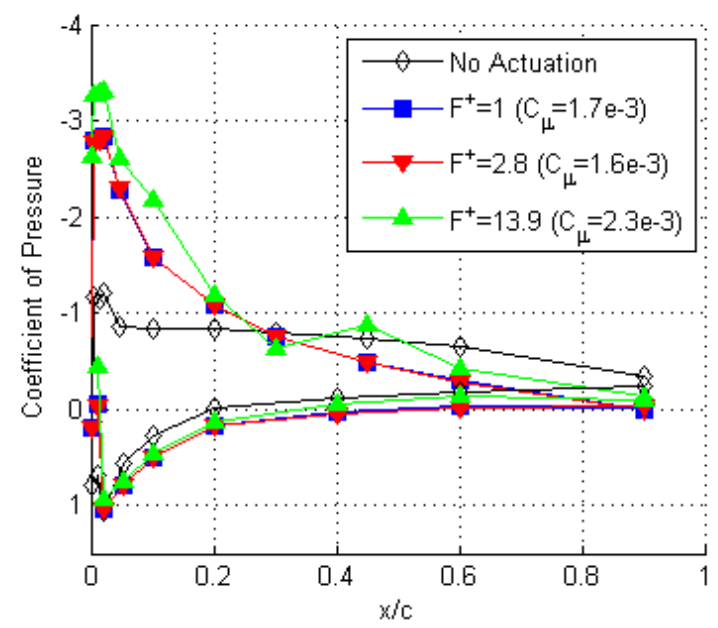

c) $2 y / b=0.85$

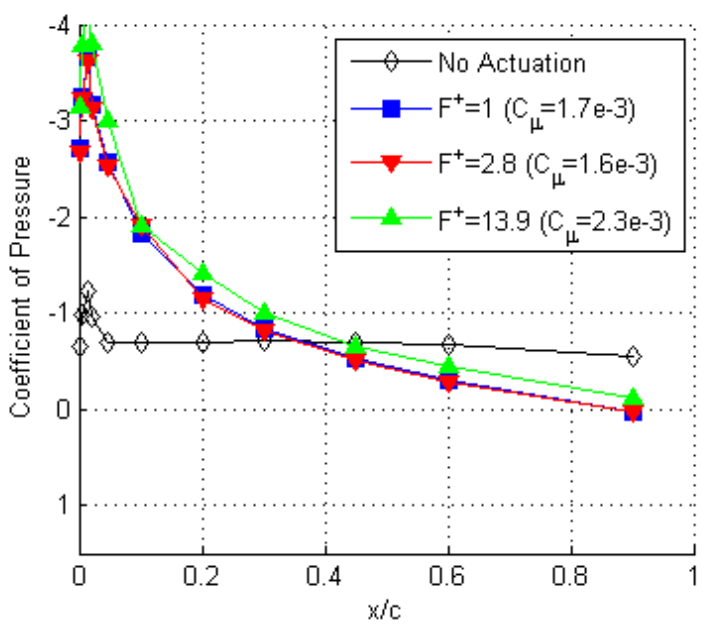

b) $2 y / b=0.70$

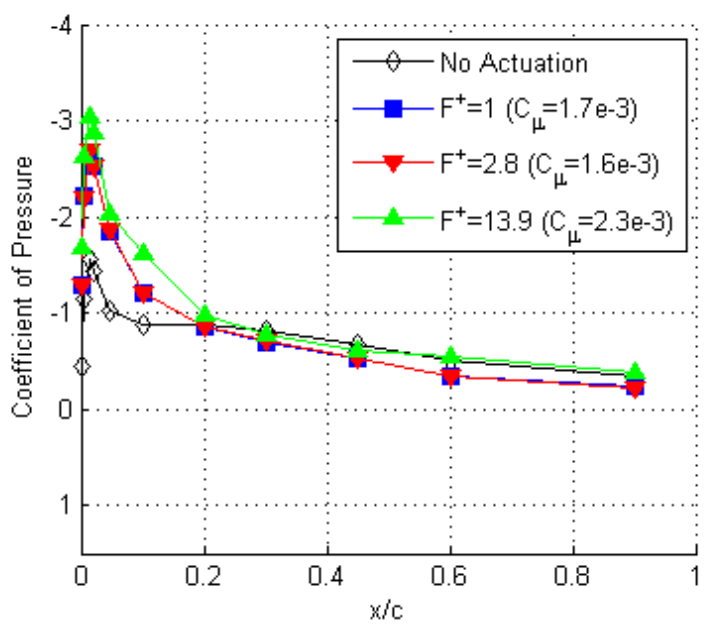

d) $2 y / b=0.93$

Figure 5-14. Frequency Sweep at full power. $R e=100,000 . \alpha=16^{\circ}$. 


\section{$5.5 \alpha=20^{\circ}$ Case}

\subsubsection{Slit Comparison}

The test points investigated at $16^{\circ}$ were also conducted $\alpha=20^{\circ}$. The first step was to evaluate the wing with no actuation in each slit configuration. The resulting pressure distribution shows that there is no significant difference between each configuration with no actuation. In each case, the flow is full separated over nearly the entire top surface.

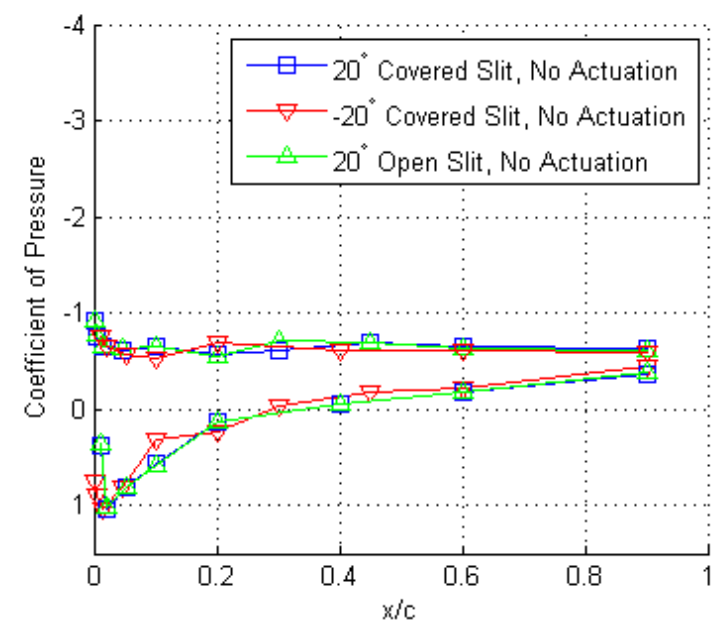

a) $2 y / b=0.38$

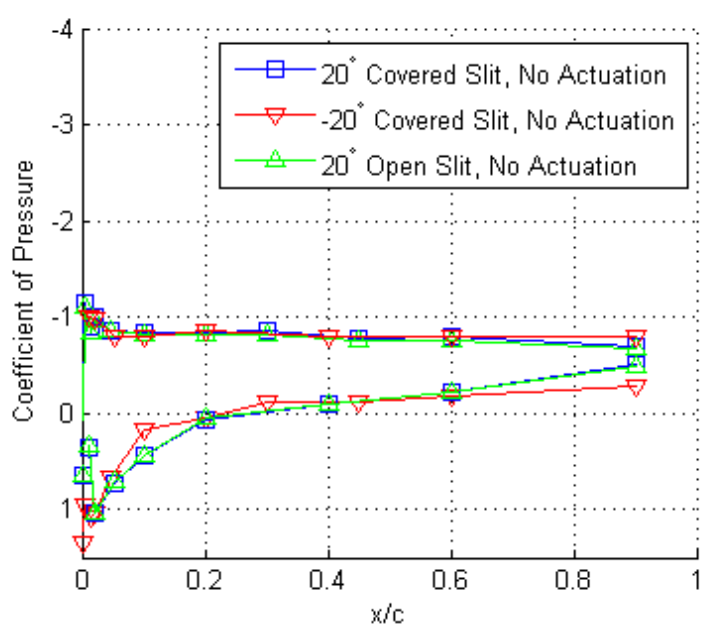

b) $2 y / b=0.85$

Figure 5-15. Effects of slit configurations with no actuation at $\alpha=20^{\circ} . R e=100,000$.

The model then was tested at $F^{+}=1$. The open slit case of this actuation did not show promising results for causing attachment, so the closed slit tests were not performed at $F^{+}=1$. 


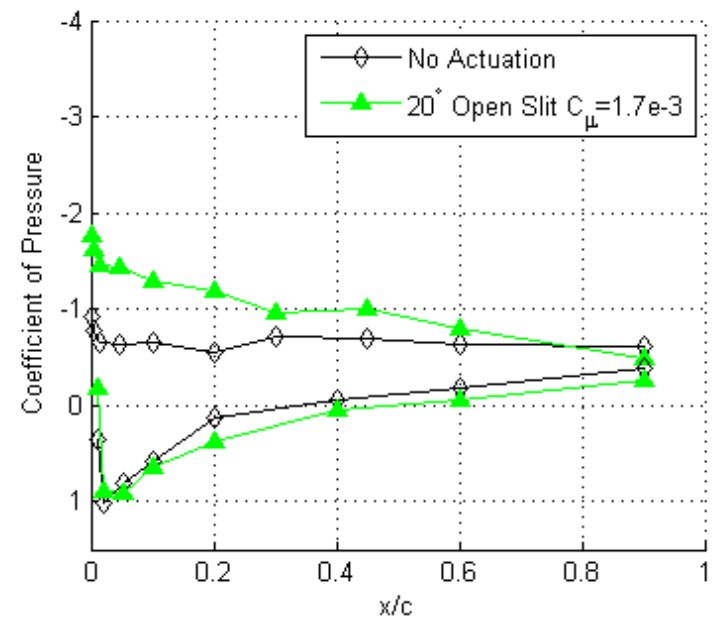

a) $2 y / b=0.38$

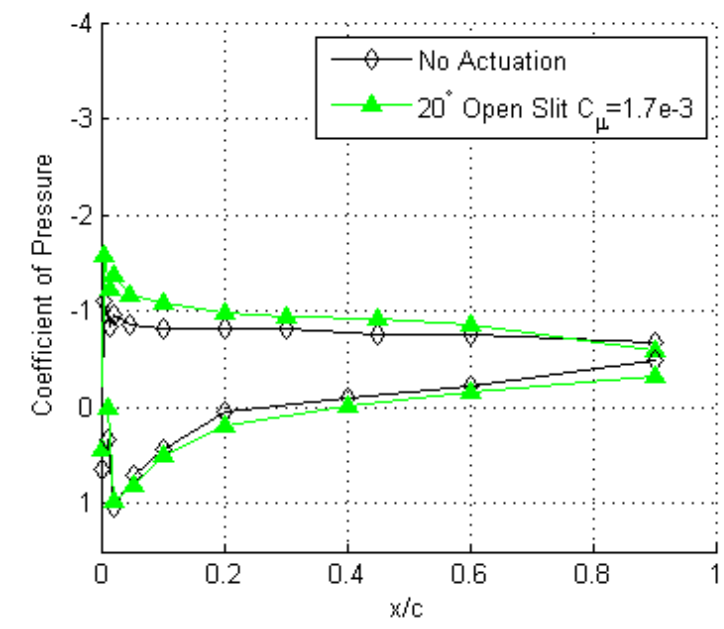

b) $2 y / b=0.85$

Figure 5-16. Effect of slit configurations at $\alpha=20^{\circ}, F^{+}=1$. $R e=100,000$.

The next test was to evaluate each slit configuration with a full power $(180 \mathrm{~V}) C_{\mu}=3.2 \mathrm{e}-2$ actuation at $F^{+}=2.8$. It can be seen in Fig. 5-17 that the open slit case was the only one that has an influence on the pressure distribution. Even in this case, there is only a moderate increase in the suction peak and the flow is separated after about $20 \%$ chord.

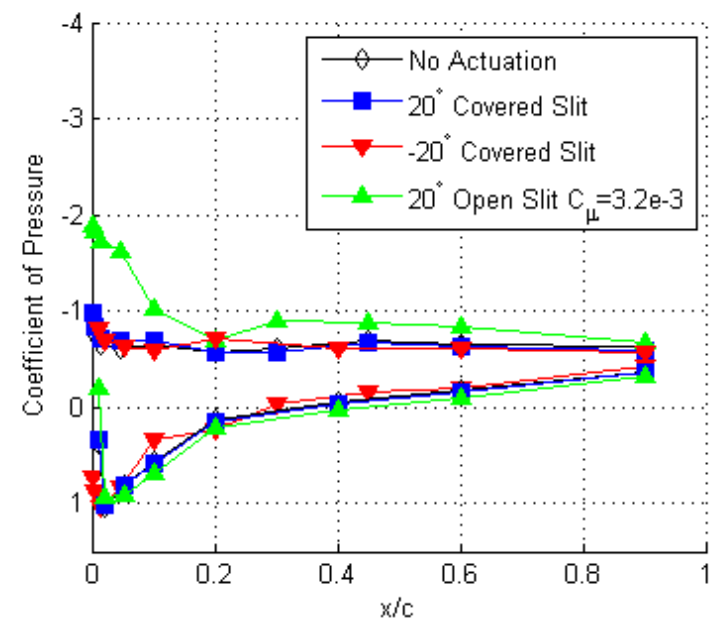

a) $2 y / b=0.38$

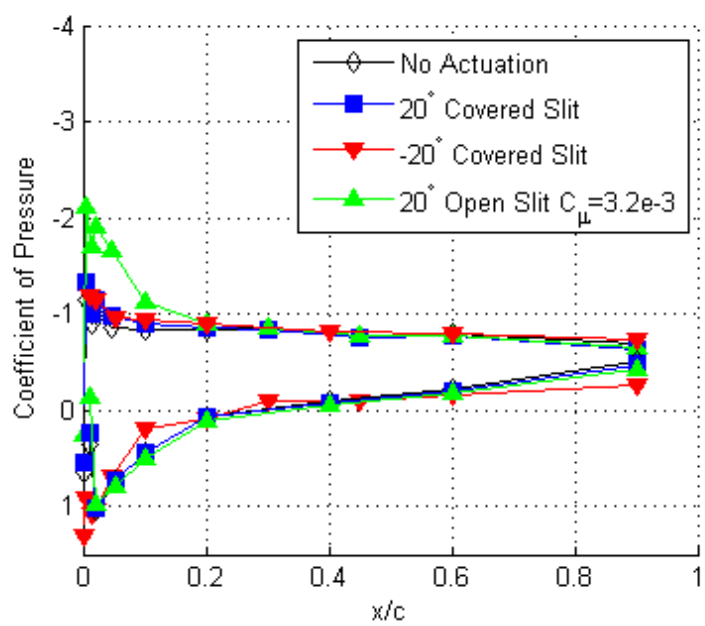

b) $2 y / b=0.85$

Figure 5-17. Effect of slit configurations at $\alpha=20^{\circ}, F^{+}=2.8$. $R e=100,000$.

The next test was at $F^{+}=13.9$. The negative angle covered slit case appeared to have a slight effect on the leading edge suction at $2 y / b=0.85$. The open slit case, however, was able to cause the flow to fully attach on the upper surface for the entire length of the wing. The covered slit at $\alpha=-20^{\circ}$ case appears to have more effect at $2 y / b=0.38$, near the center of the wing than towards 
the tip. In both span-wise locations, the open slit case fully attached the flow with only a little attenuation at $2 y / b=0.85$.

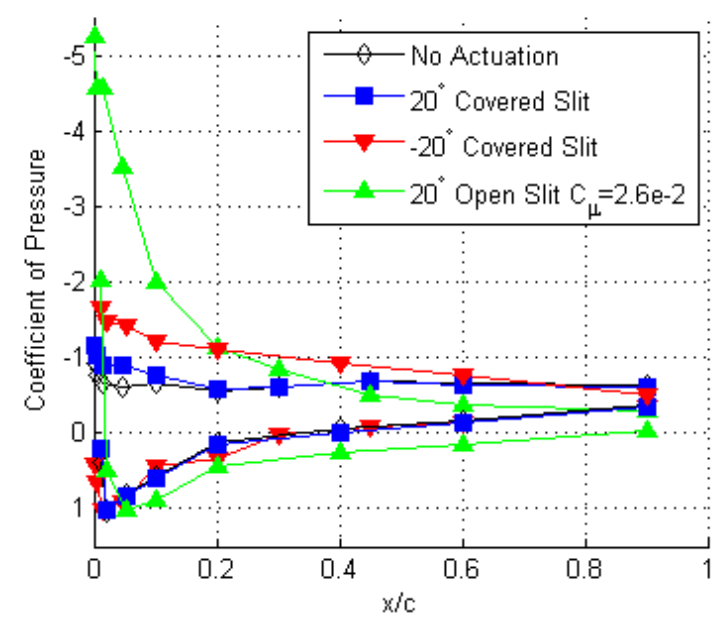

a) $2 y / b=0.38$

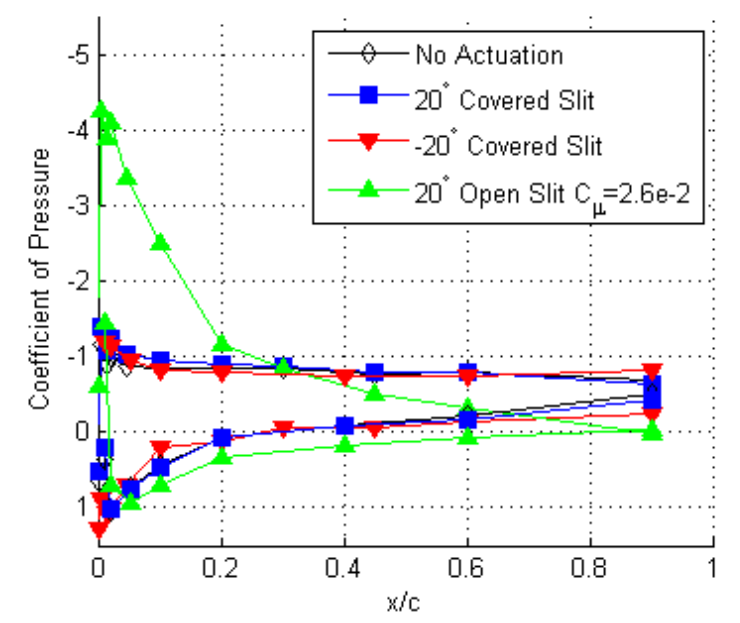

b) $2 y / b=0.85$

Figure 5-18. Effects of slit configurations at $\alpha=20^{\circ}, F^{+}=13.9 . R e=100,000$.

The most significant result of the slit configuration testing at $20^{\circ}$ was that the covered slit cases did not influence the flow nearly as much as they did at $16^{\circ}$. The open slit cases were then tested for the rest of the test matrix. 


\subsubsection{Spanwise Effect of Actuation Amplitude}

The amplitude test at $20^{\circ}$ was conducted at $F^{+}=13.9$, since this frequency was the only one to definitively cause full attachment. At the lower power actuation with $C_{\mu}=2.3 \mathrm{e}-3$, there is very little effect at $2 y / b=0.38$, but full attachment past $2 y / b=0.70$. This case supports the expected separation pattern where separation begins at the trailing edge of the wing root and travels outward toward the tip. ${ }^{20}$ In this case, the lower power actuation is able to cause attachment towards the wingtip, but only to a point between $2 y / b=0.687$ and 0.846 . The higher power actuation at $C_{\mu}=2.6 \mathrm{e}-2$ adds enough energy to suppress separation past $2 y / b=0.38$.

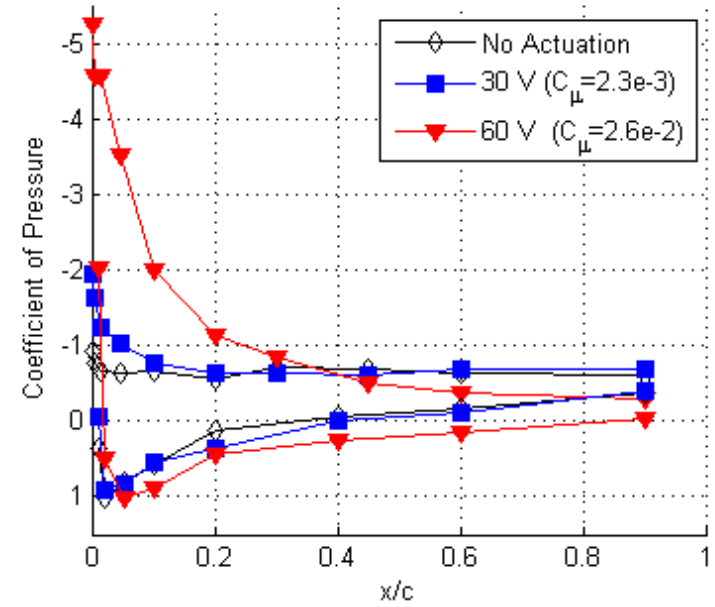

a) $2 y / b=0.38$

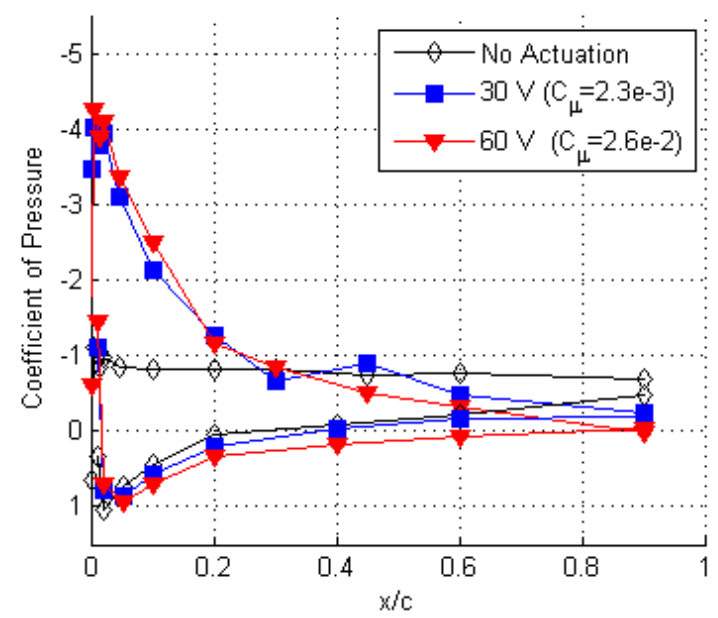

c) $2 y / b=0.85$

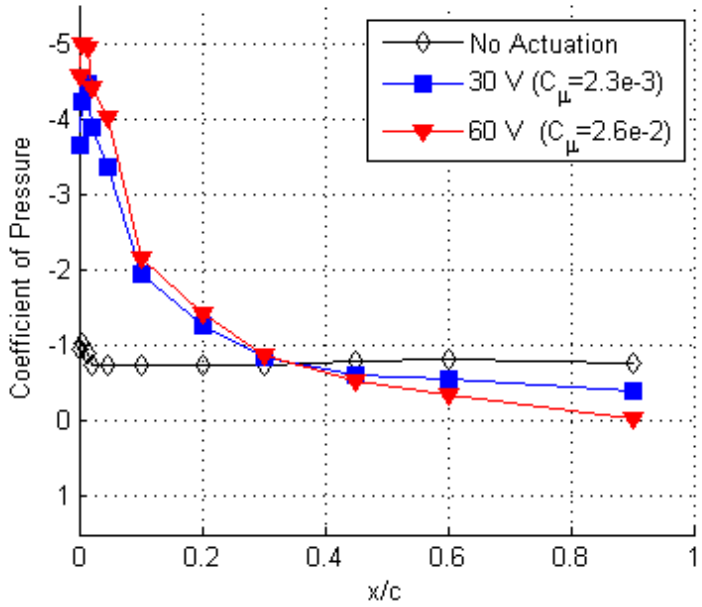

b) $2 y / b=0.70$

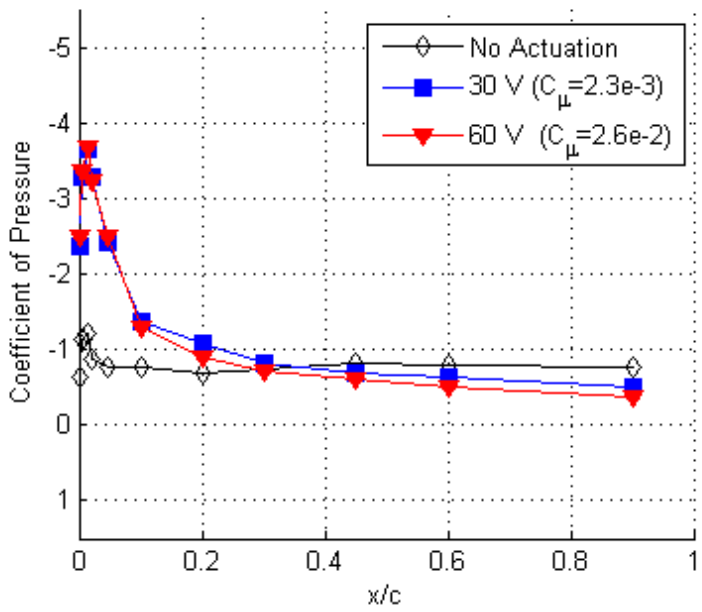

d) $2 y / b=0.93$

Figure 5-19. Effects of actuation power at $\alpha=20^{\circ}, F^{+}=13.9 . R e=100,000$. 


\subsection{Spanwise Effect of Actuation Frequency}

Figure 5-19 shows the results of the $20^{\circ}$ case for various frequencies while holding momentum coefficient constant. The same actuations were used here as in the $16^{\circ}$ case, resulting in a momentum coefficient of approximately $2 \mathrm{e}-3$ at $F^{+}=1,2.8$, and 13.9. Surprisingly, the $F^{+}=13.9$ actuation was the only one that had any major impact on the flow around the wing. Close to the root of the wing, the flow remains separated, but a clear suction peak develops by $2 y / b=0.70$ for the $F^{+}=13.9$ actuation. The other frequencies had no major impact on the flow.

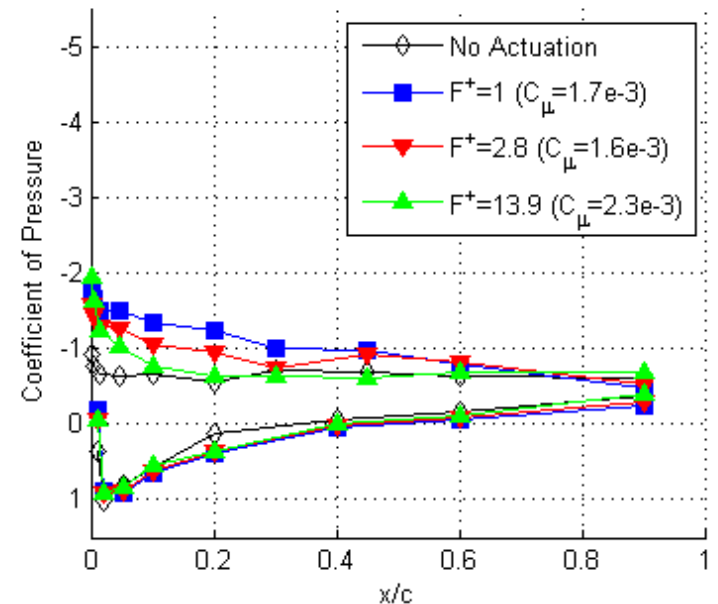

a) $2 y / b=0.38$

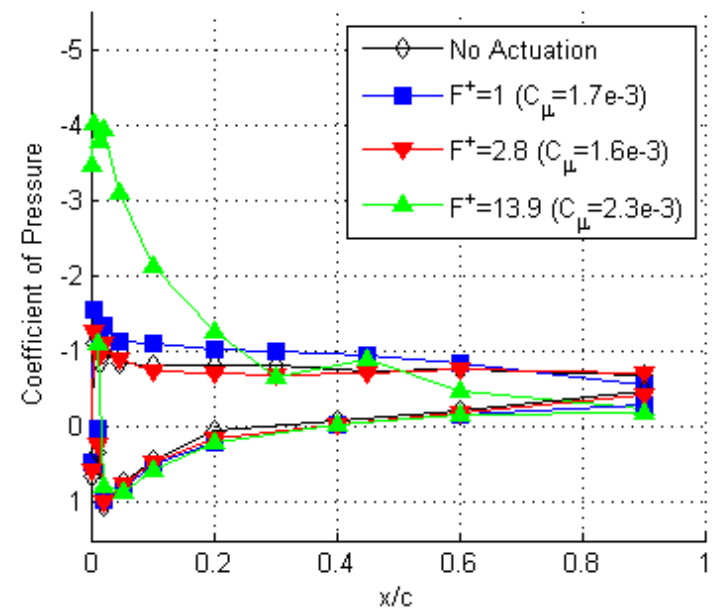

c) $2 y / b=0.85$

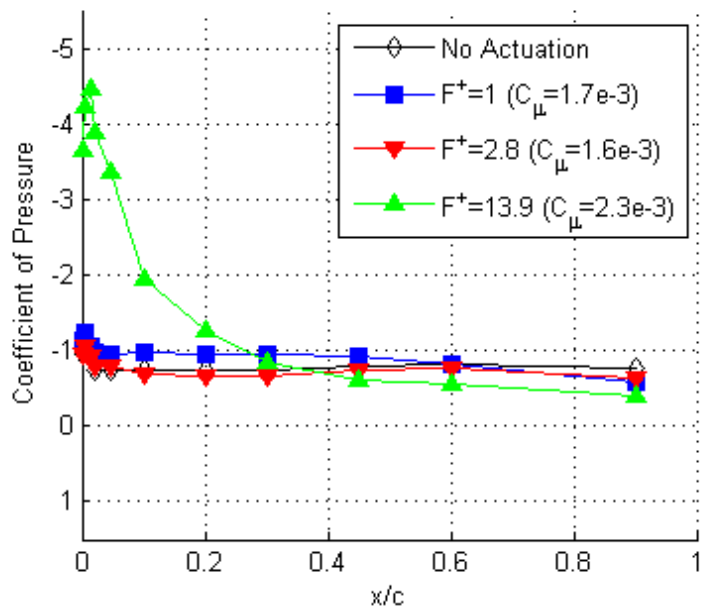

b) $2 y / b=0.70$

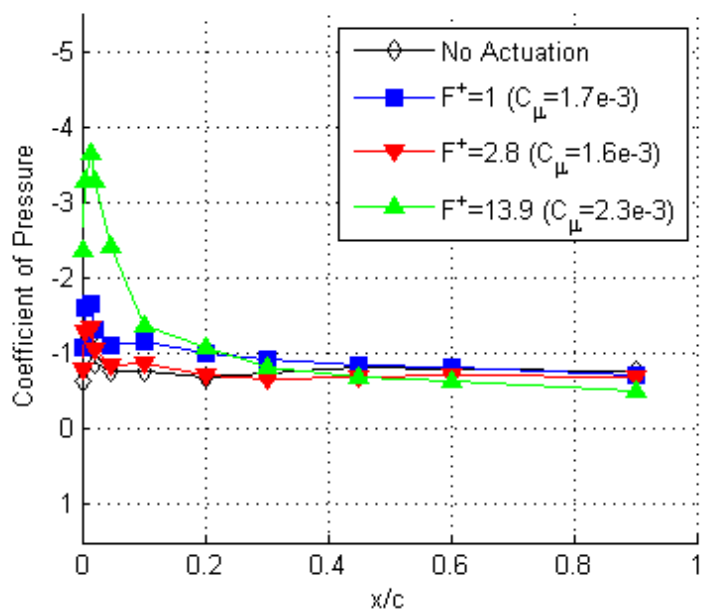

d) $2 y / b=0.93$

Figure 5-20. Effects of frequency sweep. $R e=100,000 . \alpha=20^{\circ}$. 


\subsection{Lift Coefficient Comparison}

For illustrative purposes, it is helpful to see the results of the changing lift distribution in the form of a $C_{l}$ vs $\alpha$ curve. Figure 5-21 shows the section lift coefficient at $2 y / b=0.38$ and 0.85 calculated with the panel method with $\mathrm{C}_{\mathrm{p}}$ at the trailing edge approximated by the average of the pressure coefficients at the adjacent two points. This shows at both locations that the open slit is fully overcoming separation and causing attachment at $20^{\circ}$. Also, both types of actuation are causing attachment at $16^{\circ}$.

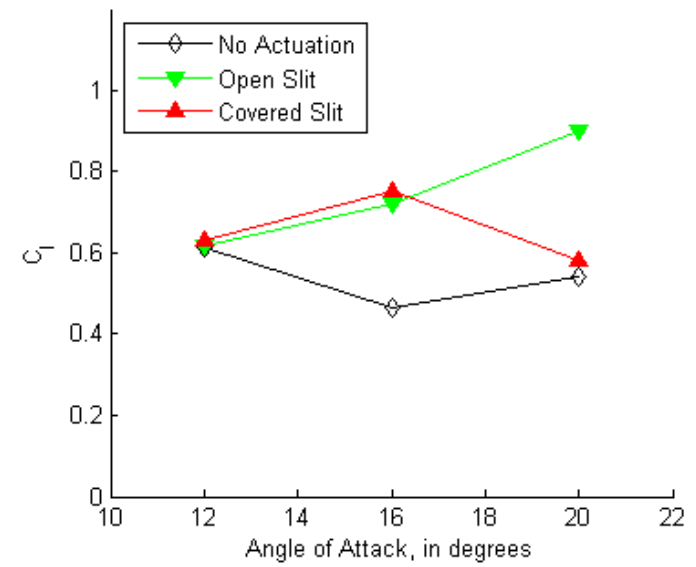

a) $2 y / b=0.38$

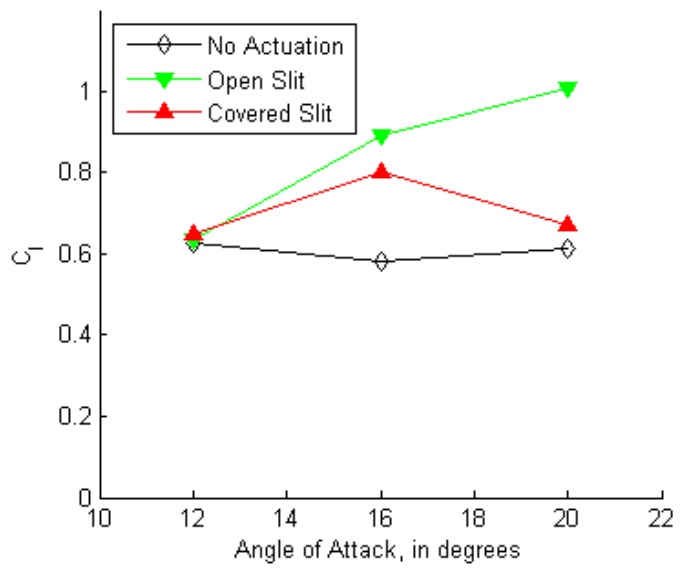

b) $2 y / b=0.85$

Figure 5-21. Section lift coefficient. $R e=100,000, F^{+}=13.9$.

\subsection{Vibration}

The final piece of testing was to evaluate the vibration present in the model surface for various actuations. Because it became known that the surface vibration was causing the flow attachment in some cases, this investigation was undertaken to give insight into the situation. It was desired to compare results for open and covered slit configurations.

Figures 5-22 and 5-23 show the vibration data from the $16^{\circ}$ case with a $500 \mathrm{~Hz}\left(\mathrm{~F}^{+}=13.9\right)$ actuation for the covered and open slit cases, respectively. This frequency was chosen because the vibration was seen to have the most effect on attachment. Indeed, the peak acceleration of the covered slit case was $8.7 \mathrm{G}$ while the exposed open slit case had peaks of $5.1 \mathrm{G}$. The more 
powerful vibration in the covered slit case perhaps explains the attachment observed earlier in Figure 5.12 at $\alpha=16^{\circ}$. A comparison of peak-to-peak vibration strength for various frequencies between open and covered slit is shown in Figure 5-24. As shown in the figure, the vibration strength for the covered slit case is consistently higher than the open slit case.

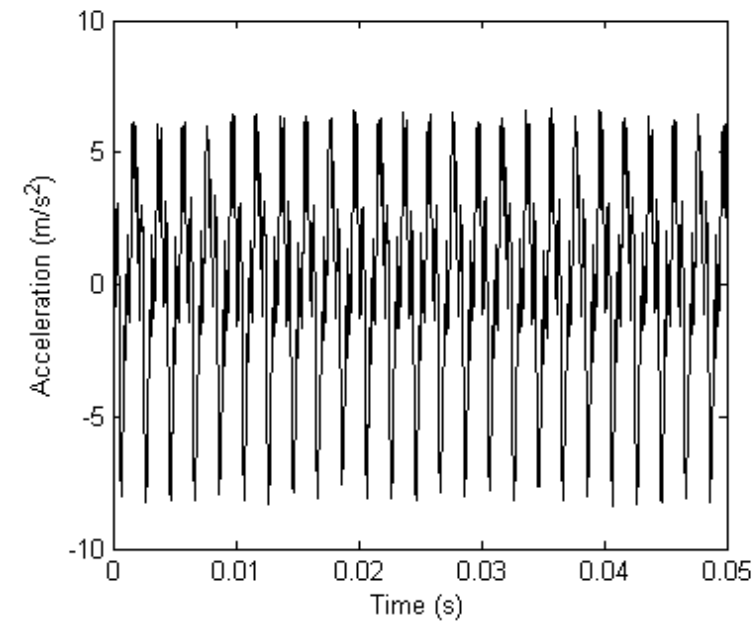

Figure 5-22. Vibration sample for covered slit case at $\alpha=16^{\circ} . F^{+}=13.9$.

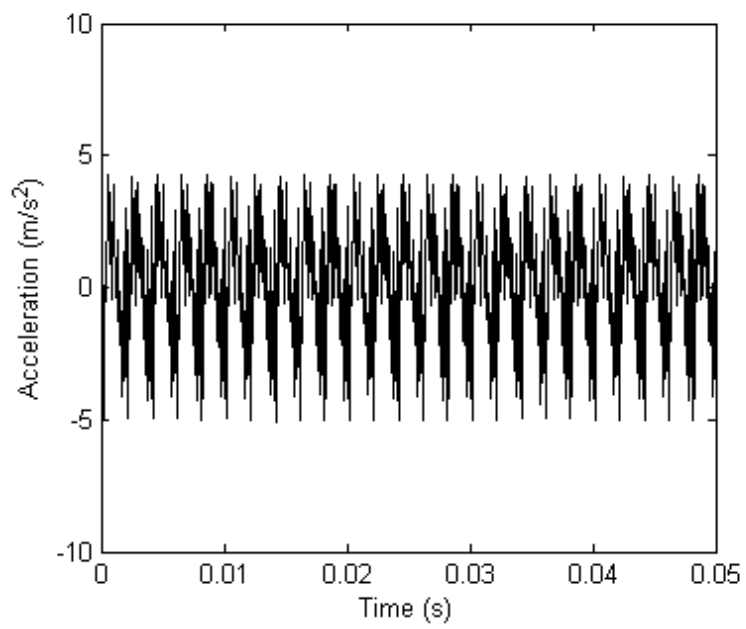

Figure 5-23. Vibration sample for open slit case at $\alpha$ $=16^{\circ} . F^{+}=13.9$. 


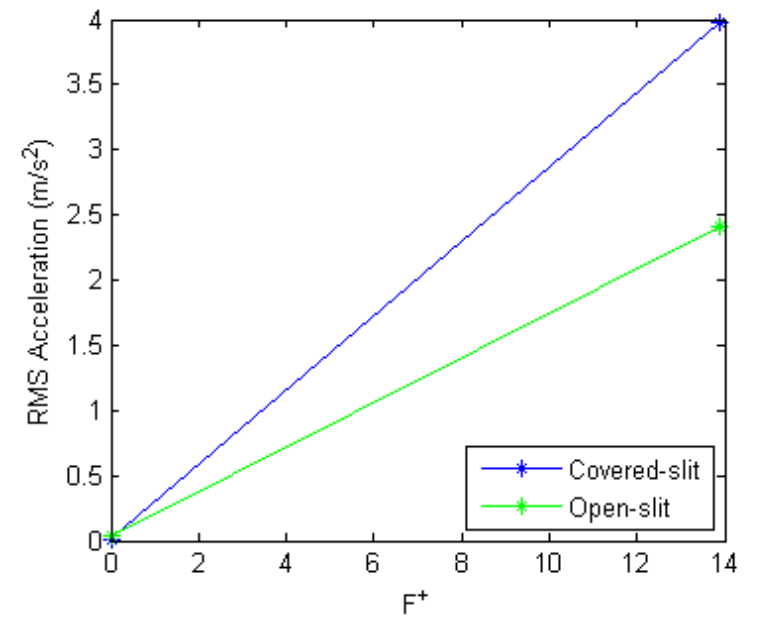

Figure 5-24. Average vibration for slit comparison test at $\mathrm{Re}=100,000, \alpha=16^{\circ}, 60 \mathrm{~V}$.

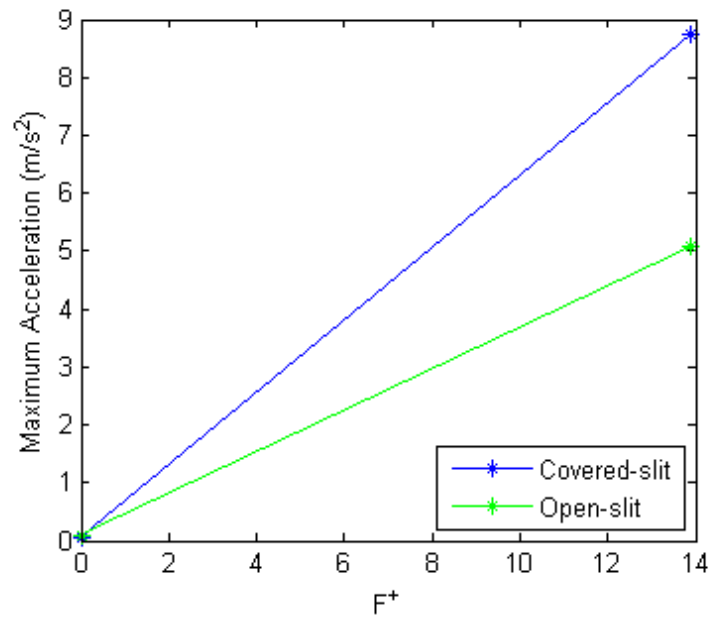

Figure 5-25. Maximum vibration for slit comparison test at $\operatorname{Re}=100,000, \alpha=16^{\circ}, 60 \mathrm{~V}$.

The main frequencies of 36,100 , and $500 \mathrm{~Hz}$ were tested. The results show that there is not a noticeable increase in vibration strength from $60 \mathrm{~V}$ to $180 \mathrm{~V}$ for the $36 \mathrm{~Hz}$ and $100 \mathrm{~Hz}$ cases. The $100 \mathrm{~Hz}$ actuation did have significantly higher peak vibration acceleration at $180 \mathrm{~V}$, when compared to the $60 \mathrm{~V}$ actuation.

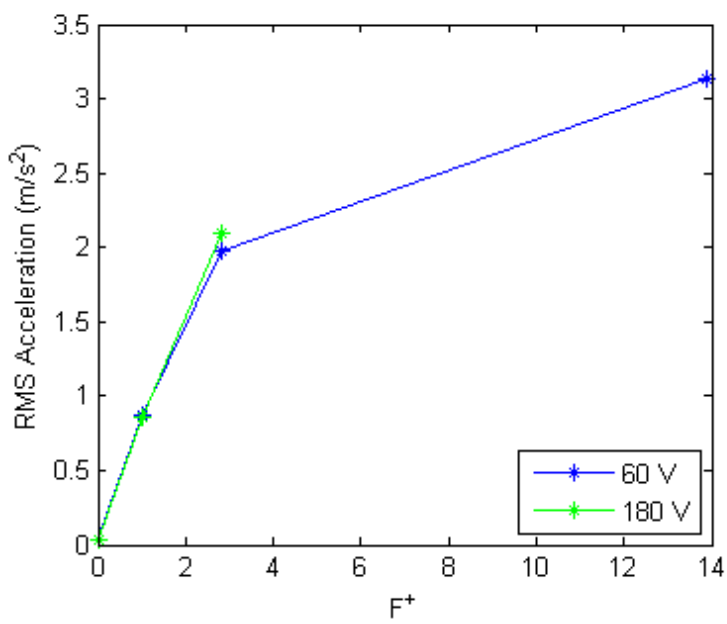

Figure 5-26. Average vibration for frequency and amplitude variation with open slit at $R e=100,000$, $\boldsymbol{\alpha}=\mathbf{2 0}$.

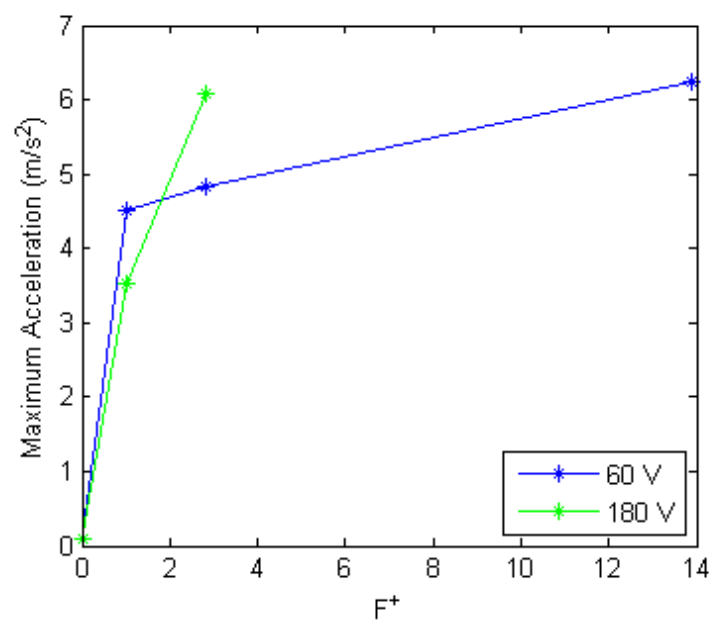

Figure 5-27. Maximum vibration for frequency and amplitude variation with open slit at $R e=100,000$, $\boldsymbol{\alpha}=\mathbf{2 0}$. 


\subsection{Experimental Uncertainty}

\subsubsection{Hotwire}

The uncertainty of the hotwire was based on the calibration of the sensor. Because the sensor was measuring a changing quantity, the standard deviation could not be taken. The best way to obtain the uncertainty was to compare the measured value to a constant flow at a known velocity. This is the purpose of the hotwire calibrator. The calibration is a fourth-order polynomial and the difference between the calibration curve and the true measurement is recorded for each calibration point. Based on the calibration figure, the maximum uncertainty in each reading is approximately $1 \%$ FS. This is enough to be reasonably confident in the hotwire measurements.

The uncertainty in the voltage reading was also estimated to be $1 \times 10-5 \mathrm{~V}$ by an analysis of the resulting data from a steady flow sample. From this, the uncertainty in $C_{\mu}$ was calculated to be $1.4 \times 10^{-5}$. This accuracy is also enough to give confidence in the hotwire measurements. 


\subsubsection{Pressure}

Pressure measurement was the basis for this experiment. For this reason it was of vital importance to be very confident that the resulting pressure distribution was accurate enough to use for analysis.

The uncertainty for each case of the $16^{\circ}$ slit comparison test is shown again in Fig 5-27 with error bars on each data point. It can be seen that the uncertainty is very small compared to the magnitude of the measurements. For this reason, we can be confident that the experimental results are accurate. An example of the uncertainty analysis for the pressure measurement is included in the appendices.

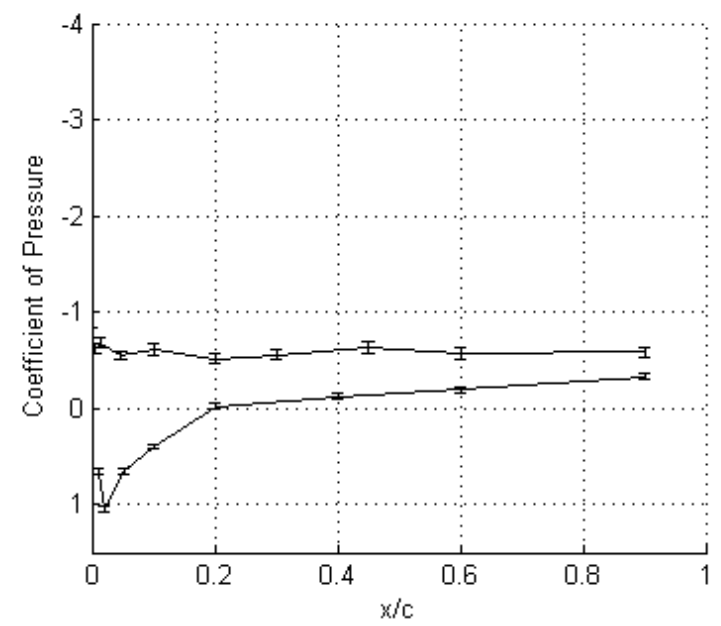

a) $16^{\circ}$ No actuation

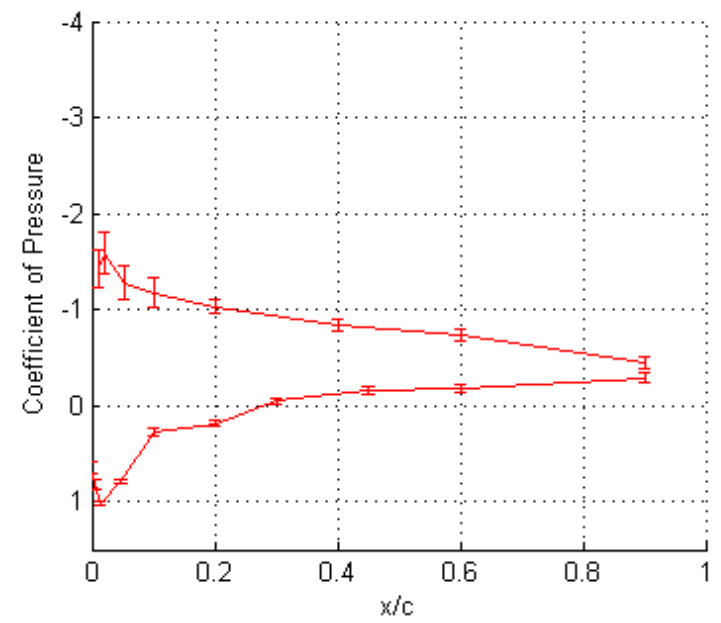

c) $-16^{\circ}$ closed slit

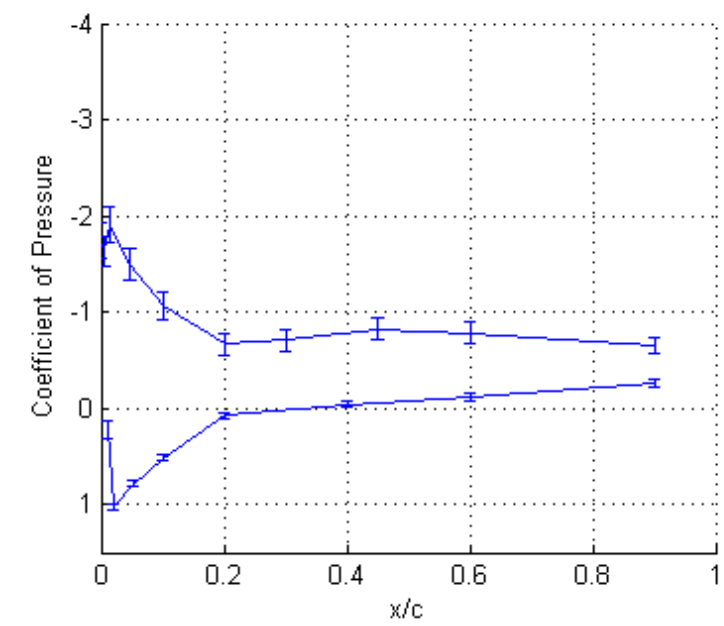

b) $16^{\circ}$ closed slit

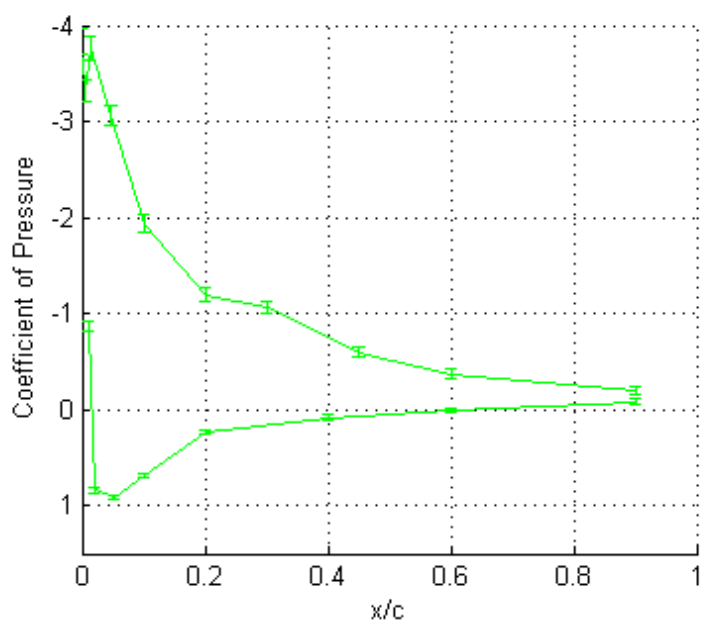

d) $16^{\circ}$ open slit

Figure 5-28. Uncertainty by slit condition for $\alpha=16^{\circ}, \mathrm{F}+=\mathbf{2 . 8}, \mathrm{Re}=\mathbf{1 0 0 , 0 0 0}$. 


\subsubsection{Vibration}

The uncertainty for the vibration measurement was based on the accuracy of the sensor listed by the manufacturer. A sample was taken with no actuation to confirm that there were not major random errors present

The manufacturer stated performance of the PCB 352C22 accelerometer is a sensitivity of 10 $\mathrm{mV} /\left(\mathrm{m} / \mathrm{s}^{2}\right) \pm 15 \%$ and a frequency range of 1 to $10,000 \mathrm{~Hz} \pm 5 \%$. This accuracy was assumed to be sufficient for the purposes of this experiment. 


\section{Conclusions}

An experimental study has been done to evaluate the use of a piezoelectric synthetic jet actuator at $10 \%$ chord on a NACA 0015 finite wing up to $\alpha=20^{\circ}$ at $R e_{C}=100,000$ to control separation. There are several conclusions from this experiment:

1. The actuation is able to delay the separation over the NACA 0015 finite wing model up to $\alpha=20^{\circ}$. For all the $C_{\mu}$ values tested, the synthetic jet excitation is effective at $F^{+}=1$, 2.8, and 13.9 at $\alpha=16^{\circ}$, but only at $F^{+}=13.9$ at $\alpha=20^{\circ}$.

2. At $\alpha=16^{\circ}$, the $C_{p}$ suction peak under the synthetic jet excitation at $F^{+}=1,2.8$, and 13.9 all gradually reduce from $C_{p} \cong-4$ at in the inboard area to about $C_{p} \cong-3$ near the wingtip, about $25 \%$ reduction. The situation is similar for $F^{+}=13.9$ at $\alpha=20^{\circ}$ except at $2 y / b=$ 0.30, the most inboard testing position, where the excitation shows almost no effect.

3. The surprising result is that slit is not the only actuation influencing the flow. For $F^{+}$ from 1 to 2.8 , the synthetic jet is indeed the most effective configuration and is successful in causing flow attachment as seen in previous experiments. For $F^{+}=13.9$, however, the flow is successfully attached with the vibration alone without the slit at $16^{\circ}$. At $20^{\circ}$, this configuration was not successful in delaying separation. 


\section{REFERENCES}

1. Vijaya, M. S., Piezoelectric Materials and Devices: Applications in Engineering and Medical Sciences. Taylor \& Francis Group, LLC, Florida, 2013.

2. White, F. M., Viscous Fluid Flow, Third Edition. McGraw-Hill, New York, 2006.

3. Barlow, J. B., Rae, W. H. Jr., Pope, A., Low-Speed Wind Tunnel Testing, $3^{\text {rd }}$ Edition. John Wiles \& Sons, Inc., 1999.

4. Anderson, J. D., Fundamentals of Aerodynamics, $4^{\text {th }}$ Edition. McGraw-Hill, New York, 2007. Pp362-378.

5. Joslin, R. D., Miller, D. N., Fundamentals and Applications of Modern Flow Control. AIAA, Virginia, 2009.

6. Greenblatt, D., Wygnanski, I.J., The control of flow separation by periodic excitation. Progress in Aerospace Sciences 36 (2000) 487-545.

7. Abbott, I. H., Von Doenhoff, A. E., Theory of Wing Sections. Dover Publications, Inc, 1959.

8. Greenblatt, D., Dual Location Separation Control on a Semispan Wing. AIAA Journal, Vol. 45, No. 8, August 2007.

9. Milholen W. E. II, Chokani, N., McGhee, R. J. Development of Semispan Model Test Techniques, Journal of Aircraft Vol. 33 No. 6, November - December 1996.

10. Mane, P., Mossi, K., Bryant R., Synthetic Jets with Piezoelectric Diaphragms. Proceedings of SPIE Vol. 5761.

11. Gomes, L. D., Crowther W. J., Wood N.J., Towards a practical piezoceramic diaphragm based synthetic jet actuator for high subsonic applications - effect of chamber and orifice depth on actuator peak velocity. AIAA 2006-2859.

12. Goodfellow, S. D., Yarusevych, S., Sullivan, P. E., Momentum Coefficient as a Parameter for Aerodynamic Flow Control with Synthetic Jets. $7^{\text {th }}$ Symposium on Turbulence and Shear Flow Phenomena, 2011.

13. Traub L. W., Agarwal G., Rediniotis O. K. An Experimental Investigation on the Effects of Pulsed Air Blowing Separation Control on NACA 0015. $46^{\text {th }}$ AIAA Aerospace Sciences Meeting and Exhibit. AIAA 2008-737.

14. Seifert A., Darabi A., Wygnanski I. Delay of Airfoil Stall by Periodic Excitation. Journal of Aircraft Vol. 33, No. 4.

15. Lomas, C. G., Fundamentals of Hot Wire Anemometry. Press Sydicate of the University of Cambridge. New York, NY. 1986.

16. Goldstein, R. J., Fluid Mechanics Measurements, $2^{\text {nd }}$ Edition. Taylor \& Francis, 1996.

17. Piezo EPA-104 Manual.

18. ZOC 33/64Px and ZOC 33/64PxX2 Electronic Pressure Scanning Module, Instruction and Service Manual. July 2010.

19. Taylor, J. R., An Introduction to Error Analysis, $2^{\text {nd }}$ Edition. University Science Books, Sausalito, CA. 1997. 
20. Winkelmann, A. E. Separated Flow on a Wing at Low Reynolds Numbers. $1^{\text {st }}$ National Fluid Dynamics Congress. AIAA-88-3548. 


\section{Appendix A. Example Calculations}

\section{Momentum Coefficient:}

$C_{\mu}=\frac{2 U_{j}^{2} h}{c U_{\infty}^{2}}=\frac{2(7.3974 \mathrm{~m} / \mathrm{s})^{2}(0.0026 \mathrm{~m})}{(0.2 \mathrm{~m})(7.3 \mathrm{~m} / \mathrm{s})^{2}}=0.0267$

\section{Non-Dimensional Frequency:}

$F^{+}=\frac{f c}{U_{\infty}}=\frac{(36)(0.2 \mathrm{~m})}{7.3 \mathrm{~m} / \mathrm{s}}=0.986 \approx 1$

Wing planform area:

$S=b c=(16.8125 \mathrm{in} * 2 \mathrm{in} * 8 \mathrm{in}) \frac{1 f t^{2}}{144 \mathrm{in}^{2}}=1.87 f t^{2}$

\section{Wing volume:}

$V o l=A_{a f} b=\left(6.4839 \mathrm{in}^{2} \frac{1 \mathrm{ft}^{2}}{144 \mathrm{in}^{2}}\right)\left(2 * 16.8125 \mathrm{in} * \frac{1 \mathrm{ft}}{12 \mathrm{in}}\right)=0.126 f t^{3}$

Wind tunnel calibration corrections:

$C_{q}=\frac{q_{\text {pitot }}}{q_{\text {tunnel }}}=\frac{3.8146 \times 10^{-3}}{3.8090 \times 10^{-3}}=1.0015$

$C_{p_{\infty}}=\frac{p_{\infty_{\text {pitot }}}}{p_{\infty_{\text {tunnel }}}}=\frac{-7.0010 \times 10^{-3}}{-6.9185 \times 10^{-3}}=1.0119$

\section{Blockage correction:}

$\varepsilon_{s b}=\frac{K_{1} \tau_{1} \mathrm{Vol}}{A^{3 / 2}}=\frac{(1.04)(0.9)(0.1275)}{8^{3 / 2}}=0.00047$

$\varepsilon_{w b}=\frac{S}{4 A} C_{D u}=\frac{1.89}{4(8)} 0.02=0.0012$

$\varepsilon_{T}=\varepsilon_{s b}+\varepsilon_{w b}=(0.00047)+(0.0012)=0.00167$

$K_{\varepsilon}=\left(1+\left(\varepsilon_{T}\right)\right)^{2}=(1+(0.00167))^{2}=1.0033$ 
Pressure coefficient at $\alpha=16^{\circ} \mathrm{F}+=1 \mathrm{Re}=100,000$ port $\mathrm{A3}$ (\#30).

$C_{p}=\frac{p_{i}-p_{s} C_{p_{s}}}{\left(p_{t}-p_{s}\right) C_{q}}=\frac{-0.0207-(-0.0068)(1.0119)}{(-0.0032--0.0068)(1.0015)}=-3.833$

Vibration Strength:

$a=5 V=5 \frac{m / s^{2}}{V}(0.7173 V)=3.5856 m / s^{2}$ 


\section{Appendix B. Error Analysis Detail}

The general equation for the propagation of uncertainty is

$$
\delta q=\sqrt{\left(\frac{\partial q}{\partial x_{1}} \delta x_{1}\right)^{2}+\left(\frac{\partial q}{\partial x_{2}} \delta x_{2}\right)^{2}+\cdots+\left(\frac{\partial q}{\partial x_{n}} \delta x_{n}\right)^{2}}
$$

\section{Momentum Coefficient:}

The first item is the momentum coefficient given by

$$
C_{\mu}=\frac{\rho U_{j}^{2} h}{c q}=\frac{2 U_{j}^{2} h}{c U_{\infty}^{2}}
$$

The only unknown term is the jet velocity measured by the hotwire using the equation

$$
U_{j}=A V^{4}+B V^{3}+C V^{2}+D V+E
$$

The values for each term are listed below.

\begin{tabular}{|l|l|}
\hline Variable & Value \\
\hline $\mathrm{A}$ & 33.77959 \\
\hline $\mathrm{B}$ & -44.71819 \\
\hline $\mathrm{C}$ & -18.06391 \\
\hline $\mathrm{D}$ & 49.83690 \\
\hline $\mathrm{E}$ & -19.36340 \\
\hline $\mathrm{V}$ & $1.6 \mathrm{~V}$ \\
\hline$\sigma_{\mathrm{V}}$ & $0.00001 \mathrm{~V}$ \\
\hline
\end{tabular}

By computing this equation, the final uncertainty is obtained

$$
\begin{gathered}
\delta U j=\sqrt{\left[\left(4 A V^{3}+3 B V^{2}+2 C V+D\right) \sigma_{V}\right]^{2}} \\
\delta U j=\sqrt{\left[\left(\begin{array}{c}
4(33.8)(1.6)^{3}+3(-44.7)(1.6)^{2}+ \\
2(-18.1)(1.6)+(49.8)
\end{array}\right)(0.00001)\right]^{2}} \\
=0.002 \mathrm{~m} / \mathrm{s}
\end{gathered}
$$

This value can then be used in the uncertainty equation 


$$
\begin{gathered}
\delta C_{\mu}=\frac{4 U_{j} h}{c U_{\infty}^{2}} \delta U j \\
\delta C_{\mu}=\frac{4(7.3974 \mathrm{~m} / \mathrm{s})(0.0026 \mathrm{~m})}{(0.2 \mathrm{~m})(7.3 \mathrm{~m} / \mathrm{s})^{2}}(0.002 \mathrm{~m} / \mathrm{s}) \\
=1.4 \times 10^{-5}
\end{gathered}
$$

\section{Coefficient of Pressure:}

The second set of data is the airfoil pressure distribution. The pressure is given by

$$
C_{p}=\frac{p_{i}-p_{s} C_{p_{s}}}{\left(p_{t}-p_{s}\right) C_{q}}
$$

The partial derivatives are listed below.

$$
\begin{gathered}
\frac{\partial C_{p}}{\partial p_{i}}=\frac{-1}{C_{q}\left(p_{s}-p_{t}\right)} \\
\frac{\partial C_{p}}{\partial p_{s}}=\frac{p_{i}-p_{t} C_{p_{s}}}{C_{q}\left(p_{s}-p_{t}\right)^{2}} \\
\frac{\partial C_{p}}{\partial p_{t}}=\frac{-\left(p_{i}-p_{s} C_{p_{s}}\right)}{C_{q}\left(p_{s}-p_{t}\right)^{2}}
\end{gathered}
$$

The substitution of these numbers into the main equation yield

$$
\delta C_{p}=\sqrt{\left[\left(\frac{-1}{C_{q}\left(p_{s}-p_{t}\right)}\right) \sigma_{p_{i}}\right]^{2}+\left[\left(\frac{p_{i}-p_{t} C_{p_{s}}}{C_{q}\left(p_{s}-p_{t}\right)^{2}}\right) \sigma_{p_{s}}\right]^{2}+\left[\left(\frac{-\left(p_{i}-p_{s} C_{p_{s}}\right)}{C_{q}\left(p_{s}-p_{t}\right)^{2}}\right) \sigma_{p_{t}}\right]^{2}}
$$

To find the uncertainty in each pressure, we must consider both the random and systematic uncertainty for each pressure measurement.

$$
\begin{gathered}
\partial p_{i}=\sqrt{p \partial_{i, r a n}^{2}+\partial p_{i, s y s}^{2}} \\
=\sqrt{\left(1.44 \times 10^{-4}\right)^{2}+\left(7 \times 10^{-5}\right)^{2}}=1.6 \times 10^{-4} \\
\partial p_{s}=\sqrt{p \partial_{s, r a n}^{2}+\partial p_{s, s y s}^{2}}
\end{gathered}
$$




$$
\begin{gathered}
=\sqrt{\left(5.93 \times 10^{-5}\right)^{2}+\left(7 \times 10^{-5}\right)^{2}}=9.2 \times 10^{-5} \\
\partial p_{t}=\sqrt{p \partial_{t, r a n}^{2}+\partial p_{t, s y s}^{2}} \\
=\sqrt{\left(6.28 \times 10^{-5}\right)^{2}+\left(7 \times 10^{-5}\right)^{2}}=9.4 \times 10^{-5}
\end{gathered}
$$

The values for the variables are listed in the table below, from data taken on February 8, 2014 for $\alpha=16^{\circ} F^{+}=1 R e=100,000$ port A3 (\#30).

\begin{tabular}{|l|l|}
\hline Variable & Value \\
\hline$p_{i}$ & -0.0207 \\
\hline$p_{t}$ & -0.0032 \\
\hline$p_{s}$ & -0.0068 \\
\hline$C_{p_{s}}$ & 1.0119 \\
\hline$C_{q}$ & 1.0015 \\
\hline$\sigma_{p_{i}}$ & $1.6 \mathrm{e}-4$ \\
\hline$\sigma_{p_{s}}$ & $9.2 \mathrm{e}-5$ \\
\hline$\sigma_{p_{t}}$ & $9.4 \mathrm{e}-5$ \\
\hline
\end{tabular}

With these numbers put in to the $\delta C_{p}$ equation, it becomes

$$
\delta C_{p}=\sqrt{\begin{array}{l}
{\left[\left(\frac{-1}{1.0015(-0.0068--0.0032)}\right) 1.6 \mathrm{e}^{-4}\right]^{2}+} \\
{\left[\left(\frac{-0.0207--0.0032(1.0119)}{1.0015(-0.0068--0.0032)^{2}}\right) 9.2 \mathrm{e}^{-5}\right]^{2}+} \\
{\left[\left(\frac{-(-0.0207--0.0068(1.0119))}{1.0015(-0.0068--0.0032)^{2}}\right) 9.4 \mathrm{e}^{-5}\right]^{2}}
\end{array}}
$$

After performing the calculation, this becomes

$$
\delta C_{p}=0.165
$$

Figure $5-27 \mathrm{~b}$ is shown again to illustrate the results of this computation. The calculation of pressure error was made in the pressure calculation script shown in Appendix D. 


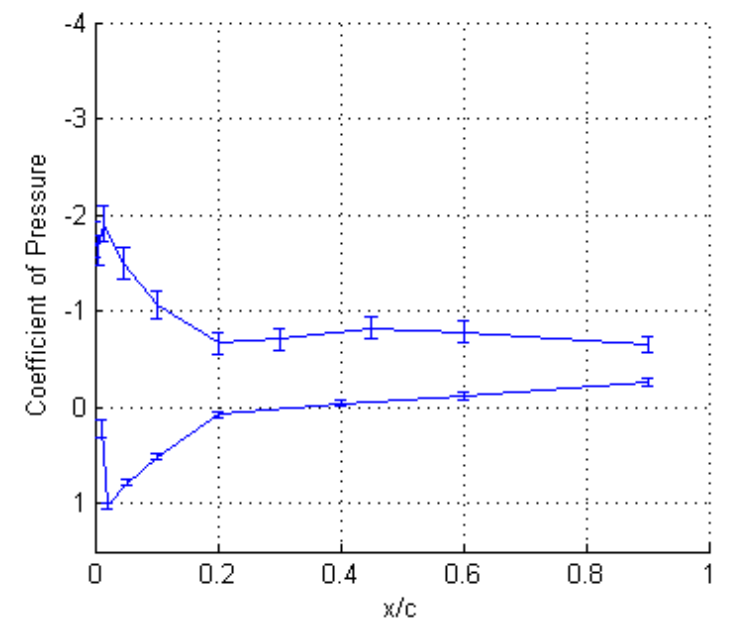

Figure 5-27b. Uncertainty of $16^{\circ}$ closed slit case.

\section{Vibration Strength:}

The third set of data is the vibration data for the model surface. The load cell calibration results in a linear trend line represented by

$$
a=A V
$$

The partial derivative with respect to $\mathrm{V}$ is

$$
\frac{\partial a}{\partial V}=A
$$

After taking the necessary partial derivatives and inserting them to Eq. $\mathrm{X}$, the respective uncertainty is

$$
\delta a=(A) \sigma_{V}
$$

After performing the necessary calculation, the uncertainty is

$$
\delta a=5 \frac{\mathrm{m} / \mathrm{s}^{2}}{\mathrm{~V}}(0.0015 \mathrm{~V})=0.0075 \mathrm{~m} / \mathrm{s}^{2}
$$




\section{Appendix C. Cp Calculation}

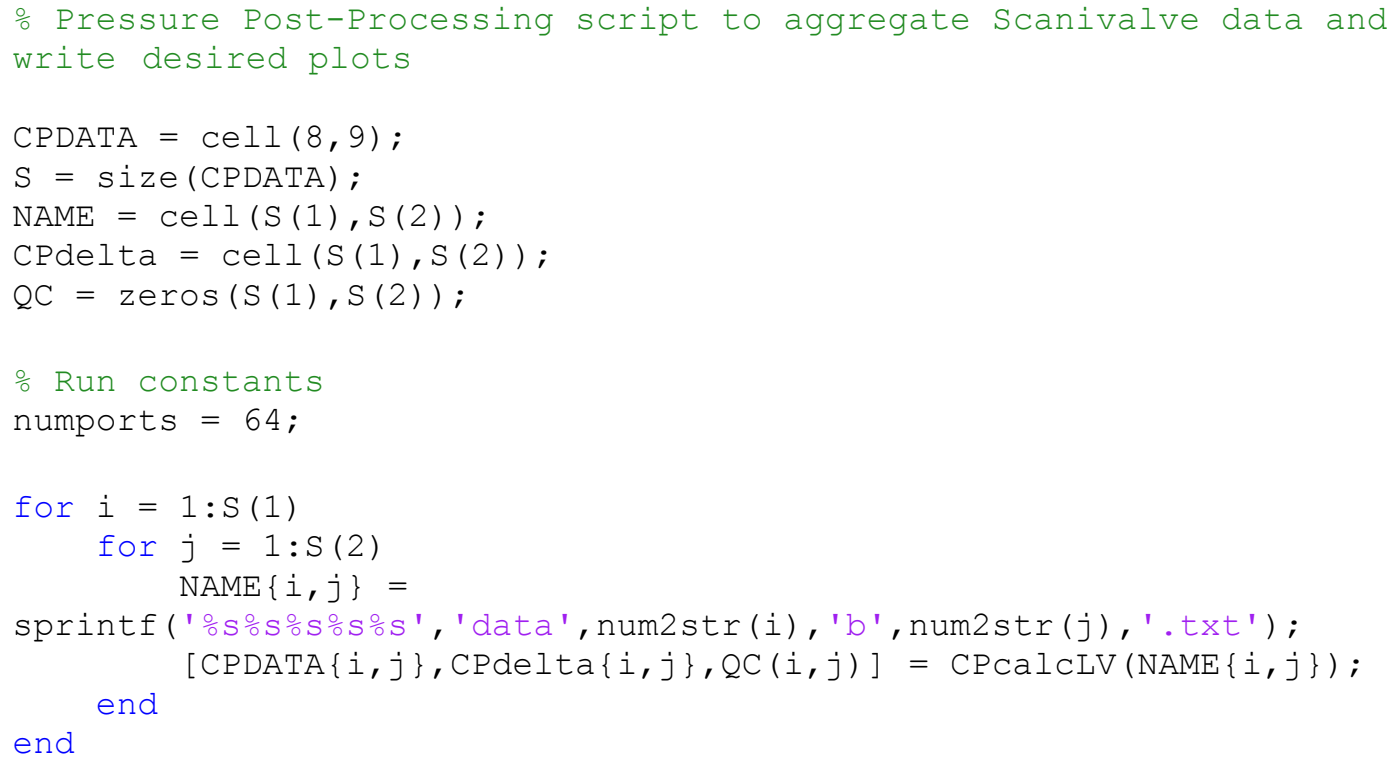




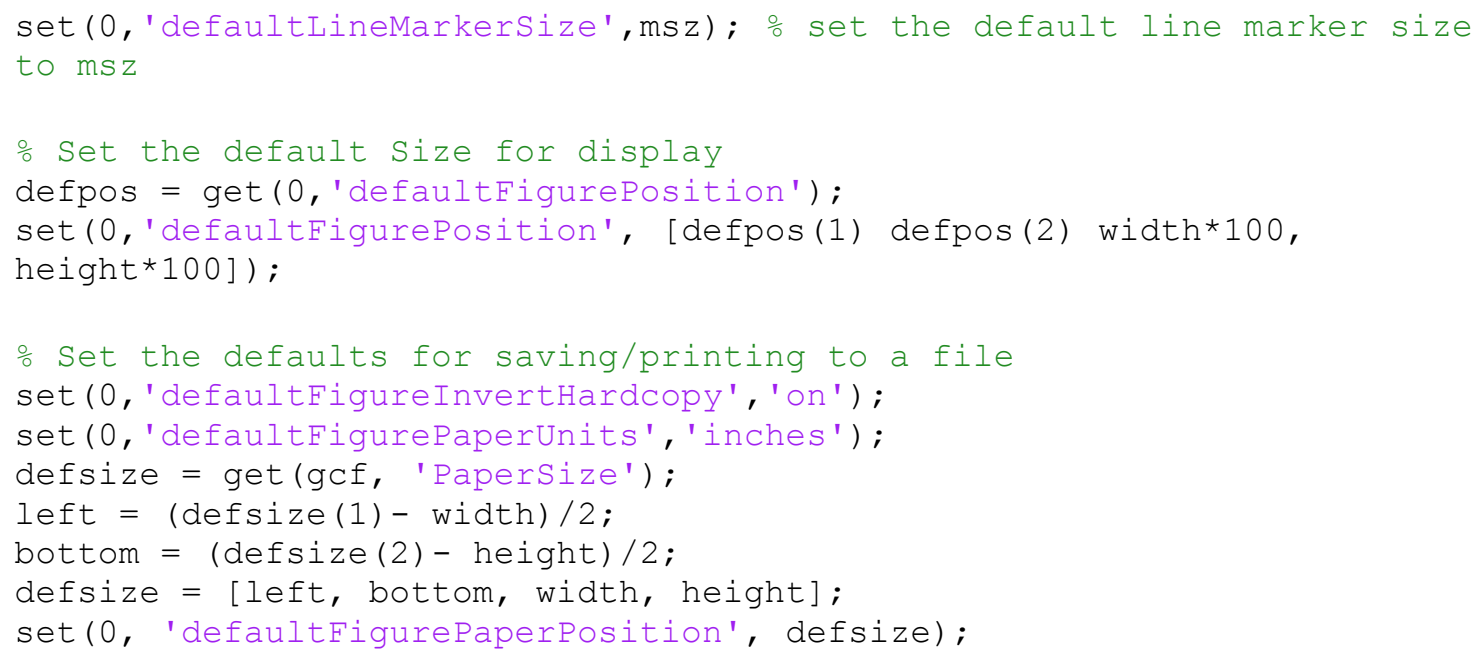




\section{Appendix D. Pressure Calculation Script}

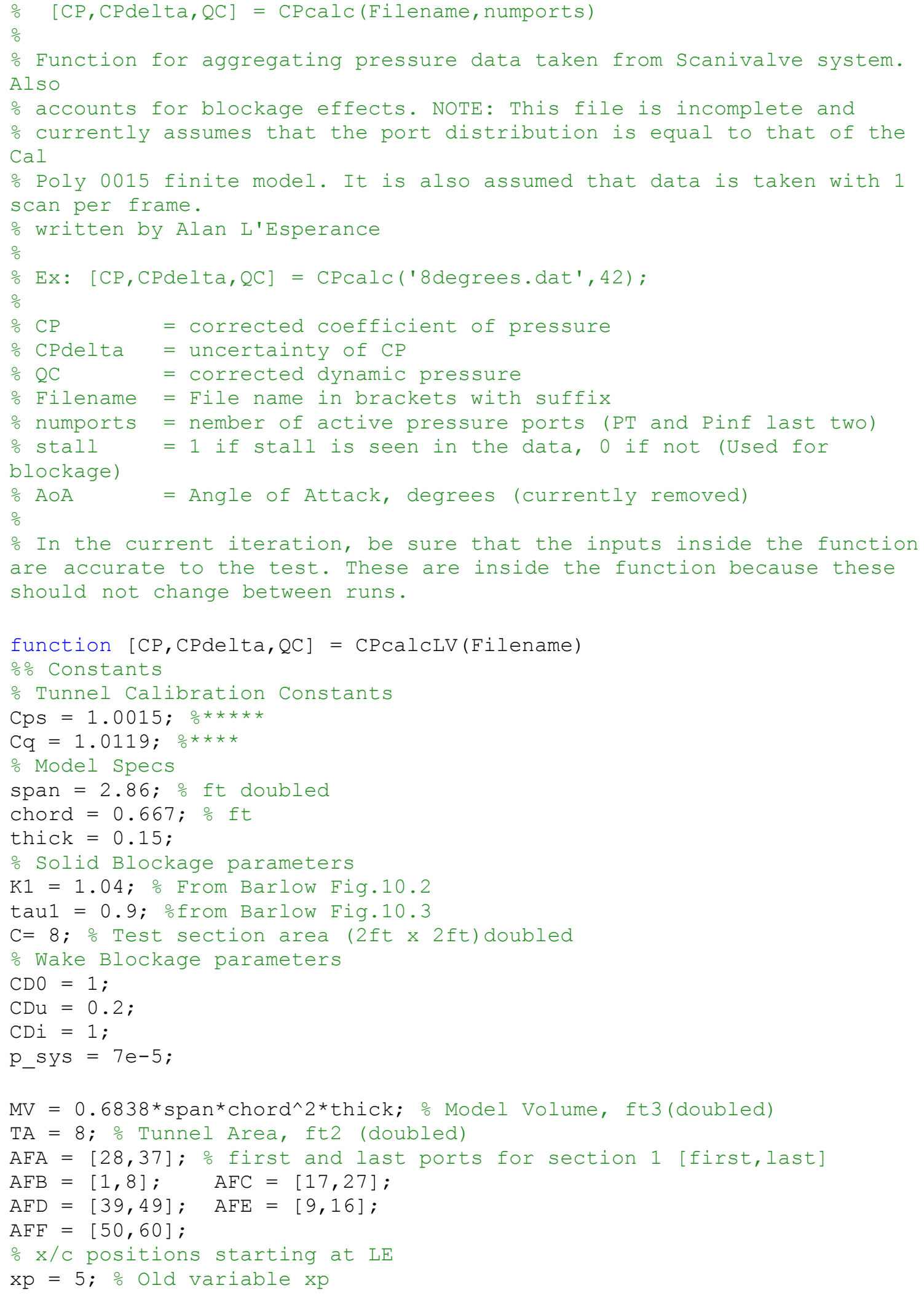




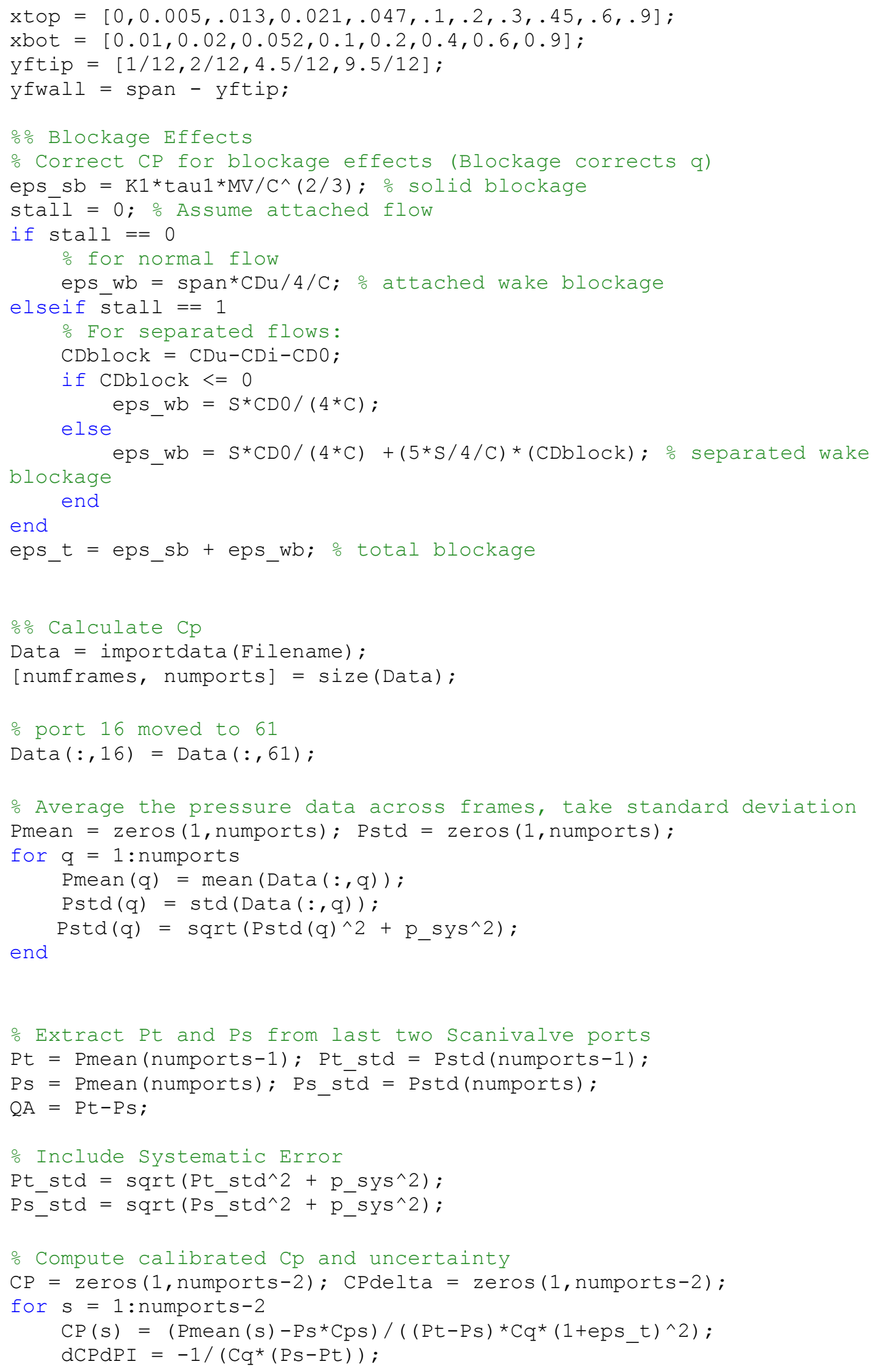




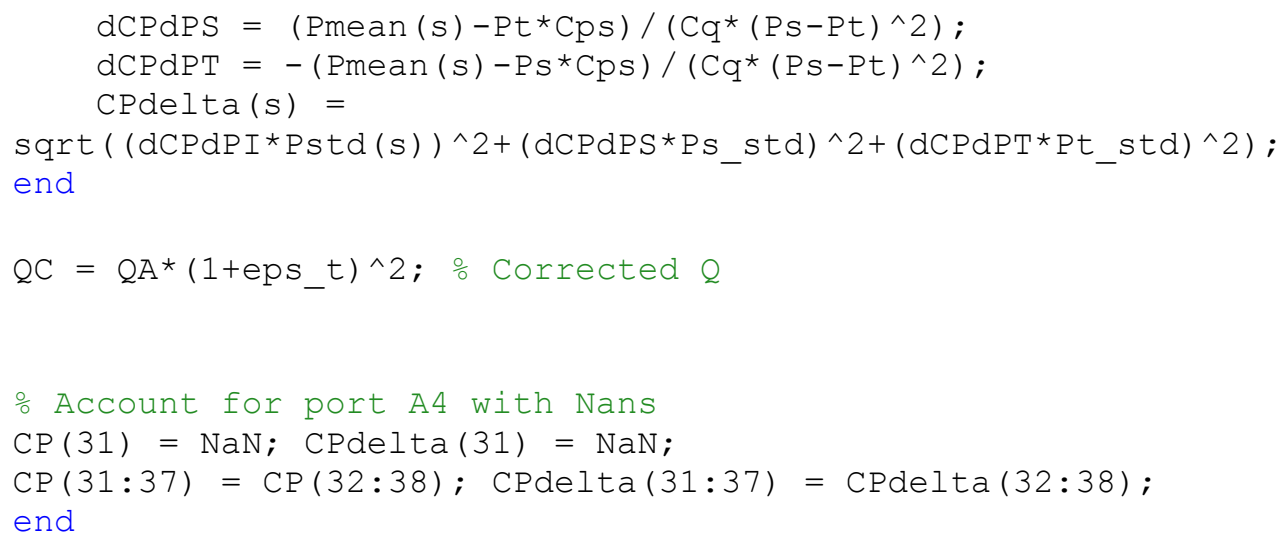




\section{Appendix E. Acceleration Calculation Script}

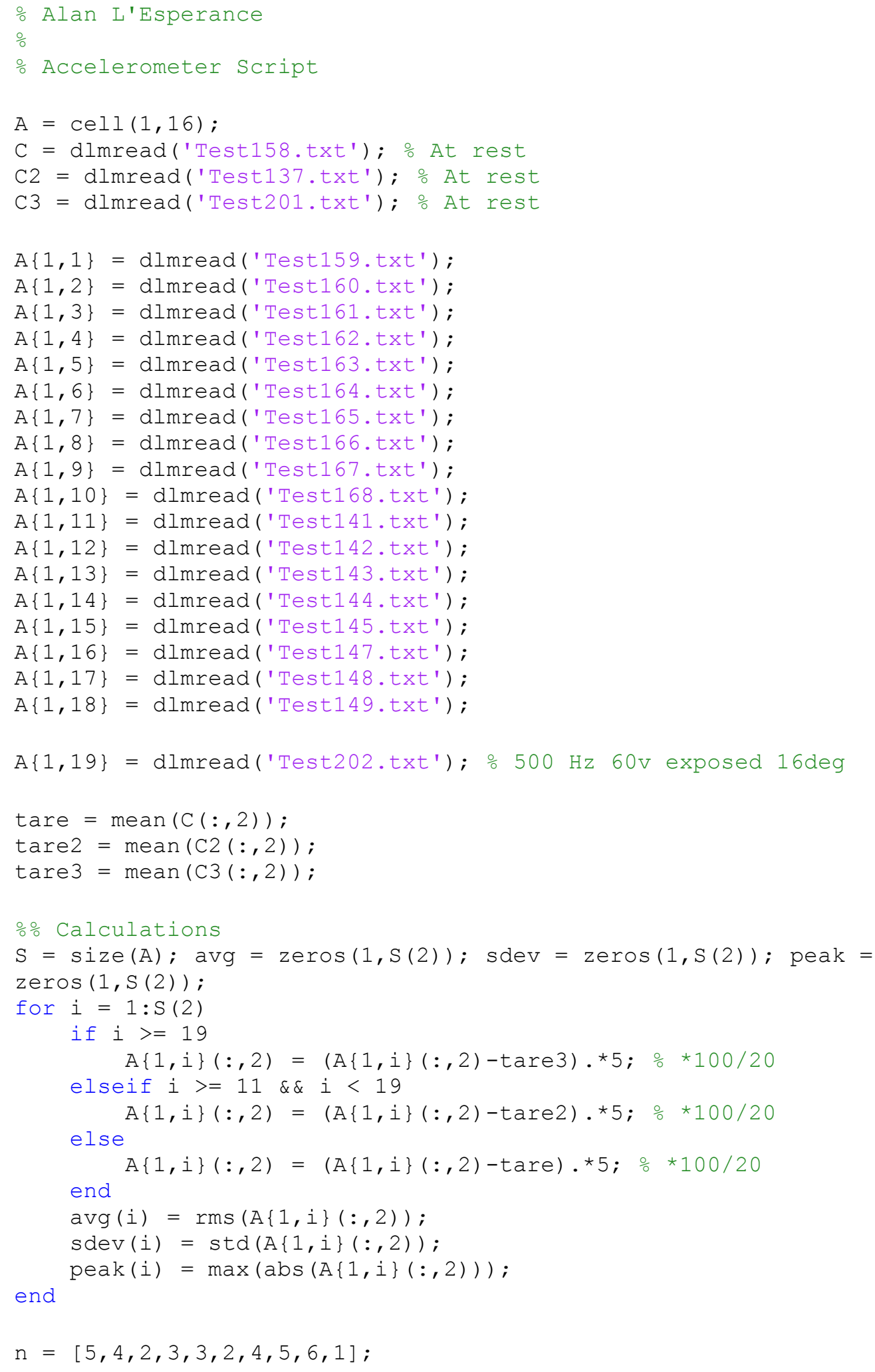




\section{Appendix F. Hotwire Data Processing Script}

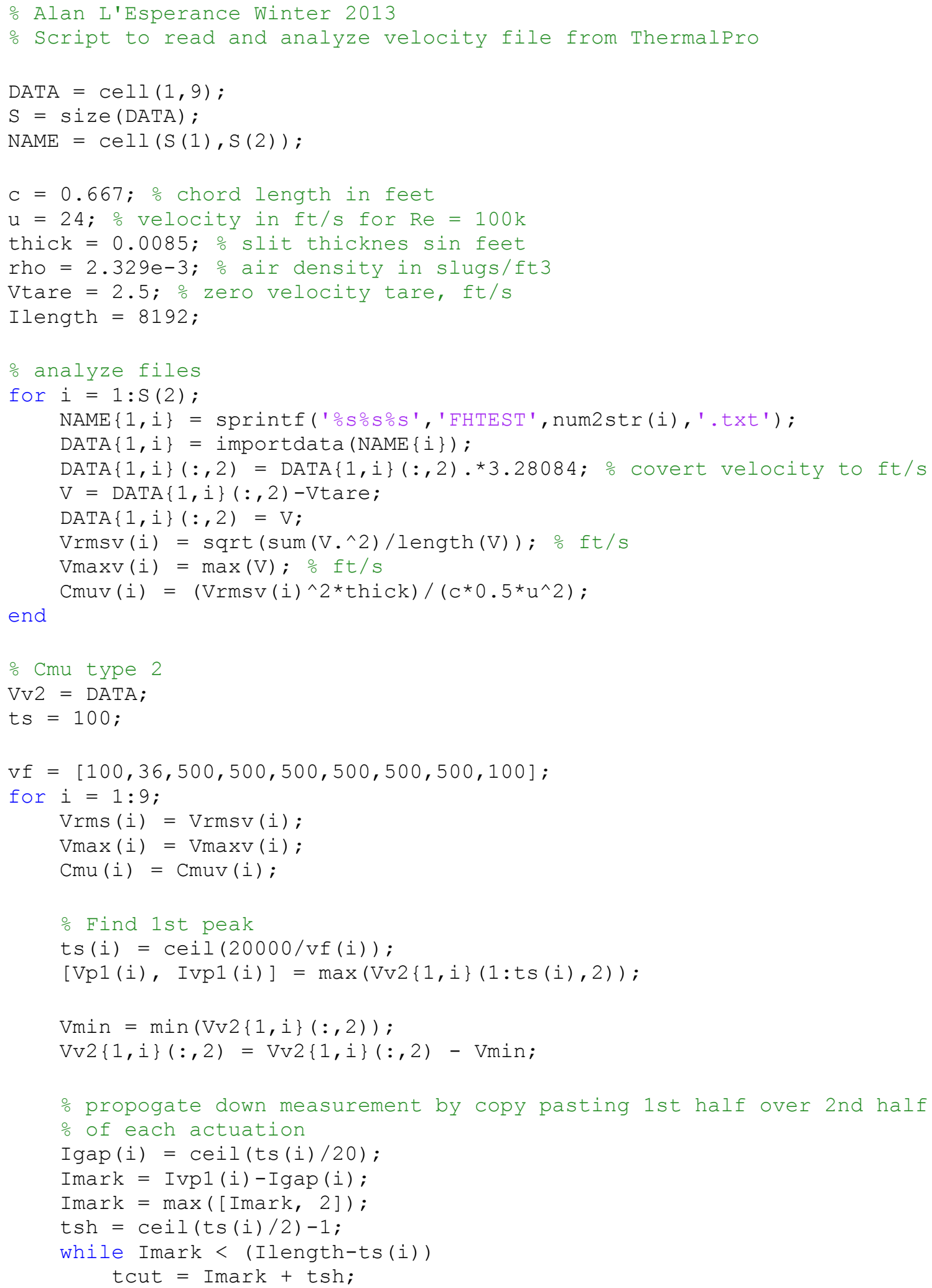




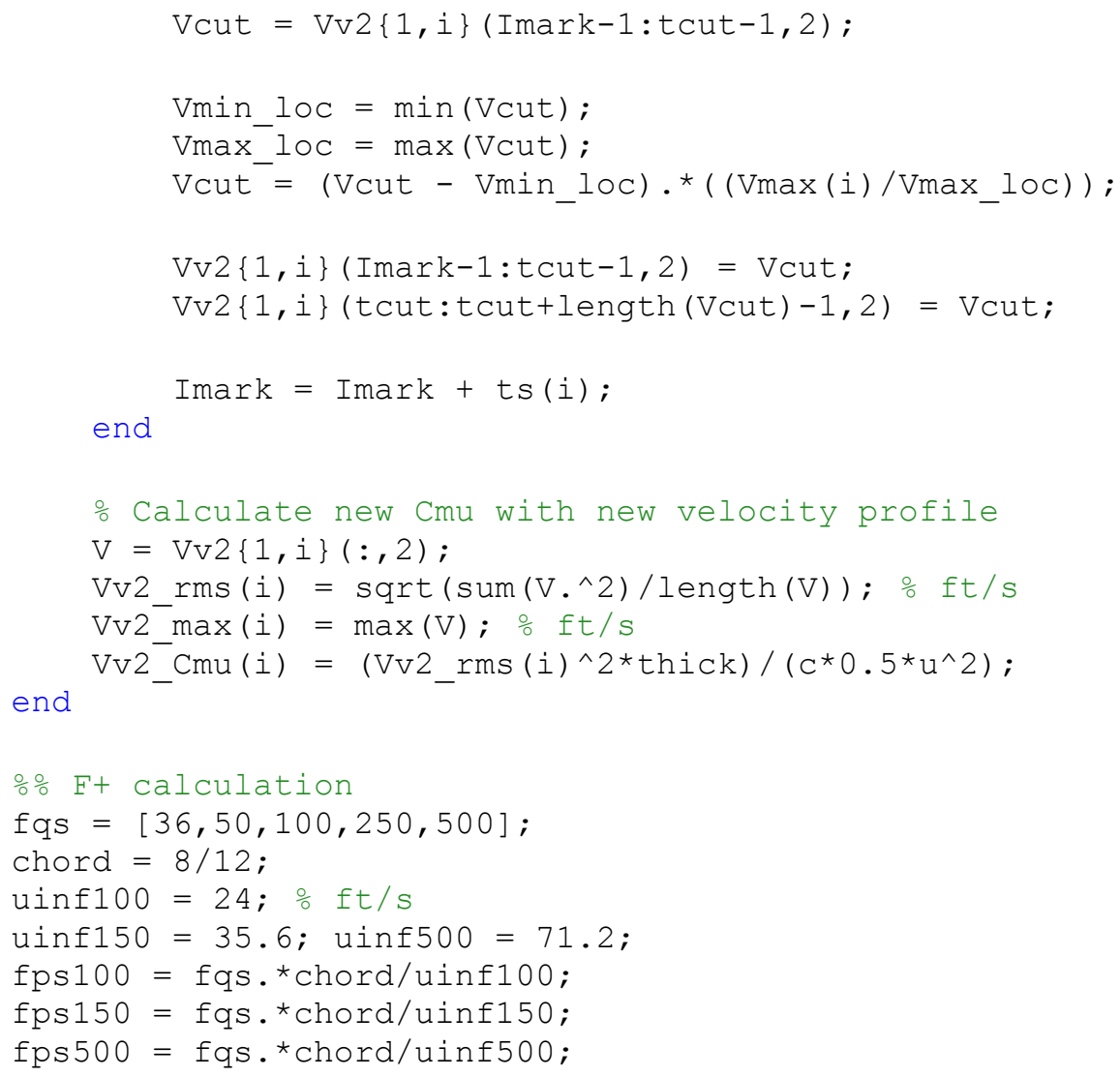

